NBER WORKING PAPER SERIES

\title{
GLOBAL VALUE CHAINS AND EFFECTIVE EXCHANGE RATES AT THE COUNTRY-SECTOR LEVEL
}

\author{
Nikhil Patel \\ Zhi Wang \\ Shang-Jin Wei \\ Working Paper 20236 \\ http://www.nber.org/papers/w20236 \\ NATIONAL BUREAU OF ECONOMIC RESEARCH \\ 1050 Massachusetts Avenue \\ Cambridge, MA 02138 \\ June 2014, Revised March 2019
}

We are grateful to George Alessandria, Pol Antras, Michael Devereux, Charles Engel, Enisse Kharroubi, Giovanni Lombardo, Stephanie Schmitt-Grohe, Hyun Song Shin, Christian Upper, Martin Uribe and our discussants Martin Berka, Beata Javorcik, Ayako Saiki and Giorgio Valente, as well as participants in various seminars and conferences for helpful comments and discussions. The views expressed here are those of the authors and do not necessarily correspond to those of the institutions they are affiliated with, nor those of the National Bureau of Economic Research.

NBER working papers are circulated for discussion and comment purposes. They have not been peer-reviewed or been subject to the review by the NBER Board of Directors that accompanies official NBER publications.

(C) 2014 by Nikhil Patel, Zhi Wang, and Shang-Jin Wei. All rights reserved. Short sections of text, not to exceed two paragraphs, may be quoted without explicit permission provided that full credit, including $\odot$ notice, is given to the source. 
Global Value Chains and Effective Exchange Rates at the Country-Sector Level

Nikhil Patel, Zhi Wang, and Shang-Jin Wei

NBER Working Paper No. 20236

June 2014, Revised March 2019

JEL No. F1,F3

\section{ABSTRACT}

The real effective exchange rate (REER) is one of the most cited statistical constructs in openeconomy macroeconomics. We show that the models used to compute these numbers are not rich enough to allow for the rising importance of global value chains. Moreover, because different sectors within a country participate in international production sharing at different stages, sector level variations are also important for determining competitiveness. Incorporating these features, we develop a framework to compute REER at both the sector and country level and apply it on inter-country input-output tables to study the properties of the new measures of REER for 35 sectors in 40 countries.

Nikhil Patel

Bank for International Settlements

nikhil.patel@bis.org

Zhi Wang

Schar School of Policy and Government

George Mason Universty

3351 Fairfax Drive, MS 3B1,

Alington, VA 22201

zwang36@gmu.edu

\author{
Shang-Jin Wei \\ Graduate School of Business \\ Columbia University \\ Uris Hall 619 \\ 3022 Broadway \\ New York, NY 10027-6902 \\ and NBER \\ shangjin.wei@columbia.edu
}




\section{Introduction}

The Real Effective Exchange Rate (REER) is one of the the most quoted indices in international economics. It measures competitiveness by quantifying the sensitivity of demand for output originating from a particular country as a function of changes in world prices. ${ }^{1}$ Many institutions including most central banks around the world devote substantial time, effort and resources into computing and analyzing these REER indices.

Most of these standard REER measures make a number of simplifying assumptions which are increasingly becoming questionable in a world characterized by global value chains. For instance, they assume that every country exports only final goods which are produced without using imported intermediate goods, and that each country can be characterized by a single representative sector, implicitly imposing that all sectors within a country are identical in terms of their interaction with each other and the rest of the world.

The pitfall associated with these assumptions can be illustrated in the context of a stylized world with three countries involved in a global value chain-China, Japan and the US. Suppose Japan manufactures raw materials for the production of a mobile phone and ships it to China which acts as an assembly point. China in turn exports the finished product to the US, where it is consumed by US consumers. Not recognizing this global value chain structure, traditional models would assume that Japan exports final goods to China, and hence a depreciation of the Japanese currency hurts Chinese competitiveness. In reality however, a decrease in the price of Japanese components could very well lead to an increase in demand for China's output and hence an improvement of its competitiveness, i.e a depreciation of its REER. This example shows that REER computed using the standard frameworks is not only inaccurate in terms of magnitude, but may also have the wrong sign. Accounting for such influences is becoming increasingly more important given the rise in intermediate-goods trade in the last two decades as shown by Wang et al. (2013). ${ }^{2}$

Addressing these issues through the lens of a macroeconomic model designed to capture global value chains and sectoral heterogeneity within and across countries, the paper makes four contributions to the literature on REER.

First, we depart from the single sector framework and allow for multiple sectors within each country. Sectors differ in the nature and extent of their interaction with each other and

\footnotetext{
${ }^{1}$ See Chinn (2006) for a primer on the concept of REER and Rogoff (2005) for an application and discussion.

${ }^{2}$ For OECD countries Miroudot et al. (2009) find the share of trade in intermediate goods and services to be $56 \%$ and $73 \%$ respectively. As emphasized in Baldwin and Lopez-Gonzalez (2012), intermediate goods trade and vertical specialization have grown many-fold in developing countries starting in the 1980s (see also Wang et al. (2013)) Also important is the import content of exports, epitomized by the prevalence of processing trade involving Asian economies, especially China. Koopman et al. (2012) find that the import content of exports is as high as 90 percent for some sectors in China.
} 
with sectors in the rest of the world, both in terms of sourcing inputs as well as selling their output. We build on the literature (in particular Bems and Johnson (2017), henceforth BJ) that has already shown the importance of distinguishing intermediate and final goods trade in measuring REER, and find that allowing for sectoral heterogeneity provides an even bigger improvement in the quantification of REER as compared to incorporating imported inputs in a single sector framework.

Sectoral heterogeneity affects both components of REER-weights as well as prices, and partly reflects the fact that sectors that are typically prominent exporters are also simultaneously large importers, and hence models which aggregate them with sectors that are non-traded, overstate the domestic value added content in exports and hence the impact of changes in foreign prices on competitiveness as measured by the REER.

Second, acknowledging that value added and gross output (part of which is gross exports) become delinked in the presence of imported inputs, we develop separate REER measures for value added (GVC-REER) and gross output (Q-REER). While value added competitiveness is the primary object of interest, gross output competitiveness may also be useful in certain contexts. For instance, productivity gains from exports may be linked to gross exports rather than their value added counterparts, due to positive spillovers from imported inputs and technology.

Third, apart from country-level REERs, we also develop REER measures at the sectoral level. With increasing specialization and trade in intermediate inputs, inter-sectoral linkages between countries differ substantially from aggregate country level relationships. Wang et al. (2013)have documented and explored various dimensions of this heterogeneity and have found that different sectors in a country tend to participate in cross-border production sharing by different extents and in different ways. They show that some sectors mostly engage in regional value chains (i.e., buying or selling intermediate inputs with neighboring countries), whereas others engage in truly global value chains (i.e., sourcing and selling a significant amount of inputs to countries on different continents). This implies substantial heterogeneity in changes in competitiveness across sectors to a given change in foreign prices. An aggregate country level measure is incapable of capturing these. Indeed, we find several instances where the REERs move in opposite directions for different sectors within a country. This makes sectoral REERs a useful addition to the information set of policy makers.

Fourth, we apply the framework to a bilateral context and develop a new measure of bilateral real exchange rate (GVC-RER) that provides an improvement upon the current measures by acknowledging the presence of sectoral heterogeneity and trade in inputs.

We take the framework to the data by parametrizing the model using global input output tables from the world input-output database (WIOD), and create a database of REER weights 
and REER indices for 40 countries and 1435 country-sector pairs for the period 1995-2009. The results highlight the importance of the novel features introduced in the modeling part. For instance, we find that while allowing for the distinction between intermediate and final goods flows does lead to differences in REER weights (as shown by BJ), the difference is much starker once we allow for sectoral heterogeneity as well.

With regard to the much discussed case of China's REER, our results reveal two important findings over the period 1995-2009. Firstly, we find that the exchange rate appreciated more during this time when viewed in value added terms (GVC-REER) as opposed to gross output terms ( Q-REER), signaling that a depreciation in countries from which China sourced inputs lead to an increase in the competitiveness of its exports which was greater than that of its own domestic factors of production. Secondly, when viewed in a bilateral context against the US, the appreciation of the Chinese exchange rate from 1995-2009 was much more pronounced (i.e the case for the exchange rate being "undervalued" during this time is much weaker) under our GVC-RER scheme that correctly accounts for China's complex participation in global value chains, compared to the standard measures which ignore these features.

On the debate on imbalances within the eurozone, our results based on the bilateral GVC-RER between Greece and Germany indicate that the fall in competitiveness for Greece (i.e an appreciation) vis-a-vis Germany from 1995-2009 was much larger when measured through GVC-RER as opposed to the conventional real exchange rate measure, indicating that the standard bilateral REER measure underestimated the extent to which lack of inflation in Germany was hurting competitiveness in Greece.

Given our objective to model relatively short-term and small-scale movements in competitiveness, we take the nature of GVC and trade patterns across countries and sectors as given and do not consider the issue of endogenous off-shoring and production sharing decisions. ${ }^{3}$

The remainder of the paper is structured as follows: Section 2 presents the model that is used to derive expressions for different real effective exchange rate measures. Section 3 presents the main empirical results, and section 4 concludes.

\section{Related Literature}

This paper is a contribution to the literature on international trade and price competitiveness. As mentioned above, the most prominent and commonly cited REER measures today do not distinguish between trade in intermediate and final goods and consider all trade flows

\footnotetext{
${ }^{3}$ There is a growing literature on organization of global value chains that looks into these questions. See for instance Antràs and Chor (2013), Antràs (2014), Costinot et al. (2013) and Johnson and Moxnes (2012). Moreover, due to the complex nature of the model we solve it using log linearization techniques. This further reinforces the view that our REER indices are best suited for short-term movements resulting from shocks that are not too large so as to affect organization of Global value chains (GVCs).
} 
to be in the latter category. A few recent papers have recognized this drawback and have made attempts to address them. BJ allow for trade in intermediates and compute the REER weighting matrix at the country level. They however do not allow for sectoral heterogeneity which we find to be a critical feature in determining patterns in competitiveness, and do not consider REERs at the sector level. ${ }^{4}$

Our attempt to incorporate sector level price indices and build sector level exchange rates has a precedent in the work of Bennett and Zarnic (2009), Sato et al. (2013), Ito and Shimizu (2015), and Goldberg (2004). However, their work does not incorporate trade in intermediate goods and uses an IMF-like weighting matrix. In developing measures designed specifically to measure external (export) competitiveness, Lommatzsch et al. (2016) also construct REER indices in which they adjust the price index by putting weight on sectors in accordance with their export shares. However, they do not allow for sectoral heterogeneity in weights, which in turn also influences the relevant foreign price index used in the REER computation and hence biases the REER measure as we show in the paper. With regard to gross output competitiveness, Bayoumi et al. (2013) propose a measure in which they borrow the weighting matrix from the IMF but adjust the price indices to acknowledge the presence of imported inputs. As we show however, this only ends up being a partial adjustment as the original weighting matrix is not adjusted.

More broadly, the paper is motivated by and is linked to the relatively new but rapidly expanding literature on global value chains and their implications for macroeconomic variables (see Hummels et al., 2001, Baldwin and Lopez-Gonzalez, 2012 and Auer et al. (2017)) as well as the literature on trade statistics and export accounting in the presence of intermediate goods trade (Koopman et al. (2014) and Wang et al. (2013)).

\section{Theoretical Framework}

\subsection{The Concept of REER as a Measure of Competitiveness}

The real effective exchange rate measures change in competitiveness by quantifying changes in the demand for goods produced by a country as a function of changes in relative prices. ${ }^{5}$ If $V_{J}$ is the demand for the goods produced (or alternatively, value added) by country $J$, then the effective exchange rate of country $J$ is defined as:

\footnotetext{
${ }^{4}$ While the model in BJ does allow for different sectors (as in Johnson (2014)) they so not explore the role of sectoral heterogeneity in computing aggregate REERs and take a single sector version of their model to the data.

${ }^{5}$ In this literature the use of the word "competitiveness" is appropriate only in the context of price competitiveness, and does not necessarily extend to the notion of competitiveness measured in terms of profits, market shares, ease of doing business, etc.
} 


$$
\triangle R E E R_{J}=\triangle V_{J}=G_{J}\left(\{\triangle p\}_{i=1}^{n}\right)
$$

where $\{\triangle p\}_{i=1}^{n}$ is a vector of price changes in all countries including the home country. Note that by assumption no other variables except the prices explicitly enter the function $G($.$) .$ Hence, the REER is a partial equilibrium construct where the primitive shocks that lead to the observed price changes are not modeled. The demand side of the economy is also assumed to be exogenous, and the aggregate final demand is assumed to be constant (although demand is allowed to switch between different goods in response to changes in prices).

The function $G_{J}($.$) is homogenous of degree zero, so that if all prices (including the$ home price) double, then the relative demands remain unchanged, and since by construction aggregate demand is held fixed, the absolute demand for each good also remains unaffected. Examples of the function $G($.$) include the commonly used trade weighted exchange rates$ defined for countries which take the of the form

$$
\triangle R E E R_{J}=\sum_{i=1}^{n} w_{J, i}\left(\triangle p_{i}\right)=\sum_{i=i ; i \neq j}^{n} w_{J, i}\left(\triangle p_{i}-\triangle p_{J}\right)=\sum_{i=1}^{n} w_{J, i}\left(\triangle p_{i J}\right)
$$

where, $w_{J, i}$ is the weight assigned by country $J$ to country $i$, and $\triangle p_{i J}$ is the bilateral exchange rate between countries $J$ and $i$, and the second equality uses the homogeneity of degree zero for $G_{J}($.$) .$

Such models of REER measurement do not assume balanced trade or any restrictions on the trade balance. In our empirical framework, trade balances are allowed to be non-zero in the steady state and are calibrated to their observed counterparts in the data. This is in line with the partial equilibrium setup common in the literature in which the demand side is exogenous.

\subsection{The Model}

Consider a world economy comprising $n$ countries. There are $m$ sectors within each country. Each country-sector is called a "production entity" and there are a total number $n m$ of these production entities in the world economy. Each entity uses a production function with its own value added and a composite intermediate input which can contain intermediate inputs from all $m n$ entities including itself. The output of each entity can be used either as a final good (consumed in any of the $n$ countries) or as an input by another entity. Hence there are a total of $n m$ producers and $n m+n$ consumers ( $n m$ entities plus $n$ final goods consumers) in the economy. Both the production function and final goods consumption aggregators are nested CES (constant elasticity of substitution) aggregators which are described in detail 
next.

\section{Production}

The production function for entity $(c, l)$ is given by the expression: ${ }^{6}$

$$
Q_{l}^{c}=\left[\left(w_{l}^{v c}\right)^{1 / \sigma^{3}}\left(V_{l}^{c}\right)^{\frac{\sigma^{3}-1}{\sigma^{3}}}+\left(w_{l}^{X c}\right)^{1 / \sigma^{3}}\left(X_{l}^{c}\right)^{\frac{\sigma^{3}-1}{\sigma^{3}}}\right]^{\frac{\sigma^{3}}{\sigma^{3}-1}}
$$

Here, $V_{l}^{c}$ is the value added by the entity, $X_{l}^{c}$ is an aggregate bundle of intermediate inputs, and $\sigma^{3}$ is the elasticity of substitution between the two inputs. $X_{l}^{c}$ is in turn a CES aggregate, combining inputs from each entity $(i, s)$, denoted by $X_{s l}^{i c}$, in a three stage nested CES aggregate with elasticities of substitution $\sigma^{2}, \sigma^{1 h}$ and $\sigma^{1}$ as follows:

The intermediate input $X_{l}^{c}$ is and aggregate of $m$ sectoral components,

$$
X_{l}^{c}=\left[\sum_{s=1}^{m}\left(w_{s l}^{c}\right)^{1 / \sigma^{2}}\left(X_{s l}^{c}\right)^{\frac{\sigma^{2}-1}{\sigma^{2}}}\right]^{\frac{\sigma^{2}}{\sigma^{2}-1}}
$$

each of which is in turn a combination of the sector $s$ input from the domestic sector and an aggregate sector $s$ input form foreign sectors. The elasticity of substitution between these two inputs is $\sigma_{s}^{1 h}$. $^{7}$

$$
X_{s l}^{c}=\left[\left(w_{s l}^{c c}\right)^{1 / \sigma_{s}^{1 h}}\left(X_{s l}^{c c}\right)^{\frac{\sigma_{s}^{1 h}-1}{\sigma_{s}^{1 h}}}+\left(w(f)_{s l}^{c}\right)^{1 / \sigma_{s}^{1 h}}\left(X(f)_{s l}^{c}\right)^{\frac{\sigma_{s}^{1 h}-1}{\sigma_{s}^{1 h}}}\right]^{\frac{\sigma_{s}^{1 h}}{\sigma_{s}^{1 h}-1}}
$$

For the sector $s$ foreign input bundle, inputs from all foreign countries from that sector are aggregated to form sectoral intermediate inputs $\left\{X(f)_{s l}^{c}\right\}_{s=1}^{m}$. In other words, $X(f)_{s l}^{c}$ is the aggregate sector $s$ foreign intermediate input used in production by country $c$ sector $l$

$$
X(f)_{s l}^{c}=\left[\sum_{i=1, i \neq c}^{n}\left(w_{s l}^{i c}\right)^{1 / \sigma_{s}^{1}}\left(X_{s l}^{i c}\right)^{\frac{\sigma_{s}^{1}-1}{\sigma_{s}^{1}}}\right]^{\frac{\sigma_{s}^{1}}{\sigma_{s}^{1}-1}}, s=1,2, . . m
$$

Here $X_{s l}^{i c}$ denotes inputs from country $i$ sector $s$ used in production by country $c$ sector $l$, the $w^{\prime}$ s are aggregation weights and $\sigma^{1}$ is the (constant) elasticity of substitution between different foreign varieties of the sector $s$ output in the production function of entity $(c, l)$

\footnotetext{
${ }^{6}$ Notation: We use superscripts to denote countries and subscripts to denote sectors. When 2 scripts are present, the first one denotes the source country and the second denotes the destination country. For example, $X_{s l}^{i c}$ denotes output produced by (source) country $i$ sector $s$ that is used by (destination) country $c$ sector $l$.

${ }^{7}$ With this two step framework we are allowing for a distinction between "macro" $\left(\sigma^{1 h}\right)$ and "micro" $\left(\sigma^{1}\right)$ elasticities for each sector, which is a feature of the data documented in the literature-see Feenstra et al. (2014).
} 


\section{Preferences}

A country specific final good is obtained by aggregating goods from all $\mathrm{nm}$ production entities in two stages.

$$
\begin{gathered}
F_{s}^{c}(f)=\left[\sum_{i=1, i \neq c}^{n}\left(\kappa_{s}^{i c}\right)^{1 / \theta_{s}^{1}(c)}\left(F_{s}^{i c}\right)^{\frac{\theta_{s}^{1}(c)-1}{\theta_{s}^{1}(c)}}\right]^{\frac{\theta_{s}^{1}(c)}{\theta_{s}^{s}(c)-1}} \\
F_{s}{ }^{c}=\left[\left(\kappa_{s}^{c c}\right)^{1 / \theta_{s}^{1 h}(c)}\left(F_{s}^{c c}\right)^{\frac{\theta_{s}^{1}(c)-1}{\theta_{s}^{1}(c)}}+\left(\kappa(f)_{s}^{c}\right)^{1 / \theta_{s}^{1 h}(c)}\left(F(f)_{s}^{c}\right)^{\frac{\theta_{s}^{1 h}(c)-1}{\theta_{s}^{1 h}(c)}}\right]^{\frac{\theta_{s}^{1 h}(c)}{\theta_{s}^{1 h}(c)-1}} \\
F^{c}=\left[\sum_{s=1}^{m}\left(\kappa_{s}^{c}\right)^{1 / \theta^{2}(c)}\left(F_{s}^{c}\right)^{\frac{\theta^{2}(c)-1}{\theta^{2}(c)}}\right]^{\frac{\theta^{2}(c)}{\theta^{2}(c)-1}}
\end{gathered}
$$

\section{Market clearing:}

Gross output from an entity is absorbed either as an intermediate input or a final good (we do not allow for inventory accumulation or any inter-temporal effects). Thus the following market clearing condition holds $\forall(c, l)$

$$
Q_{l}^{c}=\sum_{i=1}^{n} F_{l}^{c i}+\sum_{j=1}^{m} \sum_{k=1}^{n} X_{l j}^{c k}
$$

\subsection{Computation of Effective Exchange Rate Weighting Matrices}

In order to define the exchange rates we take prices and final demands in all countries as given and compute the demand for value added and gross output of different entities as functions of changes in the price of value added, which we take as exogenously given.

\section{Demand for value added as a function of price of value added: (GVC-REER)}

The appendix shows that the demand for value added can be written as

$$
\operatorname{vec}\left(\hat{V}_{l}^{c}\right)=W_{V} \operatorname{vec}\left(\hat{p}(V)_{l}^{c}\right)+W_{F V} \operatorname{vec}\left(\hat{F}^{c}\right)
$$

Here $\left(\operatorname{vec}\left(\hat{V}_{l}^{c}\right)\right)_{n m X 1}$ is the vector of changes in value added stacked across all countries and sectors, and $W_{V}$ and $W_{F}$ are $n m$ by $n m$ matrices derived in the appendix. Assuming the change in final demand vec $\left(\hat{F}^{c}\right)$ to be zero, the $n m$ by $n m$ matrix premultiplying $v e c\left(\hat{p}(V)_{l}^{c}\right)$ 
can be interpreted as a matrix of weights for the real effective exchange rate, as it measures how the demand for value added originating in a country-sector changes when price of value added changes in any other entity.

\section{Interpretation in the case with uniform elasticity:}

Appendix C shows that under the uniform elasticity assumption the weight assignment by country sector $(h, l)$ to country-sector $(c, s)$ where $(h, l) \neq(c, s)$ can be written as follows:

$$
w_{l s}^{h c}=\sum_{k=1}^{n}\left[\frac{\left(p(V)_{l}^{h} V_{l}^{h k}\right)\left(p(V)_{s}^{c} V_{s}^{c k}\right)}{\left(p(V)_{l}^{h} V_{l}^{h}\right)\left(P^{K} F^{k}\right)}\right],(h, l) \neq(c, s)
$$

where we use lower case $w$ to denote uniform elasticity weights. The weight assigned by country sector $(h, l)$ to country-sector $(c, s)$ where $(h, l) \neq(c, s)$ is a weighted sum of the value added created by country-sector $(c, s)$ and absorbed by each of the countries $k(=1, . ., n)$, where the weights are given by the value added created by $(h, l)$ that is absorbed in the same country $k$. This captures both mutual and third country competition, because the weight is high if both $\left(p(V)_{l}^{h} V_{l}^{h k}\right)$ and $\left(p(V)_{s}^{c} V_{s}^{c k}\right)$ are high, which happens when both $(h, l)$ and $(c, s)$ have a high share of value added exports to country $k$.

\section{Relaxing the Uniform Elasticity Assumption}

In this paper, we focus primarily on the uniform elasticity case in order to focus on our main contribution, which is to highlight the role of sectoral heterogeneity in computing REER indices. Here we provide a brief flavor of the results when the uniform elasticity assumption is relaxed, and further results, with examples are developed in the appendix.

Proposition 2.1. Suppose all production and consumption elasticities are uniform and equal to $\sigma$ and $\theta$ respectively. ${ }^{8}$ Then starting at the uniform elasticity equilibrium, the effect of a change in elasticity on the weight assigned by entity $(h, l)$ to entity $(c, s)$ is given by:

$$
\frac{\partial w_{l s}^{h c}}{\partial \theta}=w_{l s}^{h c}-\frac{v_{l}^{h} v_{s}^{c} \sum_{c_{1}=1}^{n} \sum_{c_{2}=1}^{n} \sum_{k=1}^{m} b_{l k}^{h c_{1}} b_{s k}^{c c_{1}}\left(p(Q)_{k}^{c_{1}} F_{k}^{c_{1} c_{2}}\right)}{p(V)_{l}^{h} V_{l}^{h}},(h, l) \neq(c, s)
$$

Proof(sketch): See appendix $C$.

Here $b$ is used to denote elements of the global Leontief inverse matrix and $p(Q)$ is used to denote price of gross output.(2.13) shows that an increase in elasticity of substitution

\footnotetext{
${ }^{8}$ This is equivalent to assumption (A2) in section 2.4
} 
of consumption holding everything else constant (including the production elasticity) has two opposing effects on the weight assigned by home entity $(h, l)$ to the foreign entity $(c, s)$. The two terms correspond to the expenditure switching and complementarity effect. In particular, the first effect (expenditure switching) is positive and is given by the uniform elasticity weight $w_{l s}^{h c}$, which is always positive in the uniform elasticity case. In addition, there is the countervailing complementarity effect which comes from the second term on the right hand side. This term is high when the products $b_{l k}^{h c_{1}} b_{s k}^{c c_{1}}$ are high for various entities indexed by $\left(c_{1}, k\right)$, which in turn happens if the outputs of the two entities are used together in production (i, e entities such as $\left(c_{1}, k\right)$ which use the output of $(c, s)$ as an input, also uses the output of $(h, l)$ as an input).

Intuitively, when the price of $(c, s)$ decreases, its quantity demanded increases. This effect is greater the greater is the elasticity of substitution between goods $(\theta)$. Moreover, an increase in demand for $(c, s)$ will end up increasing the output of $(h, l)$ if it is highly complementary with $(c, s)$.

\section{Gross Output Competitiveness}

We also derive the demand for aggregate output as a function of the price of value added (this is analogous to the "goods" REER measure proposed in Bayoumi et al. (2013) (See appendix for steps of proof).

$$
\operatorname{vec}\left(\hat{Q}_{l}^{c}\right)=W_{Q} \operatorname{vec}\left(p(\hat{V})_{l}^{c}\right)+W_{F Q} \operatorname{vec}\left(\hat{F}^{c}\right)
$$

Here $W_{Q}$ is an $n m$ by $n m$ weighting matrix derived in appendix B. Again putting the

change in final demand $v e c\left(\hat{F}^{c}\right)$ to be zero, the $n m$ by $n m$ matrix premultiplying $v e c\left(\hat{p}_{l}^{v c}\right)$ can be interpreted as a matrix of weights for the real effective exchange rate with regard to gross competitiveness, i.e it measures how the demand for output of a country-sector changes with changes in prices of other country-sectors. This is in contrast to the first measure defined above, which looks at changes in demand for value added. (As is shown in 2.2, the two are the same in the special case where gross output is the same as value added)

\subsection{Building Country-level REER From Ground Up:}

\section{Value added weights at the country level}

This section provides a method to aggregate the country-sector level weights derived above and defines country level weights analogous to the ones commonly discussed in the literature. We show that the aggregated weights so derived in general do not correspond to 
any of the ones proposed in the literature except in knife-edge cases. This is attributable to the fact that our measure exploits inter-sectoral linkages between countries to provide a more comprehensive measure of competitiveness than what can be obtained by using just country level data.

To derive the expression for country-level value added weights, we start with the following decomposition of the nominal GDP of country $c$ into its different sectoral components:

$$
p(V)^{c} V^{c}=\sum_{l=1}^{m} p(V)_{l}^{c} V_{l}^{c}
$$

Here, $p(V)_{l}^{c}$ denotes the price index of value added for sector $l$ in country $c$, and $V_{l}^{c}$ is the corresponding real value added.

$\log$ linearizing this equation we get:

$$
\hat{p}(V)^{c}+\hat{V}^{c}=\sum_{l=1}^{m}\left(\frac{p(V)_{l}^{c} V_{l}^{c}}{p(V)^{c} V^{c}}\right)\left[\hat{p}(V)_{l}^{c}+\hat{V}_{l}^{c}\right]
$$

Stacking the $n$ equations in (2.16) we can write the system in matrix notation as:

$$
\operatorname{vec}\left(\hat{p}(V)^{c}\right)_{n X 1}+\operatorname{vec}\left(\hat{V}^{c}\right)_{n X 1}=R_{V}\left[\operatorname{vec}\left(\hat{p}(V)_{l}^{c}\right)_{n m X 1}+\operatorname{vec}\left(\hat{V}_{l}^{c}\right)_{n m X 1}\right]
$$

where

$$
\left(R_{V}\right)_{n X n m}=\left(\begin{array}{cccc}
S_{1}^{V} & 0_{m}^{\prime} & . . & 0_{m}^{\prime} \\
0_{m}^{\prime} & S_{2}^{V} & & : \\
: & & . . & : \\
0_{m}^{\prime} & 0_{m}^{\prime} & . . & S_{n}^{V}
\end{array}\right)
$$

and $\left(S_{i}^{V}\right)_{1 X m}=\left(\frac{p(V)_{1}^{i} V_{1}^{i}}{p(V)^{i} V^{i}}, \frac{p(V)_{2}^{i} V_{2}^{i}}{p(V)^{i} V^{i}}, . ., \frac{p(V)_{m}^{i} V_{m}^{i}}{p(V)^{i} V^{i}}\right)$ and $0_{m}$ is an $m$ by 1 matrix of zeros. By definition the change in the GDP deflator is the weighted sum of change in its components and hence (2.17) reduces to

$$
\operatorname{vec}\left(\hat{V}^{c}\right)_{n X 1}=R_{V}\left[\operatorname{vec}\left(\hat{V}_{l}^{c}\right)_{n m X 1}\right]
$$

using (2.11) in (2.19) and imposing vec $\left(\hat{F}^{c}\right)=0$ as before we get:

$$
\operatorname{vec}\left(\hat{V}_{l}^{c}\right)=R_{V} W_{V} \operatorname{vec}\left(\hat{p}(V)_{l}^{c}\right)
$$




\section{Defining the two measures of country level value added exchange rates:}

When sector level price indices are available, (2.20) defines the change in the country level GVC-REER, i.e

$$
\triangle \log (G V C-R E E R)=W_{V}(C) \operatorname{vec}\left(\hat{p}(V)_{l}^{c}\right)
$$

where the $n$ by $n m$ matrix $W_{V}(C)=R_{V} W_{V}$ is the weighting matrix which can be interpreted as follows: the weight assigned by country $i$ to country $j$ sector $l$ is itself a weighted sum of the weights assigned by each sector of country $i$ to $(j, l)$, with the weights being proportional to the country $i$ sector's share of value added as a fraction of total value added by country $i$

$$
W_{V l}^{i j}=\sum_{s=1}^{m}\left(\frac{p(V)_{s}^{i} V_{s}^{i}}{p(V)^{i} V^{i}}\right)\left(W_{V}\right)_{s l}^{i j}
$$

If sector level prices are not available, then we need a further approximation. In particular, we need to assume a mapping between sector level prices and GDP deflator, i.e between $\hat{p}^{v c}$ and $\left\{\hat{p}_{l}^{v c}\right\}_{l=1}^{M}$. We make the relatively uninformed assumption that all sectoral level prices change in the same proportion as the aggregate GDP deflator, i.e we make the following assumption $^{9}$.

Assumption (AP):

$$
p(\hat{V})^{j}=\hat{p}(V)_{l}^{j} \forall l \forall j
$$

Using this assumption we can define our second measure of country level value added exchange rate, GVC-REER(GDPdef) as follows:

$$
\triangle \log (G V C-R E \operatorname{ER}(G D P \operatorname{def}))=W_{V}(C G) \operatorname{vec}\left(\hat{p}(V)^{c}\right)
$$

where $W_{V}(C G)=R_{V} W_{V} R_{g}$ is an $n$ by $n$ matrix of weights and $R_{g}=I_{n} \otimes 1_{m}$

\section{Link to other measures in the literature:}

Our second measure of country level exchange rates which uses only the GDP deflator (GVC-REER(GDPdef)) has an $n$ by $n$ weighting matrix as all other measures in the literature and we can hence make a comparison with them.

\footnotetext{
${ }^{9}$ For example, in a world with price rigidity and producer currency pricing, this assumption is satisfied automatically in the presence of shocks to the nominal exchange rate.
} 
Given the country-sector level weights $\left(W_{V}\right)$, the country level weights $\left(W_{V}(C G)\right)$ have an intuitive interpretation. The weight assigned by country $i$ to country $j$ is a weighted sum of the weights assigned by each sector of country $i$ to each sector of country $j$, with the weights being proportional to the home sector's share of value added as a fraction of total home value added.

$$
W_{V}(G D P d e f)^{i j}=\sum_{s=1}^{m}\left(\frac{p(V)_{s}^{i} V_{s}^{i}}{p(V)^{i} V^{i}}\right)\left(\sum_{k=1}^{m}\left(W_{V}\right)_{s k}^{i j}\right)
$$

These country level weights defined here are different from others proposed in the literature in several respects. The closest to our measure is the one by BJ who also take into account the input-output linkages in their measure and define weights in terms of value added, but do not exploit sector level linkages across countries. Because of the greater information used in our measure, it is in general different from their VAREER and IOREER, even under the assumption of all elasticities being the same. The following proposition shows that even under the uniform elasticity assumption, GVC-REER and VAREER differ from each other except in special cases.

The country level weights $\left(W_{V}(G D P d e f)\right.$ ) defined above reduce to VAREER (and IOREER) weights defined in BJ if either of the two conditions below are satisfied.

1. (A2) and the following condition

$$
v^{i} \sum_{c=1}^{n} b^{i c} F^{c j}=\sum_{l=1}^{m} v_{s}^{i} \sum_{c=1}^{n} \sum_{s=1}^{m} b_{l s}^{i c} F_{s}^{c j} \forall i, j
$$

where $v_{l}^{i}=\frac{p(V)_{l}^{i} V_{l}^{i}}{p(Q)_{l}^{i} Q_{l}^{i}}$ is the value added share for entity $(i, l)$ and $b$ denotes a generic element of the global inter-country Leontief inverse matrix.

2. (A2) and (A3), i.e no trade in intermediates

The proof is given in appendix D. The first part of the proposition shows that outside of the knife-edge case in which the above condition is satisfied, the GVC-REER(GDPdef) weights which exploit inter-sectoral linkages between countries will dominate the VAREER measure. Intuitively, condition (2.26) is satisfied if different sectors within a country are "symmetric" with regard to their input-output linkages with the rest of the world, for in that case aggregation across sectors within a country will be a closer approximation to the behavior of each individual sector. The next section will provide an example to illustrate the role played by the condition in aggregating weights at the country level.

The second part of the proposition shows that differences between GVC-REER and 
VAREER vanish when there is no trade in intermediates. This shows that if there is no trade in intermediates, then aggregating trade flows across sectors within a country does not lead to any loss of information as far as computation of real effective exchange rate is concerned. Intuitively, if all production by all entities involves only own value added and no intermediates, then there is no asymmetry between sectors within a country and hence aggregation does not lead to any loss of relevant information.

To summarize, both sector level prices (the more accurate and our preferred measure) and country level prices (as in the literature) can be used to compute REER indices using the sector level weighting matrices discussed above, yielding the following two expressions for country level GVC-REERs.

$$
\begin{gathered}
\triangle \log (G V C-R E E R)=W_{V}(C) \operatorname{vec}\left(\hat{p}(V)_{l}^{c}\right) \\
\triangle \log (G V C-R E E R(G D P \operatorname{def}))=W_{V}(C G) \operatorname{vec}\left(\hat{p}(V)^{c}\right)
\end{gathered}
$$

Where $W_{V}(C)$ and $W_{V}(C G)$ are weighting matrices of dimension $n$ by $n m$ and $n$ by $n$ respectively. The two measures of Q-REER (for gross output competitiveness are defined analogously). ${ }^{10}$ In general, weighting matrices using sector level information $\left(W_{V}^{c s}\right)$ as well as REER indices incorporating sector level price variations provide a more accurate measure of competitiveness compared to the measures which use only country level aggregate trade flows and price indices. ${ }^{11}$ This is illustrated in the example that follows.

\section{Gross output exchange rate at country level}

Following a similar procedure to the one used for GVC-REER, we can define weights and exchange rates for gross output at the country level:

$$
\begin{gathered}
\triangle \log (Q R E E R)=W_{Q}(C) \operatorname{vec}\left(\hat{p}(V)_{l}^{c}\right) \\
\triangle \log (Q R E E R(G D P \operatorname{def}))=W_{Q}(C G) \operatorname{vec}\left(\hat{p}(V)^{c}\right)
\end{gathered}
$$

Similar to GVC-REER, our benchmark measure of gross output competitiveness (equation 2.29) differs from its counterparts such as the conventional IMF and BIS REERs along three dimensions:

\footnotetext{
${ }^{10}$ The detailed derivations are provided in appendix

${ }^{11}$ Appendix D discusses the set of restrictive conditions under which the two approaches give identical expressions
} 
1. different weighting matrix

2. use of value added prices as opposed to CPI or gross output prices

3. use of sector level prices instead of aggregate country level prices.

\section{Relationship to other REER Weighting Matrices in the Literature}

We now link the two REER measures proposed in the previous section and some common REER measures in the literature with particular emphasis on whether and under what conditions the different measures in the literature can be recovered from the more general measures proposed here.

\section{Assumptions:}

$(\mathrm{A} 1) m=1$. i.e, each country has only one sector

(A2) uniform elasticity: $\sigma_{1}=\sigma_{2}=\sigma_{3}=\theta_{1}=\theta_{2}=1$

(A3) No intermediates in production and only final goods are traded.

\section{Proposition 2.2.}

1. $\operatorname{Under}(A 1)$ :

GVC-REER =IOREER $(B J)$

2. Under (A1) and (A2) :

$$
G V C-R E E R=I O R E E R=V A R E E R(B J)
$$

3. Under (A1), (A2), (A3):

$$
\begin{aligned}
& G V C-R E E R=Q-R E E R=I O R E E R=V A R E E R=\text { Goods-REER (Bayoumi et al. (2013)) } \\
& =I M F-R E E R \text { (Bayoumi et al. (2005)) } 12
\end{aligned}
$$

proof: see appendix.

The main conclusion from these results is that the GVC-REER measure does not reduce to the common measures currently in use, such as those of the Federal Reserve (Loretan, 2005), BIS (Klau et al., 2008) or IMF (Bayoumi et al., 2005), as well as the more sophisticated ones, outside of very strong assumptions.

\footnotetext{
${ }^{12}$ As mentioned before, note that the IMF uses the CPI to compute REER, but in this section we will use $I M F-R E E R$ to denote total effective exchange rates computed with IMF weights but using the GDP deflator, to make the measure comparable with other measures proposed here and in BJ
} 


\subsection{Illustrative Example: A three country global value chain}

This section presents a numerical example to illustrate the new REER measures proposed in this paper, and provides a comparison with the existing ones in the literature. ${ }^{13}$ Consider a world economy comprising three countries $(J, C$ and $U$ ) and two sectors within each country indexed by subscript $i \in\{1,2\}$. The input-output linkages are given in table 1 . The example mimics a stylized global value chain of the following form:

$$
J_{1} \rightarrow C_{2} \rightarrow(C, U)
$$

Sector $J_{1}$ in country $J$ exports raw materials to sector $C_{2}$ in country $C$, which combines them with its own value added input to produce final goods which are then subsequently consumed in $C$ and exported to $U$. The rest of the sectors only use their own value added input and sell domestically. Next, we illustrate how sectoral heterogeneity affects the measurement of REER along two dimensions-the REER weights themselves and their interaction with sectoral price changes.

\section{Sectoral heterogeneity and GVC-REER weights}

The key advantage in our REER weighting scheme compared to the literature is that the framework is flexible enough to incorporate information from input output tables like Table 1a that are at the country-sector level, whereas the other REER schemes in the literature work with input-output linkages at the country level (analogous to table 1b).

To see the consequences of the loss of information on sectoral heterogeneity that this aggregation entails, table 2 shows the weight assigned by country $U$ to country $C$ and $J$ under different REER weighting schemes. Consider first a comparison between GVC-REER and the VAREER measure of BJ. Both recognize that part of the trade between $J$ and $C$ comprises of intermediate goods, and hence assign a lower value to $W_{U C}$ than the IMF weight. However, GVC-REER has a lower value of $W_{U C}$ compared to VAREER. This is attributable to the fact that unlike VAREER, the GVC-REER recognizes that the sector in $C$ which actually competes with $U$ is $C_{2}$, and $C_{2}$ has a lower value added share than $C_{1}$. Hence, the VAREER weight, which essentially treats $U$ as competing with $C$ as a whole (which is an average of $C_{1}$ and $C_{2}$ ) puts a higher weight on $C$ as it overestimates the value added originating in $C$ that is competing with $U$ in $U^{\prime} s$ final goods market. Similarly, GVC-REER assigns a higher

\footnotetext{
${ }^{13}$ Appendix E provides a general solution for the type of three country global value chain considered in this example
} 
Table 1 - Input output table for example 2.5

(a) Sector level input-output table

\begin{tabular}{|c|c|c|c|c|c|c|c|c|c|c|c|}
\hline & & \multicolumn{2}{|c|}{$\mathrm{J}$} & \multicolumn{2}{|c|}{$\mathrm{C}$} & \multicolumn{2}{|c|}{$\mathrm{U}$} & \multirow[t]{2}{*}{ JFinal } & \multirow[t]{2}{*}{ CFinal } & \multirow[t]{2}{*}{ Ufinal } & \multirow[t]{2}{*}{ total output } \\
\hline & & $J_{1}$ & $J_{2}$ & $C_{1}$ & $C_{2}$ & $U_{1}$ & $U_{2}$ & & & & \\
\hline \multirow{2}{*}{$\mathrm{J}$} & $J_{1}$ & 0 & 0 & 0 & 2 & 0 & 0 & 1 & 0 & 0 & 3 \\
\hline & $J_{2}$ & 0 & 0 & 0 & 0 & 0 & 0 & 1 & 0 & 0 & 1 \\
\hline \multirow{2}{*}{$\mathrm{C}$} & $C_{1}$ & 0 & 0 & 0 & 0 & 0 & 0 & 0 & 2 & 0 & 2 \\
\hline & $C_{2}$ & 0 & 0 & 0 & 0 & 0 & 0 & 0 & 1 & 2.5 & 3.5 \\
\hline \multirow{2}{*}{$\mathrm{U}$} & $U_{1}$ & 0 & 0 & 0 & 0 & 0 & 0 & 0 & 0 & 2 & 2 \\
\hline & $U_{2}$ & 0 & 0 & 0 & 0 & 0 & 0 & 0 & 0 & 1 & 1 \\
\hline VA & & 3 & 1 & 2 & 1.5 & 2 & 1 & & & & \\
\hline total output & & 3 & 1 & 2 & 3.5 & 2 & 1 & & & & \\
\hline
\end{tabular}

(b) Country level input output table

\begin{tabular}{|c|c|c|c|ccccc|}
\hline \multicolumn{1}{|c}{} & \multicolumn{2}{c}{$\mathrm{J}$} & \multicolumn{1}{c}{$\mathrm{C}$} & $\mathrm{U}$ & $\mathrm{J}$ final & C final & U final & Total output \\
\hline \multirow{2}{*}{$\mathrm{J}$} & 0 & 2 & 0 & 2 & 0 & 0 & 4 \\
$\mathrm{C}$ & 0 & 0 & 0 & 0.5 & 2.5 & 2.5 & 5.5 \\
$\mathrm{U}$ & 0 & 0 & 0 & 0 & 0 & 3 & 3 \\
\cline { 2 - 5 } Value added & 4 & 3.5 & 3 & & & & \\
Total output & 4 & 5.5 & 3 & & & & \\
\hline
\end{tabular}

value to $W_{U J}$ compared to VAREER, recognizing the importance of $J$ in determining the competitiveness of $U$ through the input it supplies to $C_{2}$. The benchmark IMF measure not only fails to recognize this sectoral heterogeneity, but also implicitly assumes that all trade is in final goods, and hence no part of production carried out in $J$ is consumed in $U$. This is evident from a value of zero assigned to $W_{U J}$ under IMF framework.

Note that since neither sector in $U$ uses intermediate inputs and consequently there is no distinction between value added and gross output, and Q-REER and GVC-REER weights coincide. This equivalence breaks down only when a country imports intermediate inputs, as is the case with $C$ in this example. In this case $W_{C J}$ is higher in GVC-REER $\left(W_{C J}=0.56\right)$ than it is under the Q-REER $\left(W_{C J}=-1.33\right)$. In fact, in the latter case $W_{C J}$ is actually negative, implying that a fall in J's prices leads to an increase in the demand for $C$ 's output (although not of its value added) as it embodies the output of $J_{1}$ which becomes more competitive with the fall in its price.

\section{Sectoral heterogeneity and REER indices}

The second dimension of sectoral heterogeneity which leads to an improvement in our REER measure compared to others in the literature is the flexibility to incorporate hetero- 
Table 2 - REER weight assigned by $U$ to $J$ and $C$ under different weighting schemes for example 2.5

\begin{tabular}{ccccc}
\hline & GVC-REER & VAREER (BJ) & IMF & Q-REER \\
\hline$W_{U J}$ & 0.57 & 0.36 & 0 & 0.57 \\
$W_{U C}$ & 0.43 & 0.63 & 1 & 0.43 \\
\hline
\end{tabular}

Notes: GVC-REER and Q-REER are measures proposed in this paper. "VAREER (BJ)" stands for the value added exchange rate measure proposed in BJ and "IMF" stands for the IMF REER measure based on Bayoumi et al. (2005).

geneity in sectoral prices. As an example, consider the implications for the REER of $U$ when the price of $C_{1}$ increases, and all other prices remain unchanged (i.e $\hat{p_{c_{1}}}=1, \hat{p_{c_{2}}}=0$, $\left.\hat{p_{J_{1}}}=\hat{p}_{J_{2}}=p_{U_{1}}=p_{U_{2}}=0\right)$. Since the value added share of $C_{1}$ and $C_{2}$ in $\mathrm{C}$ are 0.57 and 0.43 respectively, the computed change in aggregate price index in $C$ is given by $\hat{p}_{c}=0.57$. Given a value of $W_{U C}=0.43$, a measure like VAREER which uses aggregate (country level) price indices and weights would compute the change in REER for $U$ that is different from $G V C-R E E R$, which recognizes that the entire weight of $W_{U C}$ is concentrated on $C_{2}$, and since $\hat{p_{c_{2}}}=0$, the $G V C-\hat{R E E} R_{U}=0$ as well. In particular:

$$
\begin{aligned}
V A \widehat{R E E} R_{U} & =W_{U C} \hat{p_{c}}=0.57 * 0.43=0.25 \\
G V C \widehat{-R E E} R_{U} & =W_{U C_{1}} \hat{p_{c_{1}}}+W_{U C_{2}} \hat{{p_{2}}_{2}}=0 * 1+0.43 * 0=0
\end{aligned}
$$

Since the only price change concerns the sector in $C$ which is entirely domestically oriented, competitiveness of $U$ should not be affected, as rightly concluded by the GVC-REER measure. Indeed, as evident in Table 3 which shows the full sector level GVC-REER weighting matrix, the weight assigned by both sectors on $U$ on $C_{1}$ is zero. ${ }^{1415}$

On the other hand, the aggregation implicit in VAREER and all other measures in the

\footnotetext{
${ }^{14}$ The diagonal entries in Table 1 are negative, indicating that an increase in "own" price has a negative impact on demand for value added, as opposed to all other prices which have a positive impact on the demand for value added from the particular country-sector.

${ }^{15}$ Note that the diagonal entries are negative (and normalized to one), indicating that an increase in its own price has a negative impact on the demand for value added for the respective country-sector. A correspondence between the numbers reported in Table 2 and Table 3 can be seen using an application of equation 2.25 (lower case is used to denote value added shares $\left(v_{U_{i}}=\frac{p_{u_{i} V_{U}}^{V}}{P_{U} V_{U}}\right)$

$\frac{W_{U J}(G D P d e f)}{W_{U C}(G D P d e f)}=\frac{v_{U_{1}}\left(W_{U_{1} J_{1}}+W_{U_{1} J_{2}}\right)+v_{U_{2}}\left(W_{U_{2} J_{1}}+W_{U_{2} J_{2}}\right)}{v_{U_{1}}\left(W_{U_{1} C_{1}}+W_{U_{1} C_{2}}\right)+v_{U_{2}}\left(W_{U_{2} C_{1}}+W_{U_{2} C_{2}}\right)}=\frac{\left(\frac{2}{3}\right) 0.41+\left(\frac{1}{3}\right) 0.32}{\left(\frac{2}{3}\right) 0.31+\left(\frac{1}{3}\right) 0.24} \simeq 1.33 \simeq \frac{W_{U J}}{W_{U C}}=\frac{0.57}{0.43}$
}

Where the last ratio corresponds to values in Table 2. Note that since we follow the practice of normalization of weights (such that own weights are equal to -1), the correspondence only obtains in ratios and not in levels. 
Table 3 - Country-Sector level weighting matrix for 2.5

\begin{tabular}{|c|c|c|c|c|c|c|c|}
\hline & & \multicolumn{2}{|c|}{$\mathrm{J}$} & \multicolumn{2}{|c|}{$\mathrm{C}$} & \multicolumn{2}{|c|}{$\mathrm{U}$} \\
\hline & & $J_{1}$ & $J_{2}$ & $C_{1}$ & $C_{2}$ & $U_{1}$ & $U_{2}$ \\
\hline \multirow{3}{*}{$\mathrm{J}$} & & -1 & 0.25 & 0.19 & 0.18 & 0.26 & 0.13 \\
\hline & $J_{2}$ & 1 & -1 & 0 & 0 & 0 & 0 \\
\hline & $C_{1}$ & 0.57 & 0 & -1 & 0.43 & 0 & 0 \\
\hline $\mathrm{C}$ & $C_{2}$ & 0.29 & 0 & 0.23 & -1 & 0.32 & 0.16 \\
\hline \multirow{2}{*}{$\mathrm{U}$} & $U_{1}$ & 0.41 & 0 & 0 & 0.31 & -1 & 0.29 \\
\hline & $U_{2}$ & 0.32 & 0 & 0 & 0.24 & 0.44 & -1 \\
\hline
\end{tabular}

literature limits their flexibility in properly deciphering such distinctions.

\subsection{Sticky prices, dollar invoicing and GVC-REER}

Like all previous attempts to quantify competitiveness via REER, the model used in this paper assumes perfect competition, and does not allow for market power and market segmentation, or for markups to vary in a meaningful way across destinations. In particular, each producer can set only one price which is common to both the domestic and each of the international markets that the product is sold in (when measured in a common currency). Under these assumptions, in section 2.4 we derived an expression for the GVC-corrected REER as follows:

$$
\triangle \log (G V C-R E E R)=W_{V}(C) \operatorname{vec}\left(\hat{p}(V)^{c}\right)
$$

In vector notation, this can be written as

$$
R \widehat{E E} R_{C}=\sum_{i \neq c} w_{c, i}\left(\hat{p}(v)_{i}-\hat{p}(v)_{c}\right)
$$

Here, $\hat{p}(v)_{i}$ and $\hat{p}(v)_{c}$ denote the changes in prices of value added in countries $i$ and $c$ respectively, measured in a common currency. If for example all prices are sticky in a particular currency (say the dollar), then $\hat{p}(v)_{i}=\hat{p}(v)_{c}=0$, and therefore $R E \hat{E} R_{c}=0$. Note that this possibility is not ruled out by the theoretical framework. On the other hand, if price stickiness differs across markets, then a single measure of price for each country $\left(\hat{p}(v)_{c}\right)$ will not be sufficient to capture price dynamics and movements in competitiveness. This would be the case for instance in a world in which the invoicing currency is different for domestic sales and exports, and prices are sticky in the currency of invoicing, as argued by Goldberg and Tille (2008) and Casas et al. (2016). We next discuss how a generalization of our framework can in principle be used to accommodate various forms of market segmentation including 
Table 4 - Country level input output table

\begin{tabular}{|c|c|c|c|c|c|c|c|}
\hline & $\mathrm{J}$ & $\mathrm{C}$ & $\mathrm{U}$ & $\mathrm{J}$ final & C final & U final & Total output \\
\hline $\mathrm{J}$ & 0 & $\mathrm{X}$ & 0 & $\mathrm{X}$ & 0 & 0 & $\mathrm{X}$ \\
\hline $\mathrm{C}$ & 0 & 0 & 0 & $\mathrm{X}$ & $\mathrm{X}$ & $\mathrm{X}$ & $\mathrm{X}$ \\
\hline $\mathrm{U}$ & 0 & 0 & 0 & 0 & 0 & $\mathrm{X}$ & $\mathrm{X}$ \\
\hline Value added & $\mathrm{X}$ & $\mathrm{X}$ & $\mathrm{X}$ & & & & \\
\hline Total output & $\mathrm{X}$ & $\mathrm{X}$ & $\mathrm{X}$ & & & & \\
\hline
\end{tabular}

dollar invoicing of exports. We do this in the context of a stylized three country model.

Market segmentation and competitiveness in a stylized three country world ${ }^{16}$

Consider a three country, one sector world economy illustrated in Table 4 (this is a one-sector version of the economy considered in section 2.5). "X" denotes all cells with non zero entries in the input output table.

The production functions for three countries are given by:

$$
\begin{gathered}
Q^{C}=\left(V^{C}\right)^{\omega^{C}}\left(X^{J, C}\right)^{1-\omega^{C}} \\
Q^{U}=V^{U} \\
Q^{J}=V^{J}
\end{gathered}
$$

Final goods consumption aggregators for the three countries are as follows:

$$
\begin{gathered}
F^{J}=\left(F^{J, J}\right)^{\eta^{J}}\left(F^{C, J}\right)^{1-\eta^{J}} \\
F^{C}=F^{C, C} \\
F^{U}=\left(F^{U, U}\right)^{\eta^{U}}\left(F^{C, U}\right)^{1-\eta^{U}}
\end{gathered}
$$

\footnotetext{
${ }^{16}$ See de Soyres et al. (2018) for a similar exercise on the characterization of price movements on exports in a bilateral setting.
} 
As shown in appendix F, the expression for GVC-REER for country $C$ in this economy can be written as follows ${ }^{17}$

$$
\begin{aligned}
G V C \widehat{-R} E E R^{C} & =\hat{V}^{C}=-\left(1-\omega^{V}\right)\left(\hat{p}^{C, C}-\hat{p}^{J, C}\right)+\eta^{U}\left(\frac{P^{C, U} F^{C, U}}{P(Q)^{C} Q^{C}}\right)\left[\hat{p}^{U, U}-\hat{p}^{C, U}\right] \\
& +\eta^{J}\left(\frac{P^{C, J} F^{C, J}}{P(Q)^{C} Q^{C}}\right)\left[\hat{p}^{J, J}-\hat{p}^{C, J}\right]
\end{aligned}
$$

Note that instead of a total of three prices (one for each country, as in the benchmark equation 2.34), we now have six different prices appearing in this expression. With perfect competition and no market segmentation, $\hat{p}^{C, C}=\hat{p}^{C, U}=\hat{p}^{C, J}$ and $\hat{p}^{J, C}=\hat{p}^{J, J}$, which reduces equation 2.41 to the generalized form 2.34. If on the other hand prices differ across markets, then equation 2.34 cannot be simplified further, and information on all export prices at the bilateral level (separately for intermediate and final goods exports) as well as domestic prices are needed to compute the GVC-REER. Even if we impose the dominant currency paradigm and assume that all international prices in a particular currency (say the US dollar), then the expression can be simplified (as $\hat{p}^{C, U}=\hat{p}^{C, J}$ ), but still requires more information on prices than in our benchmark model.

To illustrate the impact of different pricing assumptions, consider an adverse supply shock which raises costs of production in country $C$. This has the following (negative) impact on competitiveness $C$

$$
\begin{aligned}
G V C \widehat{-R} E E R^{C} & =\hat{V}^{C}=-\left(1-\omega^{V}\right)\left(\hat{p}^{C, C}\right)-\eta^{U}\left(\frac{P^{C, U} F^{C, U}}{P(Q)^{C} Q^{C}}\right)\left[\hat{p}^{C, U}\right] \\
& -\eta^{J}\left(\frac{P^{C, J} F^{C, J}}{P(Q)^{C} Q^{C}}\right)\left[\hat{p}^{C, J}\right]
\end{aligned}
$$

Case 1: Perfect competition $(\mathrm{PC})\left(\hat{p}^{C, C}=\hat{p}^{C, U}=\hat{p}^{C, J}>0\right)$

$$
\begin{aligned}
G V C-\widehat{R E E} R(P C)^{C} & =\hat{V}^{C}=-\left(1-\omega^{V}\right)\left(\hat{p}^{C, C}\right)-\eta^{U}\left(\frac{P^{C, U} F^{C, U}}{P(Q)^{C} Q^{C}}\right)\left[\hat{p}^{C, C}\right] \\
& -\eta^{J}\left(\frac{P^{C, J} F^{C, J}}{P(Q)^{C} Q^{C}}\right)\left[\hat{p}^{C, C}\right]
\end{aligned}
$$

Case 2: Dollar pricing (DP) $\left(\hat{p}^{C, C}>0, \hat{p}^{C, U}=\hat{p}^{C, J}=0\right)$

\footnotetext{
${ }^{17}$ This expression is derived under the assumption that in steady state, prices in domestic and foreign markets are equal, despite market segmentation.
} 


$$
G V C-\widehat{R E E} R(D P)^{C}=\hat{V}^{C}=-\left(1-\omega^{V}\right)\left(\hat{p}^{C, C}\right)
$$

Since $\eta^{U}\left(\frac{P^{C, U} F^{C, U}}{P(Q)^{C} Q^{C}}\right)\left[\hat{p}^{C, C}\right]>0$ and $\eta^{J}\left(\frac{P^{C, J} F^{C, J}}{P(Q)^{C} Q^{C}}\right)\left[\hat{p}^{C, C}\right]>0$, equations 2.43 and 2.45 reveal that the impact of the shock on competitiveness of $C$ will be muted in the case of dollar pricing, as expected, since the higher costs are not passed on to the price of exports.

While a complete extension on either the modeling or empirical remains beyond the scope or the present treatise (not least because it requires sectoral pricing data at a level of granularity that is not commonly available), this illustrative exercise nevertheless serves to highlight the caveats of interpreting high frequency movements in REERs computed using perfect competition frameworks like ours, and shows that they are more useful for inferring movements in competitiveness at longer horizons of at least a year or more, which is the typical duration of price stickiness (Bils and Klenow (2004))

\section{Empirical Results}

Our main source of data is the World Input-Output Database (WIOD), which provides a time series of input-output tables covering 40 countries and 35 sectors from 1995-2009 ${ }^{18} \mathrm{~A}$ detailed description of this database can be found in Timmer and Erumban (2012).

In order to focus on the role of sectoral heterogeneity, in this section we focus exclusively on the case with uniform elasticities. Appendix G provides a detailed discussion for the heterogenous elasticity case, including the estimation of elasticities and their incorporation in GVC-REERs.

\subsection{REER Weights}

Table 5 summarizes the different REER weighting matrices that are generated by our framework. In addition to the country level weights which have been studied in the literature, our framework also provides weights at various levels of disaggregation. Each of these could be of interest depending on the question at hand, and provide information which cannot be captured in the aggregated country level weights. For instance, if a price shock (whether through tariffs, productivity or the nominal exchange rate) has a heterogenous impact across different sectors in the country of origin, then the country by country-sector weighting matrix (row (2)) would provide a more accurate estimate of the impact on a foreign country as

\footnotetext{
${ }^{18}$ In this section we report the results using the 2013 release of WIOD, which covers the period 1995-2011 (with price data only available till 2009). The dataset and corresponding figures and tables using the 2016 release, which covers 2000-2014, are available upon request.
} 
Table 5 - Summary of REER weights

\begin{tabular}{lcc}
\hline & & Dimension \\
\hline & & \\
$(1)$ & Country by country & $\mathrm{n}$ by n by T \\
$(2)$ & Country by country-sector & $\mathrm{n}$ by nm by T \\
$(3)$ & Country-sector by country & $\mathrm{nm}$ by n by T \\
$(4)$ & Country-sector by country-sector & $\mathrm{nm}$ by nm by T
\end{tabular}

Note: $\mathrm{n}=$ number of countries, $\mathrm{m}=$ number of sectors, $\mathrm{T}=$ number of time periods in the sample.

Table 6 - Ranking of Countries According to REER Weight Assigned by Japan

\begin{tabular}{cccc}
\hline Rank & GVC-REER & Goods-REER & IMF \\
\hline & 'ROW' & 'ROW' & 'ROW' \\
1 & 'United States' & 'China' & 'China' \\
2 & 'China' & 'United States' & 'United States' \\
3 & 'Germany' & 'Korea' & 'Korea' \\
4 & 'Korea' & 'Taiwan' & 'Taiwan'
\end{tabular}

Notes: "ROW" stands for the rest of the world region in WIOD. "IMF" and "Goods-REER" correspond to weighting schemes proposed in Bayoumi et al. (2005) and Bayoumi et al. (2013) respectively.

opposed to the country by country weighting matrix (row (1)).

As an example to illustrate the difference in REER weights in our measure compared to others in the literature, Table 6 shows the ranking of 5 largest competitor countries for Japan in the year 2007 based on the different country-level REER schemes discussed above. The GVC-REER scheme, which acknowledges the prominence of supply chain trade between China and Japan, assigns a lower weight to China, recognizing that the final destination of exports from Japan to China is not always China itself, whereas the standard IMF weighting scheme which fails to make this distinction assigns a higher weight to China than the US, due to the high volume of gross trade between China and Japan.

With the prominence of global value chains and the accompanying divergence between gross and value added exports that has been documented in the literature, our analysis allows us to see how the relationship between gross output and value added competitiveness has evolved over time. Figure 3.1 plots the cross-sectional correlation between value added (GVC-REER) and gross output (Q-REER) REER weights for the 17 years in the sample 
Figure 3.1 - Correlation between Value added and Gross Output REER Weights

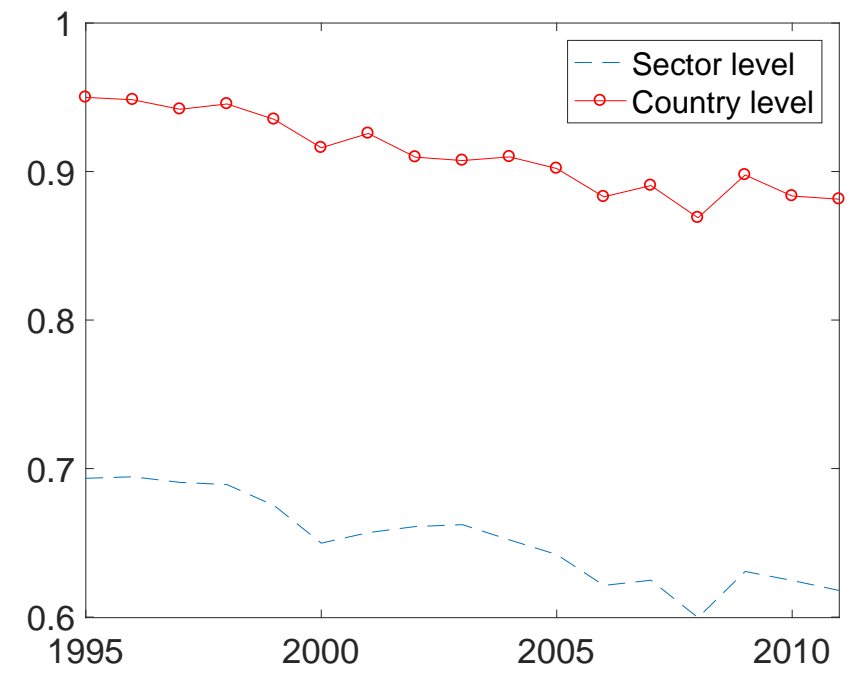

(1995-2011), showing a marked downward trend for both country and sectoral level weights.

\subsection{Sectoral REERs}

Next we combine the weights with price indices the sector level to compute REER indices. We find that sectoral GVC-REERs exhibit a substantial dispersion across countries (Figure 3.3). In the case of the US for instance, the heterogeneity in competitiveness between sectors is evident in the divergence between the electrical and optical equipment sector which has made large gains in competitiveness (as evidenced by the large decline/depreciation in REER), whereas the construction sector has moved in the opposite direction and lost competitiveness significantly. Similarly "Real estate" and "social and personal services", two large Chinese sectors, show opposite trends.

To further quantify the extent of divergence in competitiveness across sectors within a country, table 7 lists countries with the highest and lowest dispersion across sectoral GVCREERs, as measured by the average standard deviation of cross-sectional REER movements across sectors within a country in a year. The numbers show that the cross-sectional dispersion is substantial, even for the country with the lowest dispersion. In particular, on average, a standard deviation of the yearly changes in GVC-REER between different sectors is between $20 \%$ (Czech Republic) and 2\% (Malta).

Looking across countries at the evolution of competitiveness across different sector classes between 1995 and 2009, we find that Manufacturing ("secondary") sectors have experienced the sharpest fall in competitiveness both in value added and gross output terms, which 
Figure 3.2-Comparison of three REER indices for select countries
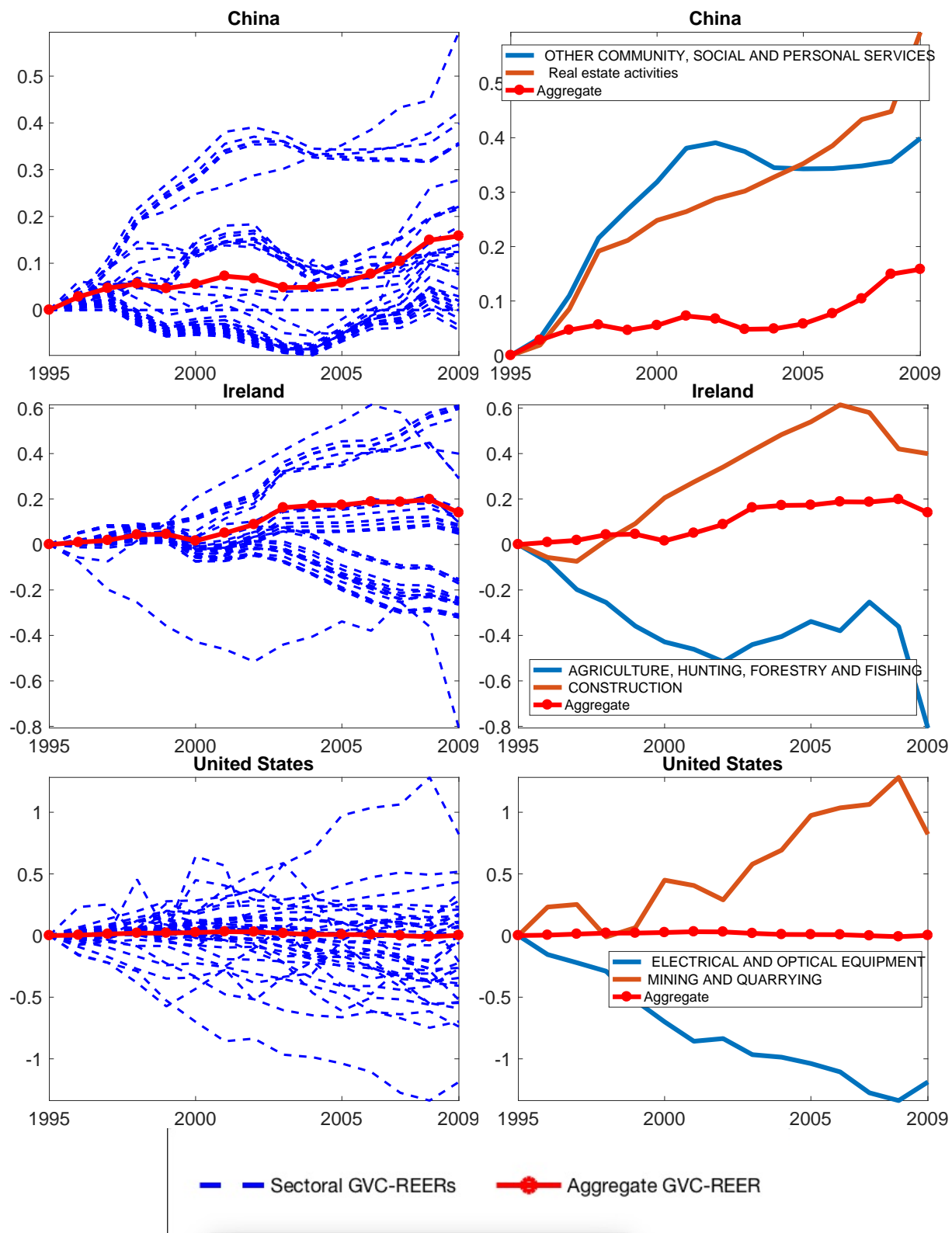
Table 7-Countries with highest and lowest divergence of REERs across sectors

\begin{tabular}{cccc}
\hline \multicolumn{2}{c}{ High Dispersion } & \multicolumn{2}{c}{ Low Dispersion } \\
\hline & & & \\
Czech Republic & 0.19 & Malta & 0.02 \\
Slovak Republic & 0.15 & China & 0.03 \\
Russia & 0.13 & Ireland & 0.04 \\
Bulgaria & 0.12 & Taiwan & 0.04 \\
Sweden & 0.11 & Spain & 0.05
\end{tabular}

Notes: This table shows 5 countries with the highest and lowest dispersion of REER movements across sectors. The dispersion is computed as the average standard deviation of REER movements within a country (i.e an average of 14 observations on the standard deviation for each time period).

Table 8 - Median Change in competitiveness from 1995-2009 across different sector groups

(a)

\begin{tabular}{|c|c|c|c|c|c|c|c|}
\hline \multicolumn{4}{|c|}{ GVC-REER (value added) } & \multicolumn{4}{|c|}{ Q-REER (Gross output) } \\
\hline & Primary & Secondary & Tertiary & & Primary & Secondary & Tertiary \\
\hline EME & -0.05 & 0.07 & -0.10 & EME & -0.06 & 0.06 & -0.08 \\
\hline $\mathrm{AE}$ & 0.07 & 0.10 & -0.09 & $\mathrm{AE}$ & 0.14 & 0.12 & -0.10 \\
\hline
\end{tabular}

Notes: The numbers represent simple medians of the cumulative change in the effective exchange rate from 1995 to 2009. "EME" and "AE" denotes emerging markets and advanced economies respectively. Full list of countries, sectors and respective classifications is available in Appendix I.

services ("tertiary)" sectors have gained competitiveness ${ }^{19}$. The primary sector has lost competitiveness in advanced economies, but has gained moderately in EMEs.

Our paper is the first to use a framework for computing REERs at the sectoral level that takes into account both input output linkages and sectoral heterogeneity in both REER weights and prices. These turn out to be significant departures in practice. As an illustration, Figure 3.3 shows a comparison between the GVC-REER and Q-REER measures proposed in this paper with two measures of sectoral REERs used by Goldberg (2004), for the electrical and optical equipment sector, a sector which is heavily involved in global value chains. For the US, the price of electrical and optical equipment has seen a sharp secular decline through the sample period, and this rightfully dominates the overall trend in GVC-REER and Q-REER which incorporate the sectoral price, unlike the measures of Goldberg (2004) which work with

\footnotetext{
${ }^{19}$ Complete classification of countries and sectors is given in Appendix I.
} 
country level prices. For China as well, the two sets of REERs show fairly different patterns. The main takeaway from such illustrations is that the additional information incorporated in the GVC-REER and Q-REER computational framework leads to significant differences when taken to the data.

\subsection{Aggregate Country level REERs}

Figure 3.4 illustrates a comparison between three different REER indices. The GVC-REER is our proposed measure of REER which incorporates input-output linkages as well as sectoral heterogeneity (in both REER weights as well as price indices). The VAREER corresponds to the value-added REER measure proposed in BJ which accounts for input-output linkages but not sectoral heterogeneity. IMF-REER is a measure which uses the IMF weighting scheme that ignores both input-output linkages as well as sectoral heterogeneity. ${ }^{20}$

As is evident in the figure differences between the measures are particularly pronounced for certain countries in certain time periods. It is also pertinent to note that the the IMR-REER and VAREER tend to have a higher comovement with one another compared to that with the GVC-REER, an observation which also confirmed later in their ability to explain the behavior of exports (section 3.6). This suggests that accounting for sectoral heterogeneity is even more important than merely accounting for the presence of input-output linkages at the aggregate country level as is done by BJ.

Our framework allows us to study the competitiveness of value added separately from that of gross output. Figure 3.5 shows a comparison of value added competitiveness (GVC-REER) and gross output competitiveness (Q-REER) for select countries. It is interesting to see that for China, the GVC-REER has appreciated in a much more secular manner compared to the more volatile Q-REER and shows a higher overall appreciation. This reflects the fact that even as Chinese labor has become more expensive over these years, the fall in imported input costs has been responsible for cushioning the impact of this rise in labor costs on output and gross output and exports. This patten also shows how ignoring value added components and looking at gross output competitiveness can lead to a false inference of the Chinese currency being undervalued.

\footnotetext{
${ }^{20}$ To make the comparison more transparent, we use the GDP deflator in constructing the IMF-REER, instead of CPI or unit labor cost which are the other commonly used alternatives.
} 
Figure 3.3-Comparison of sectoral REERs indices for the electronics sector
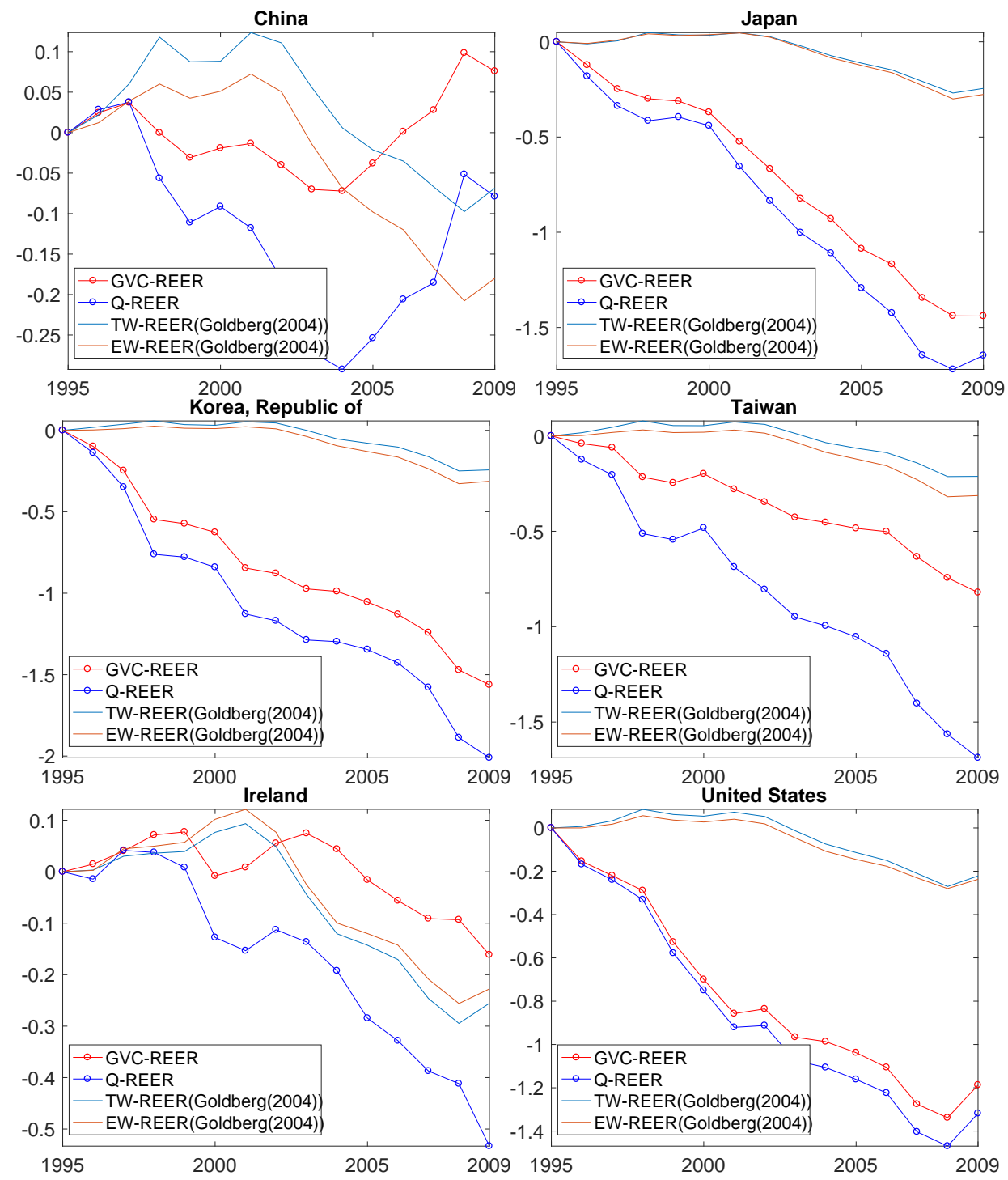

Notes: GVC-REER and Q-REER are measures proposed in this paper. TW-REER and EW-REER are trade and export weighted REERs respectively, computed at the sector level using the framework proposed by Goldberg (2004). 
Figure 3.4 - Comparison of three REER indices for select countries
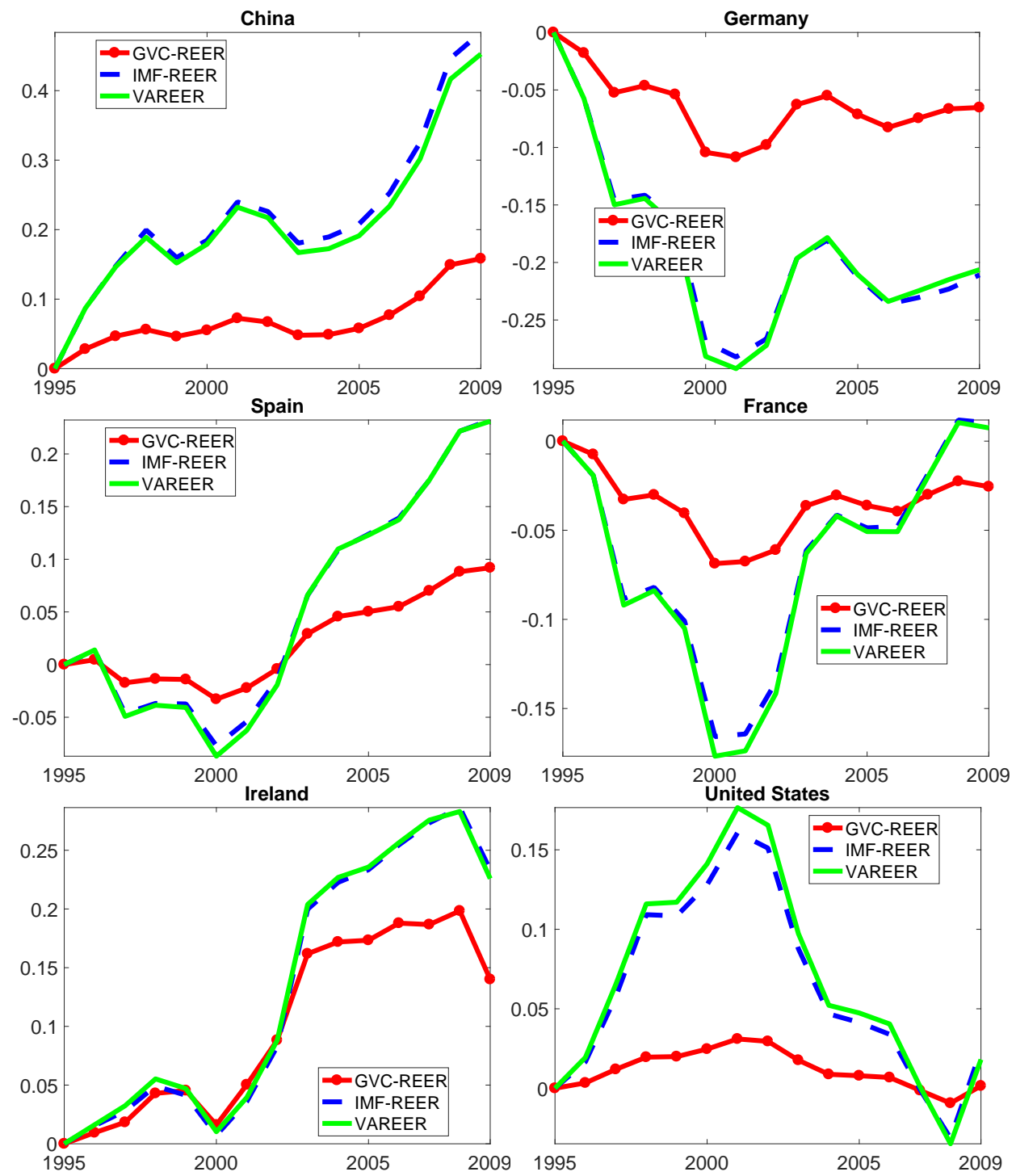

Comparison of three REER indices for select countries. The GVC-REER is our proposed measure of REER which incorporates input-output linkages as well as sectoral heterogeneity (in both REER weights as well as price indices). The VAREER corresponds to the valueadded REER measure proposed in Bems and Johnson (2017) which accounts for input-output linkages but not sectoral heterogeneity. IMF-REER is a measure which uses the IMF weighting scheme that ignores both input-output linkages as well as sectoral heterogeneity. 
Figure 3.5 - Comparison of GVC-REER and Q-REER for select countries
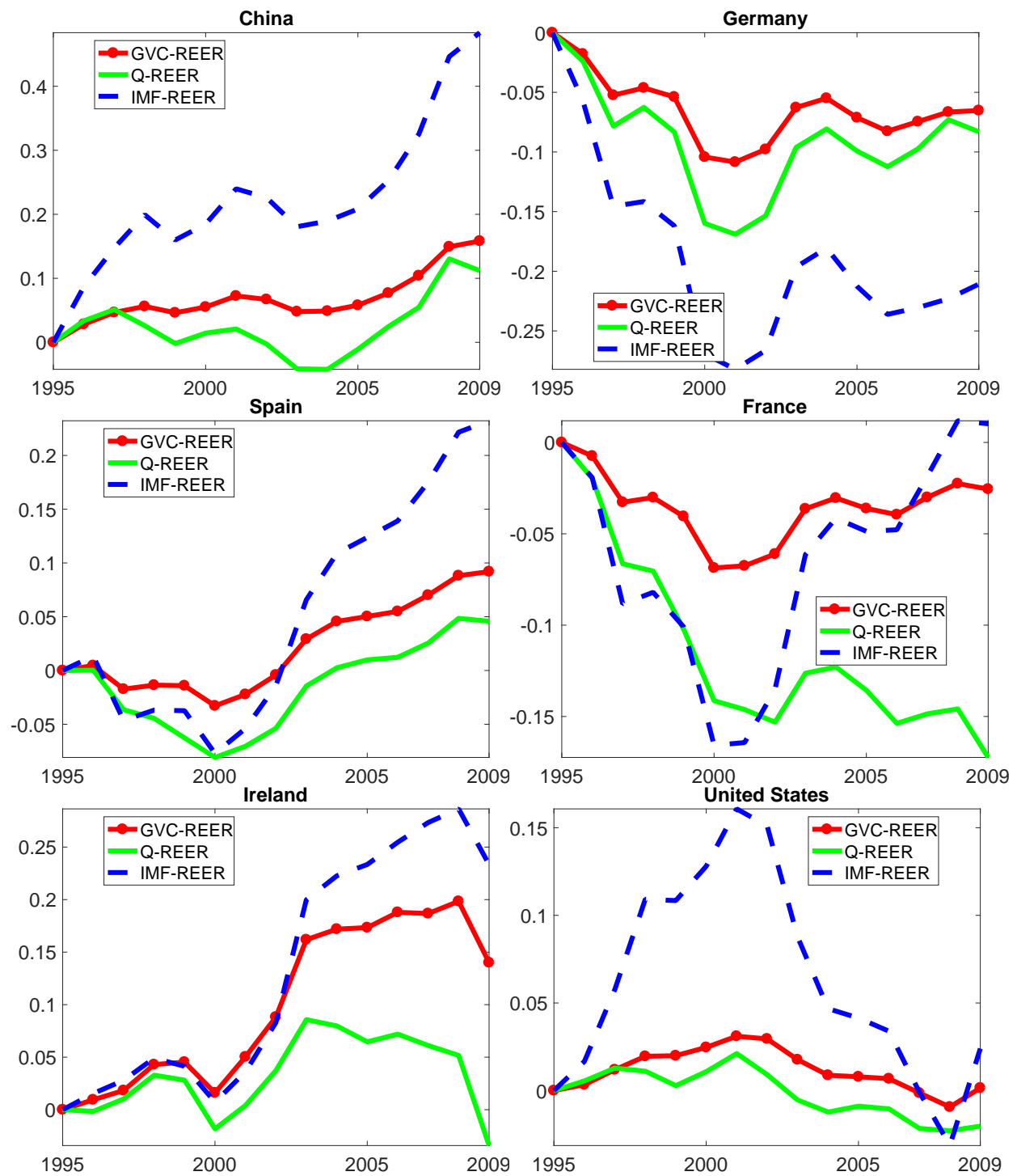

Comparison of GVC-REER and Q-REER for select countries. GVC-REER measures value added competitiveness, whereas Q-REER measures competitiveness of gross output produced by the country. 


\section{Examining the difference between GVC-REER and VAREER: The role of sec- toral heterogeneity}

As shown in the preceding sections, the GVC-REER measures improve upon VAREER by incorporating sectoral heterogeneity, which enters the former in two forms (i) REER weights, and (ii) price indices. A first indication of the degree to which sectoral heterogeneity is important is provided in the dispersion of sectoral REERs within countries (Left panels in figure 3.2 and Table 7).

To further investigate the nature and source of differences between the two measures, we decompose the difference into a term that captures the contribution of weights, and the remaining term which captures the contribution of differences in prices using the following framework.

$$
\begin{aligned}
R E E R \_G A P_{i t}= & V A R E E R_{i t}-\left(G V C-R E E R_{i t}\right) \\
= & \underbrace{\sum_{j=n}^{n} W_{t}^{i, j, V A R E E R} \hat{p}_{t}^{j}-\sum_{j=1}^{n} \sum_{s=1}^{m} W_{s, t}^{i, j, G V C-R E E R} \hat{p}_{s, t}{ }^{j}}_{\text {Term } 1} \\
= & \underbrace{\sum_{j=1}^{n}\left(W_{t}^{i, j, V A R E E R}-W_{t}^{i, j, G V C}\right) \hat{p}_{t}^{j}}_{\text {Term } 2} \\
& +\underbrace{W_{t}^{i, j, G V C} \hat{p}_{t}^{j}-\sum_{s=1}^{n} \sum_{s, t}^{m} W^{i, j, G V C-R E E R} \hat{p}_{s, t}^{j}}_{j=1}
\end{aligned}
$$

Here, $W_{t}^{i, j, V A R E E R}$ is the VAREER weighting matrix, $W_{s, t}^{i, j, G V C-R E E R}$ is the $n$ by $n m$ GVC-REER weighing matrix, and $W_{t}^{i, j, G V C}$ is the $n$ by $n$ GVC-REER weighting matrix designed to measure the departure of weights from VAREER. $\hat{p}_{t}^{j}$ is the $n$ dimensional vector of changes in the GDP deflator and $\hat{p_{s, t}}{ }^{j}$ is the $n m$ dimensional vector of sectoral price changes.

Table 9 shows a decomposition of the cumulative difference (between 1995 and 2009) between the VAREER and GVC-REER for select countries. For Brazil for instance, the table shows that the difference between the VAREER and GVC-REER between 1995 and 2009 is $4.99 \%$, implying that the Brazilian real effective exchange rate appreciated more by $4.99 \%$ according to VAREER as opposed to GVC-REER. Of this difference of , $-7.53 \%$ is attributable to differences in weighs between the two measures, and the remainder $(+2.54 \%)$ is attributable to differences in prices, implying that allowing for only sectoral heterogeneity in computing weights would have led to a larger gap pf $7.53 \%$.

Table 9 highlights the higher contribution of REER weights in explaining the gap between 
Table 9 - Decomposing the difference between GVC-REER and VAREER

\begin{tabular}{cccc}
\hline Country & REER GAP (\%) & \multicolumn{2}{c}{ Contributions (share in \%) } \\
\hline & & Weights & Prices \\
'Brazil' & -4.99 & -7.53 & 2.54 \\
'China' & -29.44 & -29.98 & 0.54 \\
'Germany' & 14.1 & 13.28 & 0.82 \\
'India' & -4.92 & -6.82 & 1.9 \\
'Romania' & -36.24 & -39.11 & 2.87 \\
'United States' & -1.66 & -1.64 & -0.02 \\
median & -5.44 & -7.3 & 0.82
\end{tabular}

REER GAP denotes the cumulative (from 1995-2009) difference between VAREER and GVC-REER in percentage points.

Figure 3.6 - Comparison of VAREER and GVC-REER weights for China and Ireland
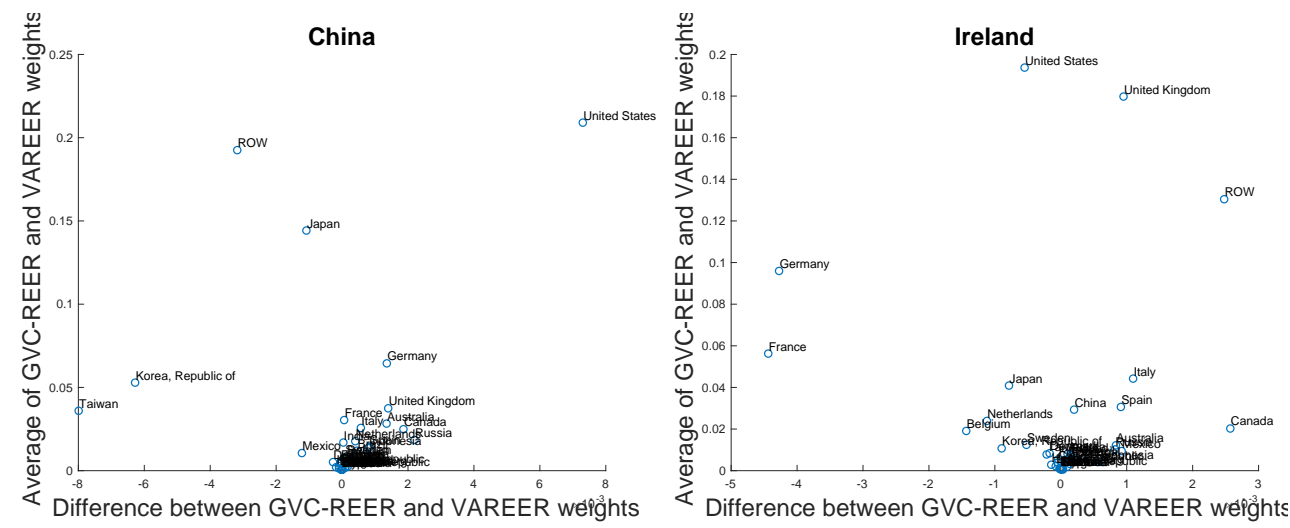

VAREER and GVC-REER. Figure 3.6 investigates this further for two countries. It shows that the differences between weights that incorporate sectoral heterogeneity (GVC-REER), and those that don't (VAREER) are higher, precisely for those trade partners for which the magnitude of the weights (measured in this case as the average between VAREER and GVCREER weights) is higher. Put differently, sectoral heterogeneity matters more in accounting for the role played by large trade competitors, for which inter-sectoral linkages are likely to be more complex and hence misrepresented by an aggregate country-level measure. As evident in figure 3.6, these trade partners that are responsible for generating large differences between GVC-REER and VAREER are the US, Japan, Korea and Taiwan in the case of China, and France, Germany and Canada in the case of Ireland.

As an example, real estate and personal and social services are large sectors in the Chinese economy, but are mostly domestic. Hence, their large appreciation (Right panel in Figure 3.2) is captured in the VAREER, but appropriately down weighted in the GVC-REER. 
Table 10 - Stability of GVC_REER weights over time: Correlation between time varying and fixed weight $G V C$-REERs

\begin{tabular}{ccc}
\hline Level of aggregation & Country level GVC-REER & Sector level GVC-REER \\
\hline Correlations & & \\
mean & 0.995 & 0.994 \\
maximum & 0.998 & 1.00 \\
minimum & 0.95 (Indonesia) & 0.77 \\
No. Of observations & 41 & 1435
\end{tabular}

Notes: This table summarizes correlations between GVC-REERs computed using time varying and fixed weights. For GVC-REER with time varying weights, weights are allowed to change in every time period and are calibrated using current year input-output tables. For the fixed weight GVC-REER, weights for the year 2005 are applied to all years in the sample (1995-2009)

\subsection{Stability of GVC-REER weights across time}

The preceding section showed the importance of accounting for sectoral heterogeneity in computing REER weights. Sectoral input-output data required to compute our benchmark GVC-REER indices is often only available at low frequency (annual or less) and with significant lags. This potentially challenges the usefulness of the GVC-REER framework developed in this paper to compute and update REERs in a timely manner. In order to check the stability of GVC-REER weights over time, we recompute them using fixed weights (calibrated to the year 2005). Table 10 shows that these GVC-REER indices computed with fixed weights exhibit a high degree of correlation with the original ones with time-varying weights, both at the country and sector level. This indicates that time variation weights is minimal and is not a significant source of variation in the GVC-REER measures, and hence using lagged input-output data to compute the GVC-REER weights is unlikely to be a major source of bias in the measurement of REER.

\subsection{Bilateral Real Exchange Rates}

The bilateral real exchange rate (RER) between countries $h$ and $f$ is typically defined as follows:

$$
R E R^{h f}=\hat{p}(V)^{f}-\hat{p}(V)^{h}
$$


where $\hat{p}^{f}$ and $\hat{p}^{h}$ are changes in aggregate (country wide) price indices measured in a common currency.

Based on the the insights gained from the previous sections we argue that to measure competitiveness of one country against another in a bilateral context, a modified version of the GVC framework proposed in this paper provides an improvement over the standard RER measures computed using an aggregate price index (such as those in Chinn, 2006) like the GDP deflator. The key insight is the same as before, that ignoring trade in intermediates and/or sectoral heterogeneity can lead to incorrect inferences regarding movements in price competitiveness. For instance, an overall increase in GDP deflator in country A relative to country B could indicate a depreciation or an increase in competitiveness for A, even if the sectors in $\mathrm{B}$ which compete more intensively with A experience an increase in relative prices. $^{21}$

We define our bilateral RER measure, the "GVC-RER" as follows

$$
G V C-R E R^{h f}=\sum_{i=1}^{m} v_{i}^{h}\left[\sum_{j=1}^{m} w_{i j}^{h h} \hat{p}(V)_{j}^{h}+\sum_{j=1}^{m} w_{i j}^{h f} \hat{p}(V)_{j}^{f}\right]
$$

Here, $v_{i}^{h}=\frac{p(V)_{i}^{h} V_{i}^{h}}{\sum_{j=1}^{m} p(V)_{j}^{h} V_{j}^{h}}$ is the share of sector $i$ in country $h$ 's total value added, so that $\sum_{i=1}^{m} v_{i}^{h}=1 .^{22}$ The $w$ s are weights that are analogous to the GVC-REER weights.

Figure 3.7 shows the comparison of the two RER measures for select country pairs. The left panel shows that while China's real exchange rate vis-a vis the US depreciated substantially between 1998 and 2004 when measured using the standard RER measure, GVC-RER measure displays a more secular appreciation through the sample period. ${ }^{23}$ The right panel shows that the loss in competitiveness for Greece (i.e an appreciation) vis a vis Germany is much larger when measured through GVC-RER as opposed to the conventional real exchange rate measure, indicating that the standard bilateral REER measure is underestimating the extent to which lack of inflation in Germany has hurt competitiveness in Greece.

\footnotetext{
${ }^{21}$ Appendix $\mathrm{H}$ provides a numerical example to illustrate this point

${ }^{22}$ Bilateral gross output effective exchange rates (Q-RER) can be defined analogously.

${ }^{23}$ Electrical and optical equipment (WIOD sector 14), a sector which has seen a substantial decline in price in the US through the sample period, provides a useful illustration of this divergence (See also Figure 3.3)While the standard RER measure gives a small weight to this sector in line with its value added share in the US economy, the GVC-RER measure gives a much higher weight, recognizing the importance of this sector as far as competitiveness with China is concerned.
} 
Figure 3.7-Comparison of GVC-RER and standard RER bilateral exchange rates
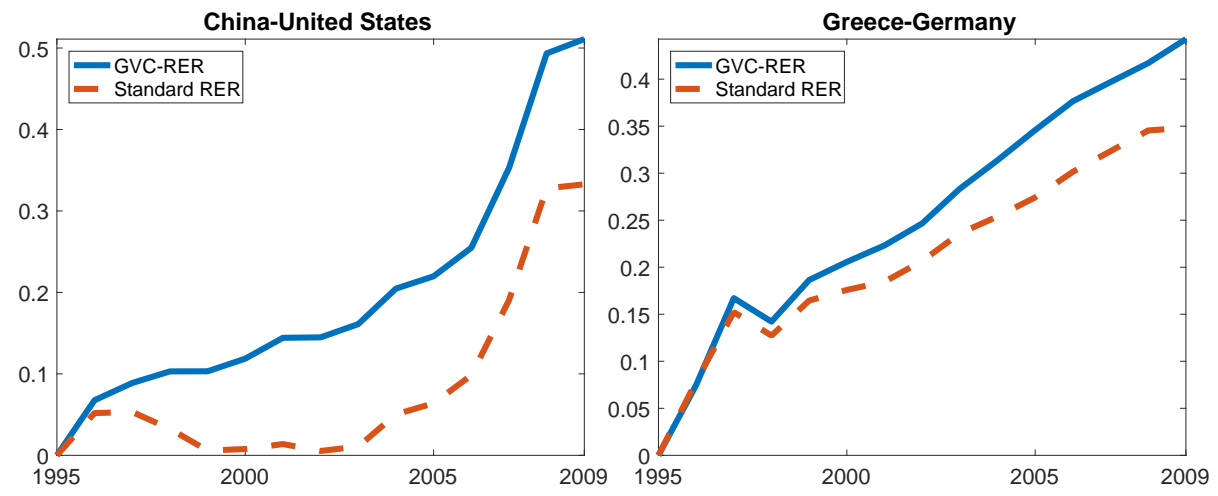

Notes: All indices are in logs and normalized to zero at the start of the sample period so the reading on the value on the y axis can be read as the percentage deviation from the start of the sample. In this figure the IMF convention is adopted so that an increase corresponds to an appreciation. GVC-REER uses weights computed under the uniform elasticity assumption. In computing these indices, the weights are normalized so that the sum of the home country and foreign country weights are equal in magnitude, as is the case with the standard RER measure. Unlike in the GVC-REER effective exchange rate computation, here the normalization of weights cannot be avoided, since otherwise the GVC-RER measure would be dominated by home prices because home sectors (especially the own sector) on average carry much higher GVC-REER weights.

\subsection{Exchange rates and exports}

The responsiveness of exports and imports to changes in the exchange rate is one of the most intensely researched areas in international economics (see Ahmed et al. (2015) and IMF (2015) for recent explorations and an overview of the literature). This section is designed to illustrate the contribution of the new REER measures constructed in shedding more light on this question.

We estimate the following model:

$$
\triangle Y_{i, t}=\beta \triangle \text { Exrate }_{i, t-1}+\text { controls }_{i, t}+\alpha_{i}+\delta_{t}+\epsilon_{i, t}
$$

where $Y_{i, t}$ denotes value added exports and trade balance (normalized by lagged GDP). We compare elasticities of the left hand side variable with respect to different measures of the exchange rate $\left(\right.$ Exrate $\left._{i, t}\right)$. The two measures proposed int his paper (GVC-REER and Q-REER) are compared with the VAREER measure of Bems and Johnson (2017), an Armington-CES REER computed in the spirit of Bems and Johnson (2017), and the BIS REER measure. In the benchmark regressions, we use one variable in the controls $s_{i, t}$ vector, namely the bilateral nominal exchange rate against the US dollar. This choice is motivated by the fact that we are interested in measuring the competitiveness, or "trade" channel of 
exchange rates. As shown by Kearns and Patel (2016) and Hofmann et al. (2016)exchange rates also affect production and exports through a "financial" channel. To control for the financial channel, we include the bilateral US dollar. ${ }^{24}$. We used the lagged value of the exchange rate to further reduce endogeneity and reverse causality concerns.

Tables 11 and 12 summarize the results. The GVC-REER measure proposed in this paper has the highest elasticity for both value added exports and the trade balance. As shown in panel (b), these results are robust to including additional controls in the regression equation. In particular, following Swarnali et al. (2017) and Kearns and Patel (2016), we include additional controls such as the growth rate of foreign demand (computed as an export-share weighted sum of of the GDP of different trading partners), domestic policy rate, GDP deflator, a country specific commodity price index, and the producer price index). ${ }^{25}$

To summarize, The GVC-REER measure substantially improves the explanatory power of exchange rates for exports and the trade balance, underlining the importance of computing the REER using a framework that is conceptually in line with the goal of measuring competitiveness. Indeed, as shown by Swarnali et al. (2017), both upstream and downstream linkages are important to quantify the correct impact of the exchange rate, and our measure accomplishes this.

\section{Conclusion}

With the rising prominence of global value chains in international trade, standard models typically used in the literature to measure price competitiveness via the real effective exchange rate (REER) are increasingly becoming obsolete. In this paper, we provide a framework for computing the REER which allows for the complex patterns of international trade (including imported inputs and global value chains) and sectoral heterogeneity in terms of how different sectors in a country differ in sourcing their inputs as well as selling their output to different entities. In doing so, the paper makes four contributions to the literature on REER measurement.

Firstly, we allow for sectoral heterogeneity within countries. We show that while allowing for intermediate inputs (i.e a distinction between value added and gross trade flows), as has already been done in the literature (most notably Bems and Johnson (2017)), does provide an improvement over classical REER measures, a major further improvement comes from allowing for sectoral heterogeneity. Sectoral heterogeneity affects both components of REER-

\footnotetext{
${ }^{24}$ The results are robust to replacing the dollar exchange rate with a debt-weighted exchange rate as in Kearns and Patel (2016)

${ }^{25}$ As before, all country level controls are in first differences, and lagged one period to limit endogeneity concerns.
} 
Table 11 - Responsiveness of exports to exchange rate

Dependent Variable: value added exports(\% change)

$(1)$

(3)

(4)

(5)

VARIABLES GVC-REER Q-REER VAREER IMF-REER BIS-REER (a) Benchmark regressions

$\begin{array}{cccccc}\text { REER Measure } & \mathbf{- 2 . 9 7 * * *} & \mathbf{- 1 . 3 0 *} & \mathbf{- 1 . 2 4 * *} & \mathbf{- 1 . 1 7 * *} & \mathbf{- 1 . 0 0 *} \\ \text { USD Exchange rate } & 1.12^{* * *} & 0.76^{*} & 1.11^{* *} & 1.06^{* *} & 0.94^{*} \\ \text { Constant } & -0.059^{*} & -0.10^{* * *} & -0.056 & -0.062 & -0.070 \\ & & & & & \\ \text { Observations } & 386 & 386 & 386 & 386 & 386 \\ \text { R-squared } & 0.531 & 0.509 & 0.522 & 0.519 & 0.512 \\ \text { Number of id } & 30 & 30 & 30 & 30 & 30\end{array}$

(b) With additional controls

$\begin{array}{cccccc}\text { REER Measure } & \mathbf{- 3 . 3 1 ^ { * * }} & \mathbf{- 1 . 1 3} & \mathbf{- 1 . 4 8} & \mathbf{- 1 . 1 2} & \mathbf{- 1 . 1 5 * *} \\ \text { USD ex rate } & 1.38^{* *} & 0.78^{*} & 1.58 & 1.26 & 1.36^{* * *} \\ \text { Commodity price } & 0.15 & 0.15 & 0.12 & 0.12 & 0.042 \\ \text { GDP deflator } & -0.80^{*} & -1.73^{* *} & -0.54 & -0.96 & -1.21 \\ \text { Policy rate } & -0.0070^{* * *} & -0.0070^{* * *} & -0.0063^{* * *} & -0.0065^{* * *} & -0.0064^{* *} \\ \text { PPI } & 0.92 & 1.32 & 0.98 & 1.05 & 1.34 \\ \text { Foreign demand } & 0.066^{*} & 0.068^{*} & 0.076^{*} & 0.077^{*} & 0.081^{* *} \\ \text { Constant } & -0.14^{* *} & -0.14^{* *} & -0.14^{* *} & -0.14^{* *} & -0.13^{* *} \\ & & & & & \\ \text { Observations } & 334 & 334 & 334 & 334 & 334 \\ \text { R-squared } & 0.641 & 0.628 & 0.628 & 0.626 & 0.633 \\ \text { Number of id } & 27 & 27 & 27 & 27 & 27\end{array}$

Notes: ${ }^{* * *} \mathrm{p}<0.01,{ }^{* *} \mathrm{p}<0.05,{ }^{*} \mathrm{p}<0.1$. GVC-REER, Q-REER are measures proposed in this paper. VAREER corresponds to the measure proposed in Bems and Johnson (2017) (under uniform elasticity), IMF-REER is a measure which uses IMF weights and country level price indices, BIS-REER is the measure published by BIS. 
Table 12 - Responsiveness of trade balance to exchange rate

\begin{tabular}{lccccc}
\hline \multicolumn{7}{l}{ Dependent Variable: } & Change in Trade Balance & & & \\
\hline & $(1)$ & $(2)$ & $(3)$ & $(4)$ & $(5)$ \\
VARIABLES & GVC-REER & Q-REER & VAREER & IMF-REER & BIS-REER \\
\hline \multicolumn{2}{l}{ (b) Benchmark Regressions } & & & & \\
REER Measure & $-2.81^{* * *}$ & $-1.18^{*}$ & $-0.90^{*}$ & $-0.92^{* *}$ & $-0.56^{* * *}$ \\
USD Exchange rate & 0.12 & -0.24 & -0.054 & -0.052 & $-0.28^{*}$ \\
Constant & $0.050^{* *}$ & 0.0093 & 0.035 & 0.035 & 0.015 \\
& & & & & \\
Observations & 416 & 416 & 416 & 416 & 446 \\
R-squared & 0.207 & 0.171 & 0.171 & 0.173 & 0.151 \\
Number of id & 30 & 30 & 30 & 30 & 30 \\
\hline
\end{tabular}

(b) With additional controls

$\begin{array}{lccccc}\text { REER Measure } & -2.50^{* * *} & -0.98^{* *} & -0.29 & -0.19 & -0.41 \\ \text { USD ex rate } & 0.46 & 0.067 & -0.096 & -0.18 & 0.031 \\ \text { Commodity price } & -0.013 & -0.0082 & -0.0087 & -0.011 & -0.031 \\ \text { GDP deflator } & 0.40 & -0.24 & -0.40 & -0.51 & -0.37 \\ \text { Policy rate } & 0.011^{* * *} & 0.011^{* * *} & 0.011^{* * *} & 0.011^{* * *} & 0.011^{* * *} \\ \text { PPI } & 0.32 & 0.62 & 0.62 & 0.64 & 0.68 \\ \text { Foreign demand } & -0.031^{* *} & -0.031^{* *} & -0.026^{*} & -0.026^{*} & -0.023 \\ \text { Constant } & 0.065^{*} & 0.059 & 0.065 & 0.066 & 0.068^{*} \\ & & & & & \\ \text { Observations } & 361 & 361 & 361 & 361 & 361 \\ \text { R-squared } & 0.238 & 0.226 & 0.215 & 0.215 & 0.218 \\ \text { Number of id } & 27 & 27 & 27 & 27 & 27\end{array}$

Notes: ${ }^{* * *} \mathrm{p}<0.01,{ }^{* *} \mathrm{p}<0.05,{ }^{*} \mathrm{p}<0.1$. Notes: Robust standard errors in parentheses $* * *$ $\mathrm{p}<0.01,{ }^{*} \mathrm{p}<0.05,{ }^{*} \mathrm{p}<0.1$. GVC-REER, Q-REER are measures proposed in this paper. VAREER corresponds to the measure proposed in Bems and Johnson (2017) (under uniform elasticity), IMF-REER is a measure which uses IMF weights and country level price indices, BIS-REER is the measure published by BIS. 
weights as well as prices. Secondly, we separately quantify and develop REER measures for value added and gross output. Thirdly, apart from country-level REERs, we develop REER measures at the sectoral level. This allows us to study behaviors in competitiveness across sectors within a country, as well as across countries a finer level of disaggregation. Fourthly, we apply the framework to a bilateral context and develop a new measure of bilateral real exchange rate (GVC-RER) that provides an improvement upon the current measures by acknowledging the presence of sectoral heterogeneity and trade in inputs.

To illustrate the importance of these improvements made on the modeling front, we parametrize the model using global input output data from the world input output database (WIOD). We create a database of REER weights and indices for 40 countries and 1435 country-sector pairs for the period 1995-2009. The results highlight that the role of sectoral heterogeneity in both REER weights as well as indices is quantitatively important in measuring competitiveness through the REER.

This is the first paper to develop REER measures incorporating both input output linkages and sectoral heterogeneity, and leaves several avenues for further development and exploration. In order to focus on the role of sectoral heterogeneity, we have largely abstracted from the issue of heterogeneity in the elasticity of substitution across product categories (intermediate vs final goods) as well as across countries, especially in the empirical part. The model indeed allows for these features, and in the appendix we discuss estimation of these elasticities which can further improve the measures of REER.

The paper constructs a new and novel database of sectoral REERs which can be used to study competitiveness of sectors and how they have evolved over time. It can be used to address many questions, including understanding the sources and implications of the dispersion in competitiveness within countries and within sectors across countries. Following the literature to clearly illustrate our marginal contributions, we have also restricted the analysis to a partial equilibrium, and an essentially static framework. Extending this analysis to general equilibrium and understanding the role played by sectoral heterogeneity in determining competitiveness in a dynamic setting remains a promising avenue for future exploration.

\section{Bibliography}

Ahmed, S., Appendino, M., and Ruta, M. (2015). Depreciations without exports?

Antràs, P. (2014). Global production: A contracting perspective. 
Antràs, P. and Chor, D. (2013). Organizing the global value chain. Econometrica, 81(6):21272204.

Auer, R. A., Levchenko, A. A., and Sauré, P. (2017). International inflation spillovers through input linkages. Technical report, National Bureau of Economic Research.

Baldwin, R. and Lopez-Gonzalez, J. (2012). Supply-chain trade: A portrait of global patterns and several testable hypotheses. HEI manuscript.

Bayoumi, M. T., Saito, M., and Turunen, M. J. (2013). Measuring Competitiveness: Trade in Goods or Tasks? Number 13-100. International Monetary Fund.

Bayoumi, T., Lee, J., and Jayanthi, S. (2005). New rates from new weights.

Bems, R. and Johnson, R. C. (2012). Value-added exchange rates. Technical report, National Bureau of Economic Research.

Bems, R. and Johnson, R. C. (2017). Demand for value added and value-added exchange rates. American Economic Journal: Macroeconomics, 9(4):45-90.

Bennett, H. Z. and Zarnic, Z. (2009). International competitiveness of the Mediterranean quartet: A heterogeneous-product approach. IMF Staff Papers, 56(4):919-957.

Bils, M. and Klenow, P. J. (2004). Some evidence on the importance of sticky prices. Journal of political economy, 112(5):947-985.

Broda, C. and Weinstein, D. E. (2006). Globalization and the gains from variety. The Quarterly Journal of Economics, 121(2):541-585.

Casas, C., Díez, F. J., Gopinath, G., and Gourinchas, P.-O. (2016). Dominant currency paradigm. Technical report, National Bureau of Economic Research.

Chinn, M. D. (2006). A primer on real effective exchange rates: determinants, overvaluation, trade flows and competitive devaluation. Open Economies Review, 17(1):115-143.

Costinot, A., Vogel, J., and Wang, S. (2013). An elementary theory of global supply chains. The Review of Economic Studies, 80(1):109-144.

de Soyres, F., Frohm, E., Gunnella, V., and Pavlova, E. (2018). Bought, sold, and bought again: The impact of complex value chains on export elasticities.

Feenstra, R. C. (1994). New product varieties and the measurement of international prices. The American Economic Review, pages 157-177. 
Feenstra, R. C., Luck, P. A., Obstfeld, M., and Russ, K. N. (2014). In search of the armington elasticity. Technical report, National Bureau of Economic Research.

Goldberg, L. S. (2004). Industry-specific exchange rates for the United States. Federal Reserve Bank of New York Economic Policy Review, 10(1).

Goldberg, L. S. and Tille, C. (2008). Vehicle currency use in international trade. Journal of International Economics, 76(2):177-192.

Hofmann, B., Shim, I., and Shin, H. (2016). Sovereign yields and the risk-taking channel of currency appreciation. BIS Working Papers No 538.

Hummels, D., Ishii, J., and Yi, K.-M. (2001). The nature and growth of vertical specialization in world trade. Journal of international Economics, 54(1):75-96.

Imbs, J. and Mejean, I. (2015). Elasticity optimism. American Economic Journal: Macroeconomics, $7(3): 43-83$.

IMF (2015). World economic outlook (october 2015). Chapter 3.

Ito, K. and Shimizu, J. (2015). Industry-level competitiveness, productivity and effective exchange rates in east asia. Asian Economic Journal, 29(2):181-214.

Johnson, R. C. (2014). Trade in intermediate inputs and business cycle comovement. American Economic Journal: Macroeconomics, 6(4):39-83.

Johnson, R. C. and Moxnes, A. (2012). Technology, trade costs, and the pattern of trade with multi-stage production.

Justiniano, A. and Preston, B. (2010). Can structural small open-economy models account for the influence of foreign disturbances? Journal of International Economics, 81(1):61-74.

Kearns, J. and Patel, N. (2016). Does the financial channel of exchange rates offset the trade channel? BIS Quarterly Review, December 2016.

Klau, M. et al. (2008). The new BIS effective exchange rate indices. BIS Quarterly Review.

Koopman, R., Wang, Z., and Wei, S.-J. (2012). Estimating domestic content in exports when processing trade is pervasive. Journal of Development Economics, 99(1):178-189.

Koopman, R., Wang, Z., and Wei, S.-J. (2014). Tracing value-added and double counting in gross exports. The American Economic Review, pages 459-494. 
Lommatzsch, K., Silgoner, M. A., and Ramskogler, P. (2016). Trade in value added: do we need new measures of competitiveness?

Loretan, M. (2005). Indexes of the foreign exchange value of the dollar. Fed. Res. Bull., 91:1.

Miroudot, S., Lanz, R., and Ragoussis, A. (2009). Trade in intermediate goods and services. Technical report, OECD Publishing.

Rogoff, K. (2005). Rethinking exchange rate competitiveness. The Global Competitiveness Report, 2006:99-105.

Sato, K., Shimizu, J., Shrestha, N., and Zhang, S. (2013). Industry-specific real effective exchange rates and export price competitiveness: The cases of japan, china, and korea. Asian Economic Policy Review, 8(2):298-321.

Soderbery, A. (2015). Estimating import supply and demand elasticities: Analysis and implications. Journal of International Economics.

Swarnali, A., Maximiliano, A., and Ruta, M. (2017). Global value chains and the exchange rate elasticity of exports. The BE Journal of Macroeconomics, 17(1).

Thorbecke, W. (2011). Investigating the effect of exchange rate changes on China's processed exports. Journal of the Japanese and International Economies, 25(2):33-46.

Timmer, M. and Erumban, A. (2012). The world input-output database (WIOD): Contents, sources and methods. WIOD Background document available at www. wiod. org.

Wang, Z., Wei, S.-J., and Zhu, K. (2013). Quantifying international production sharing at the bilateral and sector levels. National Bureau of Economic Research (No. w19677). 


\section{Appendix}

\section{A Solution of the general model $<$ For online publication $>$}

\section{A.1 First order conditions}

\section{A.1.1 first order conditions for production:}

$$
\begin{aligned}
V_{l}^{c} & =w_{l}^{v c}\left(\frac{p(V)_{l}^{c}}{p(Q)_{l}^{c}}\right)^{-\sigma^{3}(c, l)} Q_{l}^{c} \\
X_{l}^{c} & =w_{l}^{X c}\left(\frac{p(X)_{l}^{c}}{p(Q)_{l}^{c}}\right)^{-\sigma^{3}(c, l)} Q_{l}^{c} \\
X_{s l}^{c} & =w_{s l}^{c}\left(\frac{p(X)_{s l}^{c}}{p(X)_{l}^{c}}\right)^{-\sigma^{2}(c, l)} X_{l}^{c} \\
X_{s l}^{i c} & =w_{s l}^{i c}\left(\frac{p(Q)_{s}^{i}}{p(X)_{s l}^{(f)}}\right)^{-\sigma_{s}^{1}(c, l)} X(f)_{s l}^{c} \\
X_{s l}^{c c} & =w_{s l}^{c c}\left(\frac{p(Q)_{s}^{c}}{p(X)_{s l}^{(f) c}}\right)^{-\sigma_{s}^{1 h}(c, l)} X_{s l}^{c} \\
X_{s l}^{c}(f) & =w(f)_{s l}^{c}\left(\frac{p(X)_{s l}^{(f) c}}{p(X)_{s l}^{c}}\right)^{-\sigma_{s}^{1 h}(c, l)} X_{s l}^{c}
\end{aligned}
$$

Here $q_{l}^{c}$ and $q_{s l}^{c}$ are price indices corresponding to $X_{l}^{c}$ and $X_{s l}^{c}$ respectively and are given by:

$$
\begin{gathered}
p(X)_{l}^{c}=\left[\sum_{s=1}^{m}\left(w_{s l}^{c}\right)\left(p(X)_{s l}^{c}\right)^{1-\sigma^{2}(c, l)}\right]^{\frac{1}{1-\sigma^{2}(c, l)}} \\
p(X)_{s l}^{(f) c}=\left[\sum_{i=1, i \neq c}^{n}\left(w_{s l}^{i c}\right)\left(p(Q)_{s}^{i}\right)^{1-\sigma_{s}^{1}(c, l)}\right]^{\frac{1}{1-\sigma_{s}^{1}(c, l)}} \\
p(X)_{s l}^{c}=\left[\left(w_{s l}^{c c}\right)\left(p(Q)_{s}^{c}\right)^{1-\sigma^{1 h}(c, l)}+\left(w_{l}^{X c}\right)\left(p(X)_{s l}^{(f) c}\right)^{1-\sigma^{1 h}(c, l)}\right]^{\frac{1}{1-\sigma^{1 h}(c, l)}}
\end{gathered}
$$

and price of gross output is given by: 


$$
p(Q)_{l}^{c}=\left[\left(w_{l}^{v c}\right)\left(p(V)_{l}^{c}\right)^{1-\sigma^{3}(c, l)}+\left(w_{l}^{X c}\right)\left(p(X)_{l}^{c}\right)^{1-\sigma^{3}(c, l)}\right]^{\frac{1}{1-\sigma^{3}(c, l)}}
$$

where $p(V)_{l}^{c}$ is the price of value added(i.e price of factor of production) of country $c$ sector $l$

\section{A.1.2 First order conditions for final consumption:}

$$
\begin{gathered}
F_{s}^{i c}=\kappa_{s}^{i c}\left(\frac{p(Q)_{s}^{i}}{P(f)_{s}^{c}}\right)^{-\theta_{s}^{1}(c)} F(f)_{s}^{c} \\
F_{s}^{c c}=\kappa_{s}^{c c}\left(\frac{p(Q)_{s}^{c}}{P_{s}^{c}}\right)^{-\theta_{s}^{1 h}(c)} F_{s}^{c} \\
F(f)_{s}^{c}=\kappa(f)_{s}^{c}\left(\frac{P(f)_{s}^{c}}{P_{s}^{c}}\right)^{-\theta_{s}^{1 h}(c)} F_{s}^{c} \\
F_{s}^{c}=\kappa_{s}^{c}\left(\frac{P_{s}^{c}}{P^{c}}\right)^{-\theta^{2}(c)} F^{c}
\end{gathered}
$$

Here $P_{s}^{c}$ and $P^{c}$ are price indices for sector $s$ good and aggregate good consumed by country $c$, respectively and are given by

$$
\begin{aligned}
& P_{s}^{c}(f)=\left[\sum_{i=1, i \neq c}^{n}\left(\kappa_{s}^{i c}\right)\left(p(Q)_{s}^{i}\right)^{1-\theta_{s}^{1}(c)}\right]^{\frac{1}{1-\theta_{s}^{1}(c)}} \\
& P_{s}^{c}=\left[\left(\kappa_{s}^{c c}\right)\left(p(Q)_{s}^{c}\right)^{1-\theta_{s}^{1 h}(c)}+\left(\kappa(f)_{l}^{c}\right)\left(P(f)_{s}^{c}\right)^{1-\theta_{s}^{1 h}(c)}\right]^{\frac{1}{1-\theta_{s}^{1 h}(c)}} \\
& P^{c}=\left[\sum_{s=1}^{m}\left(\kappa_{s}^{c}\right)\left(P_{s}^{c}\right)^{1-\theta^{2}(c)}\right]^{\frac{1}{1-\theta^{2}(c)}}
\end{aligned}
$$

Let $[A]_{n m X n m}$ be the input-output coefficient matrix at the country-sector level, i.e the $(i, j)^{t h}$ block which has dimension $m X m$ is given by

$$
[A]_{m X m}^{i j}=\left(\begin{array}{cccc}
a_{11}^{i j} & a_{12}^{i j} & . . & a_{1 m}^{i j} \\
a_{21}^{i j} & a_{22}^{i j} & . . & a_{2 m}^{i j} \\
: & : & : & : \\
a_{m 1}^{i j} & a_{m 2}^{i j} & . . & a_{m m}^{i j}
\end{array}\right)
$$

where $a_{s l}^{i j}$ denotes the output of $(i, s)$ used in the production of one unit of $(j, l)$, i.e 


$$
a_{s l}^{i j}=\frac{p(Q){ }_{s}^{i} X_{s l}^{i j}}{p(Q)_{l}^{j} Q_{l}^{j}}
$$

Let $[B]_{n m X n m}$ be the corresponding total requirement matrix given by

$$
[B]_{n m X n m}=\left(I_{n m}-[A]\right)^{-1}
$$

Also, define the matrix $\left[D_{Q}\right]_{n m x n m}$ to be a diagonal matrix with the $(c l)^{t h}$ diagonal entry given by $\frac{1}{p_{l}^{c} Q_{l}^{c}}$

\section{Log Linearization:}

\section{A note on notation:}

- for any variable $Y_{c d}^{a b}$, vec $\left(Y_{c d}^{a b}\right)$ denotes a vector with all components of $Y_{c d}^{a b}$ stacked together

- The stacking order is as follows: $d, c, b, d$. i, e first the home sector index changes, followed by foreign sector, followed by home country and finally foreign country

$$
-\operatorname{vec}\left(Y_{c d}^{b}\right), \operatorname{vec}\left(Y_{c}^{a b}\right) \text { etc are defined accordingly. }
$$

- Examples in a 2 by 2 case $(m=n=2)$

$$
\begin{aligned}
& -\operatorname{vec}\left(Y_{c d}^{a b}\right)=\left(Y_{11}^{11}, Y_{12}^{11}, Y_{21}^{11}, Y_{22}^{11}, Y_{11}^{12}, Y_{12}^{12}, Y_{21}^{12}, Y_{22}^{12}, Y_{11}^{21}, Y_{12}^{21}, Y_{21}^{21}, Y_{22}^{21}, Y_{11}^{22}, Y_{12}^{22}, Y_{21}^{22}, Y_{22}^{22}\right)^{\prime} \\
& -\operatorname{vec}\left(Y_{c d}^{b}\right)=\left(Y_{11}^{1}, Y_{12}^{1}, Y_{21}^{1}, Y_{22}^{1}, Y_{11}^{2}, Y_{12}^{2}, Y_{21}^{2}, Y_{22}^{2}\right)^{\prime}
\end{aligned}
$$

This appendix contains the log linearized first order and market clearing conditions and organizes them in stacked matrix notation which will be useful in deriving the results that follow. A variable with a " denotes log deviation from steady state.

Log linearizing and stacking components of production function and price indices:(to simplify notation further, we omit the parenthesis for gross output prices, i.e the parenthesis containing " $Q$ " is omitted)

$$
\begin{array}{cr}
\text { Raw expression } & X(f)_{s l}^{c}=\left[\sum_{i=1, i \neq c}^{n}\left(w_{s l}^{i c}\right)^{1 / \sigma_{s}^{1}(c, l)}\left(X_{s l}^{i c}\right)^{\frac{\sigma_{s}^{1}(c, l)-1}{\sigma_{s}^{1}(c, l)}}\right]^{\frac{\sigma_{s}^{1}(c, l)}{\sigma_{s}^{1}(c, l)-1}} \\
\text { Log linearized expression } & X \hat{(f})_{s l}^{c}=\sum_{i=1, i \neq c}^{n}\left(\frac{p_{s}^{i} X_{s l}^{i c}}{P(X)_{s l}^{(f) c} X(f)_{s l}^{c}}\right) \hat{X}_{s l}^{i c}
\end{array}
$$


Stacked vector:

$$
\left(\operatorname{vec}\left(\hat{X}(f)_{s l}^{c}\right)\right)=\underbrace{W_{1 X X H}}_{n m^{2} X n^{2} m^{2}} \operatorname{vec}\left(\hat{X}_{s l}^{i c}\right)
$$

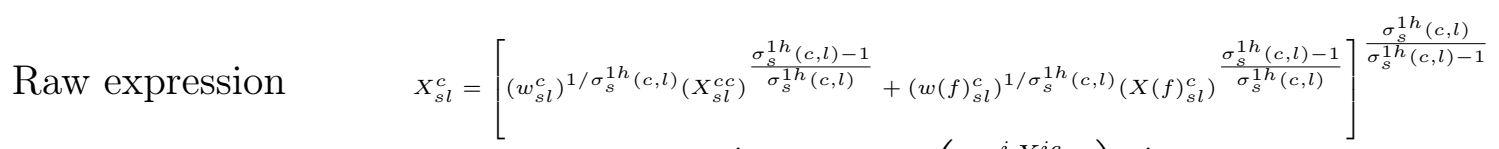
Log linearized expression

$$
\hat{X}_{s l}^{c}=\sum_{i=1}^{n}\left(\frac{p_{s}^{i} X_{s l}^{i c}}{p(X)_{s l}^{c} X_{s l}^{c}}\right) \hat{X}_{s l}^{i c}
$$

Stacked Vector:

$$
\left(\operatorname{vec}\left(\hat{X}_{s l}^{c}\right)\right)=\underbrace{W_{1 X X}}_{n m^{2} X n^{2} m^{2}} \operatorname{vec}\left(\hat{X}_{s l}^{i c}\right)
$$

$$
\text { Raw expression } \quad X_{l}^{c}=\left[\sum_{s=1}^{m}\left(w_{s l}^{c}\right)^{1 / \sigma^{2}(c, l)}\left(X_{s l}^{c}\right)^{\frac{\sigma^{2}(c, l)-1}{\sigma^{2}(c, l)}}\right]^{\frac{\sigma^{2}(c, l)}{\sigma^{2}(c, l)-1}}
$$

Log linearized expression

$$
\hat{X}_{l}^{c}=\sum_{s=1}^{m}\left(\frac{p(X) q_{s l}^{c} X_{s l}^{c}}{p(X)_{l}^{c} X_{l}^{c}}\right) \hat{X}_{s l}^{c}
$$

Stacked vector:

$$
\operatorname{vec}\left(\hat{X}_{l}^{c}\right)=\left(W_{2 X X}\right)_{n m X n m^{2}} \operatorname{vec}\left(\hat{X}_{s l}^{c}\right)
$$

Raw expression $\quad q(f)_{s l}^{c}=\left[\sum_{i=1, i \neq c}^{n}\left(w_{s l}^{i c}\right)\left(p_{s}^{i}\right)^{1-\sigma_{s}^{1}(c, l)}\right]^{\frac{1}{1-\sigma_{s}^{1}(c, l)}}$ Log linearized expression $\quad \hat{q}_{s l}^{c}(f)=\sum_{i=1, i \neq c}^{n}\left(\frac{p_{s}^{i} X_{s l}^{i c}}{p(X)_{s l}^{c} X_{s l}^{c}}\right) \hat{p_{s}^{i}}$

Stacked vector:

$$
\operatorname{vec}\left(\hat{q}_{s l}^{c}(f)\right)=\left(W_{1 X P H}\right)_{n m^{2} X n m} \operatorname{vec}\left(\hat{p}_{s}^{i}\right)
$$


Raw expression $\quad q_{s l}^{c}=\left[\left(w_{s l}^{c c}\right)\left(p_{s}^{c}\right)^{1-\sigma^{1 h}(c, l)}+\left(w_{l}^{X c}\right)\left(p(X)^{(f) c}{ }_{s l}\right)^{1-\sigma^{1 h}(c, l)}\right]^{\frac{1}{1-\sigma^{1 h}(c, l)}}$ Log linearized expression $p(\hat{X})_{s l}^{c}=\sum_{i=1}^{n}\left(\frac{p_{s}^{i} X_{s l}^{i c}}{p(X)_{s l}^{c} X_{s l}^{c}}\right) \hat{p_{s}^{i}}$

Stacked vector:

$$
\operatorname{vec}\left(p(\hat{X})_{s l}^{c}\right)=\left(W_{1 X P}\right)_{n m^{2} X n m} \operatorname{vec}\left(\hat{p}_{s}^{i}\right)
$$

Raw expression $\quad p(X)_{l}^{c}=\left[\sum_{s=1}^{m}\left(w_{s l}^{c}\right)\left(p(X)_{s l}^{c}\right)^{1-\sigma^{2}(c, l)}\right]^{\frac{1}{1-\sigma^{2}(c, l)}}$

Log linearized expression $\quad \hat{q}_{l}^{c}=\sum_{s=1}^{m}\left(\frac{p(X)_{s l}^{c} X_{s l}^{c}}{p(X)_{l}^{c} X_{l}^{c}}\right) \hat{q_{s l}^{c}}$

Stacked vector:

$$
\operatorname{vec}\left(\hat{q}_{l}^{c}\right)=\left(W_{2 X p}\right)_{n m X n m^{2}} \operatorname{vec}\left(p(\hat{X})_{s l}^{c}\right)
$$

Raw expression $\quad P_{s}^{c}(f)=\left[\sum_{i=1, i \neq c}^{n}\left(\kappa_{s}^{i c}\right)\left(p_{s}^{i}\right)^{1-\theta_{s}^{1}(c)}\right]^{\frac{1}{1-\theta_{s}^{1}(c)}}$

Log linearized expression $\quad P(\hat{f})_{s}^{c}=\sum_{i=1, i \neq c}^{n}\left(\frac{p_{s}^{i} F_{s}^{i c}}{P(f)_{s}^{c} F(f)_{s}^{c}}\right) \hat{p}_{s}^{i}$

Stacked vector:

$$
\operatorname{vec}\left(\hat{P}_{s}^{c}\right)_{n m X 1}=\left(W_{1 F P H}\right)_{n m X n m} v e c\left(p_{s}^{i}\right)_{n m X 1}
$$

Raw expression $\quad P_{s}^{c}=\left[\left(\kappa_{s}^{c c}\right)\left(p_{s}^{c c}\right)^{1-\theta_{s}^{1 h}(c)}+\left(\kappa(f)_{l}^{c}\right)\left(P(f)_{s}^{c}\right)^{1-\theta_{s}^{1 h}(c)}\right]^{\frac{1}{1-\theta_{s}^{1 h}(c)}}$

Log linearized expression $\quad \hat{P}_{s}^{c}=\sum_{i=1}^{n}\left(\frac{p_{s}^{i} F_{s}^{i c}}{P_{s}^{c} F_{s}^{c}}\right) \hat{p}_{s}^{i}$

Stacked vector:

$$
\operatorname{vec}\left(\hat{P}_{s}^{c}\right)_{n m X 1}=\left(W_{1 F P}\right)_{n m X n m} \operatorname{vec}\left(p_{s}^{i}\right)_{n m X 1}
$$




$$
\begin{array}{cc}
\text { Raw expression } & P^{c}=\left[\sum_{s=1}^{m}\left(\kappa_{s}^{c}\right)\left(P_{s}^{c}\right)^{1-\theta^{2}(c)}\right]^{\frac{1}{1-\theta^{2}(c)}} \\
\text { Log linearized expression } & \hat{P}^{c}=\sum_{s=1}^{m}\left(\frac{P_{s}^{c} F_{s}^{c}}{P^{c} F^{c}}\right) \hat{P}_{s}^{c}
\end{array}
$$

Stacked vector:

$$
\operatorname{vec}\left(\hat{P}^{c}\right)_{n X 1}=\left(W_{2 F P}\right)_{n X n m} \operatorname{Vec}\left(\hat{P}_{s}^{c}\right)_{n m X 1}
$$

Final goods consumption first order conditions:

$$
\begin{aligned}
\hat{F_{s}^{i c}} & =-\theta_{s}^{1}(c)\left(\hat{p}_{s}^{i}-P(f)_{s}{ }^{c}\right)+\hat{F(f)_{s}{ }^{c}} \\
\hat{F_{s}^{c c}} & =-\theta_{s}^{1 h}(c)\left(\hat{p}_{s}^{c}-\hat{P}_{s}{ }^{c}\right)+\hat{F}_{s}{ }^{c} \\
F(f)_{s}^{c} & =-\theta_{s}^{1 h}(c)\left(\hat{P}(f)_{s}^{c}-\hat{P}_{s}{ }^{c}\right)+\hat{F}_{s}{ }^{c} \\
\hat{F}_{s}^{c} & =-\theta^{2}(c)\left(\hat{P}_{s}^{c}-\hat{P}^{c}\right)+\hat{F}^{c}
\end{aligned}
$$

We can combine these 4 conditions to write:

$$
\begin{aligned}
& \hat{F}_{s}^{i c}=-\theta_{s}^{1}(c) \hat{p}_{s}^{i}+\left(\theta_{s}^{1}(c)-\theta_{s}^{1 h}(c)\right) \hat{P(f)_{s}^{c}}+\left(\theta_{s}^{1 h}(c)-\theta^{2}(c)\right) \hat{P}_{s}^{c}+\theta^{2}(c) \hat{P}^{c}+\hat{F}^{c} \\
& \hat{F}_{s}^{c c}=-\theta_{s}^{1 h}(c) \hat{p}_{s}^{c}+\left(\theta_{s}^{1 h}(c)-\theta^{2}(c)\right) \hat{P}_{s}^{c}+\theta^{2}(c) \hat{P}^{c}+\hat{F}^{c}
\end{aligned}
$$

We can now stack the above $n^{2} m$ equations to write a single matrix equation as follows:

$$
\begin{aligned}
\operatorname{vec}\left(\hat{F_{s}^{i c}}\right)_{n^{2} m X 1} & =J_{F}(i \neq c)\left[\left(Y_{1}\right)_{n^{2} m X n m} \operatorname{vec}\left(\theta_{s}^{1}(c)\right)_{n m X 1}\right] \odot\left[\left(Y_{2}\right)_{n^{2} m X n m} \operatorname{vec}\left(\hat{p}_{s}^{i}\right)_{n m X 1}\right] \\
& --J_{F}(i=c)\left[\left(Y_{1}\right)_{n^{2} m X n m} \operatorname{vec}\left(\theta_{s}^{1 h}(c)\right)_{n m X 1}\right] \odot\left[\left(Y_{2}\right)_{n^{2} m X n m} \operatorname{vec}\left(\hat{p}_{s}^{i}\right)_{n m X 1}\right] \\
& +J_{F}(i \neq c)\left[Y_{1}\left(\operatorname{vec}\left(\theta_{s}^{1}(c)\right)_{n m X 1}-\operatorname{vec}\left(\theta_{s}^{1 h}(c)\right)_{n m X 1}\right)\right] \odot\left[Y_{1} \operatorname{vec}\left(\hat{P}(f)_{s}^{c}\right)_{n m X 1}\right] \\
& +\left(Y_{1} \operatorname{vec}\left(\theta_{s}^{1 h}(c)\right)_{n m X 1}-\left(Y_{3}\right)_{n^{2} m X n} \operatorname{vec}\left(\theta^{2}(c)\right)_{n m X 1}\right) \odot\left(Y_{1} \operatorname{vec}\left(\hat{P}_{s}^{c}\right)_{n m X 1}\right) \\
& +\left[Y_{3} \operatorname{vec}\left(\theta^{2}(c)\right)_{n m X 1}\right] \odot\left[Y_{3} \operatorname{vec}\left(\hat{P}^{c}\right)_{n X 1}\right]+Y_{3} \hat{F}^{c}
\end{aligned}
$$

where $Y_{1}=1_{n} \otimes I_{n m}, Y_{2}=I_{n} \otimes 1_{n} \otimes I_{m}, Y_{3}=1_{n} \otimes I_{n} \otimes 1_{m}, \odot$ is the element by element multiplication operator for two vectors and $J_{F}(x)$ is an $n^{2} m$ by 1 vector with ones in all indices that satisfy the condition $x$ and zero elsewhere. 
Combining this with (A.29) and (A.28),

$$
\operatorname{vec}\left(\hat{F_{s}^{i c}}\right)_{n^{2} m X 1}=Z_{F} \operatorname{vec}\left(\hat{p}_{s}^{i}\right)_{n m X 1}+Y_{3} \hat{F}^{c}
$$

where

$$
\begin{aligned}
\left(Z_{F}\right)_{n^{2} m X n m} & =J_{F}(i \neq c)\left[\left(Y_{1}\right)_{n^{2} m X n m} \operatorname{vec}\left(\theta_{s}^{1}(c)\right)_{n m X 1}\right] \odot\left[\left(Y_{2}\right)_{n^{2} m X n m}\right] \\
& --J_{F}(i=c)\left[\left(Y_{1}\right)_{n^{2} m X n m} \operatorname{vec}\left(\theta_{s}^{1 h}(c)\right)_{n m X 1}\right] \odot\left[\left(Y_{2}\right)_{n^{2} m X n m}\right] \\
& +J_{F}(i \neq c)\left[Y_{1}\left(\operatorname{vec}\left(\theta_{s}^{1}(c)\right)_{n m X 1}-\operatorname{vec}\left(\theta_{s}^{1 h}(c)\right)_{n m X 1}\right)\right] \odot\left[Y_{1} W_{F H}\right] \\
& +\left(Y_{1} \operatorname{vec}\left(\theta_{s}^{1 h}(c)\right)_{n m X 1}-\left(Y_{3}\right)_{n^{2} m X n} \operatorname{vec}\left(\theta^{2}(c)\right)_{n m X 1}\right) \odot\left(Y_{1} W_{1 F P}\right) \\
& +\left[Y_{3} \operatorname{vec}\left(\theta^{2}(c)\right)_{n m X 1}\right] \odot\left[Y_{3} W_{2 F P} W_{1 F P}\right]
\end{aligned}
$$

Log linearizing Production first order conditions:

$$
\begin{gathered}
V_{l}^{c}=w_{l}^{v c}\left(\frac{p_{l}^{v c}}{p_{l}^{c}}\right)^{-\sigma^{3}(c, l)} Q_{l}^{c} \\
X_{l}^{c}=w_{l}^{X c}\left(\frac{q_{l}^{c}}{p_{l}^{c}}\right)^{-\sigma^{3}(c, l)} Q_{l}^{c} \\
X_{s l}^{c}=w_{s l}^{c}\left(\frac{q_{s l}^{c}}{q_{l}^{c}}\right)^{-\sigma^{2}(c, l)} X_{l}^{c} \\
X_{s l}^{i c}=w_{s l}^{i c}\left(\frac{p_{s}^{i}}{q(f)_{s l}^{c}}\right)^{-\sigma_{s}^{1}(c, l)} X(f)_{s l}^{c} \\
X_{s l}^{c c}=w_{s l}^{c c}\left(\frac{p_{s}^{c}}{q_{s l}^{c}}\right)^{-\sigma_{s}^{1 h}(c, l)} X_{s l}^{c} \\
X_{s l}^{c}(f)=w(f)_{s l}^{c}\left(\frac{q(f)_{s l}^{c}}{q_{s l}^{c}}\right)^{-\sigma_{s}^{1 h}(c, l)} X_{s l}^{c} \\
\hat{X_{s l}^{i c}=}-\sigma_{s}^{1}(c, l) \hat{p}_{s}^{i}+\sigma_{s}^{1}(c, l) p(\hat{X})_{s l}^{(f) c}+\hat{X}_{(f)}^{c} \\
\hat{X_{s l}^{c c}}=-\sigma_{s}^{1 h}(c, l) \hat{p}_{s}^{c}+\sigma_{s}^{1 h}(c, l) p(\hat{X})_{s l}^{c}+\hat{X}_{s l}^{c} \\
\hat{X_{s l}^{c}(f)}=-\sigma_{s}^{1 h}(c, l) p(\hat{X})_{s l}^{(f) c}+\sigma_{s}^{1 h}(c, l) p(\hat{X})_{s l}^{c}+\hat{X}_{s l}^{c} \\
\hat{X_{s l}^{c}}=-\sigma^{2}(c, l) p(\hat{X})_{s l}^{c}+\sigma^{2 h}(c, l) p(\hat{X})_{l}^{c}+\hat{X}_{l}^{c}
\end{gathered}
$$




$$
\begin{aligned}
\hat{X}_{s l}^{i c} & =-\sigma_{s}^{1}(c, l) \hat{p}_{s}^{i}+\left(\sigma_{s}^{1}(c, l)-\sigma_{s}^{1 h}(c, l)\right) p(\hat{X})+\left(\sigma_{s}^{1 h}(c, l)-\sigma^{2}(c, l)\right) p(\hat{X})_{s l}^{c} \\
& +\left(\sigma^{2}(c, l)-\sigma^{3}(c, l)\right) p(\hat{X})_{l}^{c}+\sigma^{3}(c, l) \hat{p}_{l}^{c}+\hat{Q}_{l}^{c} \\
\hat{X}_{s l}^{c c} & =-\sigma_{s}^{1 h}(c, l) \hat{p}_{s}^{c}+\left(\sigma_{s}^{1 h}(c, l)-\sigma^{2}(c, l)\right) p(\hat{X})_{s l}^{c} \\
& +\left(\sigma^{2}(c, l)-\sigma^{3}(c, l)\right) \hat{q}_{l}^{c}+\sigma^{3}(c, l) \hat{p}_{l}^{c}+\hat{Q}_{l}^{c}
\end{aligned}
$$

These $n^{2} m^{2}$ equations can be stacked to write

$$
\begin{aligned}
\operatorname{vec}\left(\hat{X}_{s l}^{i c}\right)_{n^{2} m^{2}} & =-J_{X}(i \neq c)\left[C_{1} \operatorname{vec}\left(\sigma_{s}^{1}(c, l)\right)_{n m^{2} X 1}\right] \odot\left[C_{3} \operatorname{vec}\left(\hat{p}_{s}^{i}\right)_{n m X 1}\right] \\
& -J_{X}(i=c)\left[C_{1} \operatorname{vec}\left(\sigma_{s}^{1 h}(c, l)\right)_{n m^{2} X 1}\right] \odot\left[C_{3} \operatorname{vec}\left(\hat{p}_{s}^{i}\right)_{n m X 1}\right] \\
& +J_{X}(i \neq c)\left[C_{1}\left(\operatorname{vec}\left(\sigma_{s}^{1}(c, l)\right)_{n m^{2} X 1}-\operatorname{vec}\left(\sigma_{s}^{1 h}(c, l)\right)_{n m^{2} X 1}\right)\right] \odot\left[C_{1} p(\hat{X})_{s l}^{(f) c}\right] \\
& +\left[C_{2}\left(\operatorname{vec}\left(\sigma^{2}(c, l)\right)_{n m X 1}-\operatorname{vec}\left(\sigma^{3}(c, l)\right)_{n m X 1}\right)\right] \odot\left[C_{2} p(\hat{X})_{l}^{c}\right] \\
& +\left[C_{1} \operatorname{vec}\left(\sigma_{s}^{1 h}(c, l)\right)_{n m^{2} X 1}-C_{2} \operatorname{vec}\left(\sigma^{2}(c, l)\right)_{n m X 1}\right] \odot\left[C_{1} p(\hat{X})_{s l}^{c}\right] \\
& +\left[C_{2} \operatorname{vec}\left(\sigma^{3}(c, l)\right)_{n m X 1}\right] \odot\left[C_{2} \operatorname{vec}\left(\hat{p}_{s}^{i}\right)_{n m X 1}\right]+C_{2} \hat{Q}_{l}^{c}
\end{aligned}
$$

where $C_{1}=1_{n} \otimes I_{n m^{2}}, C_{2}=1_{n} \otimes I_{n} \otimes 1_{m} \otimes I_{m}, C_{3}=I_{n} \otimes 1_{n} \otimes I_{m} \otimes 1_{m} . J_{X}(y)$ is an $n^{2} m$ by 1 vector with ones in all indices that satisfy the condition $y$ and zero elsewhere.

Combining this with (A.22) - (A.26) we get:

$$
\operatorname{vec}\left(\hat{X}_{s l}^{i c}\right)_{n^{2} m^{2}}=Z_{X} \operatorname{vec}\left(\hat{p}_{s}^{i}\right)_{n m X 1}+C_{2} \hat{Q}_{l}^{c}
$$

where

$$
\begin{aligned}
Z_{X} & =-J_{X}(i \neq c)\left[C_{1} \operatorname{vec}\left(\sigma_{s}^{1}(c, l)\right)_{n m^{2} X 1}\right] \odot\left[C_{3}\right] \\
& -J_{X}(i=c)\left[C_{1} \operatorname{vec}\left(\sigma_{s}^{1 h}(c, l)\right)_{n m^{2} X 1}\right] \odot\left[C_{3}\right] \\
& +J_{X}(i \neq c)\left[C_{1}\left(\operatorname{vec}\left(\sigma_{s}^{1}(c, l)\right)_{n m^{2} X 1}-\operatorname{vec}\left(\sigma_{s}^{1 h}(c, l)\right)_{n m^{2} X 1}\right)\right] \odot\left[C_{1} W_{X H}\right] \\
& +\left[C_{2}\left(\operatorname{vec}\left(\sigma^{2}(c, l)\right)_{n m X 1}-\operatorname{vec}\left(\sigma^{3}(c, l)\right)_{n m X 1}\right)\right] \odot\left[C_{2} W_{2 X P} W_{1 X P}\right] \\
& +\left[C_{1} \operatorname{vec}\left(\sigma_{s}^{1 h}(c, l)\right)_{n m^{2} X 1}-C_{2} \operatorname{vec}\left(\sigma^{2}(c, l)\right)_{n m X 1}\right] \odot\left[C_{1} W_{1 X P}\right] \\
& +\left[C_{2} \operatorname{vec}\left(\sigma^{3}(c, l)\right)_{n m X 1}\right] \odot\left[C_{2}\right]
\end{aligned}
$$

Next, linearizing the production function we have: 


$$
\begin{gathered}
\operatorname{vec}\left(\hat{Q}_{l}^{c}\right)=\left(D_{v}\right)_{n m X n m}\left(\operatorname{vec}\left(\hat{V}_{l}^{c}\right)\right)_{n m X 1}+\left(D_{X}\right)_{n m X n m} \operatorname{vec}\left(\hat{X}_{l}^{c}\right) \\
\operatorname{vec}\left(\hat{p}_{l}^{c}\right)=D_{v} \operatorname{vec}\left(\hat{p}(V)_{l}^{c}\right)+D_{X} \operatorname{vec}\left(p(\hat{X})_{l}^{c}\right)
\end{gathered}
$$

(here $D_{v}$ and $D_{X}$ are $n m X n m$ diagonal matrices denoting the shares of value added and intermediate inputs in the production of different goods, i.e the $l c^{\text {th }}$ diagonal entry of $D_{v}$ is $\frac{p(V)_{l}^{c} V_{l}^{c}}{p(Q)_{l}^{c} Q_{l}^{c}}$ and that of $D_{X}$ is $\frac{p(X)_{l}^{c} X_{l}^{c}}{p(Q)_{l}^{c} Q_{l}^{c}}$. We can use (A.25) and (A.26) in (A.45)to obtain the following expression linking price of gross output and price of value added:

$$
\operatorname{vec}\left(\hat{p}_{l}^{c}\right)=\left(I-D_{X} W_{2 X P} W_{1 X P}\right)^{-1} D_{V} \operatorname{vec}\left(p(\hat{V})_{l}^{c}\right)
$$

The market clearing conditions (2.10) can be linearized as:

$$
\hat{Q_{j}^{i}}=\sum_{h=1}^{n} \sum_{l=1}^{m} \frac{X_{j l}^{i h}}{Q_{j}^{i}} \hat{X}_{j l}^{i h}+\sum_{h=1}^{n} \frac{F_{j}^{i h}}{Q_{j}^{i}} \hat{F_{j}^{i h}}
$$

As before, these can be written in stacked form by creating matrices $S_{X}$ and $S_{F}$ from the above equations to yield:

$$
\operatorname{vec}\left(\hat{Q}_{l}^{c}\right)=\left(S_{F}\right)_{n m X n^{2} m} \operatorname{vec}\left(\hat{F_{s}^{f c}}\right)+\left(S_{X}\right)_{n m X n^{2} m^{2}} \operatorname{vec}\left(\hat{X}_{s l}^{f c}\right)
$$

\section{B Derivations of the expressions for GVC-REER and Q-REER((2.11) and}

From (A.48) and (A.42) we get

$$
\operatorname{vec}\left(\hat{Q}_{l}^{c}\right)\left[I_{n m}-S_{X} C_{2}\right]=\left(S_{X} Z_{X}+S_{F} Z_{F}\right) \operatorname{vec}\left(\hat{p}_{l}^{c}\right)+S_{F} Y_{3} \operatorname{vec}\left(\hat{F}^{c}\right)
$$

Using (A.46) in (B.1)and rearranging we get:

$$
\begin{aligned}
\operatorname{vec}\left(\hat{Q}_{l}^{c}\right)= & {\left[I_{n m}-S_{X} C_{2}\right]^{-1}\left(S_{X} Z_{X}+S_{F} Z_{F}\right)\left(I-D_{X} W_{2 X P} W_{1 X P}\right)^{-1} D_{V} \operatorname{vec}(p(\hat{V}) \dot{k} \text {. } 2) } \\
& +\left[I_{n m}-S_{X} C_{2}\right]^{-1} S_{F} Y_{3} \operatorname{vec}\left(\hat{F}^{i}\right)
\end{aligned}
$$

This is equation (2.14) in the main text.

Next, starting from the linearized production function vec $\left(\hat{Q}_{l}^{c}\right)=D_{v} v e c\left(\hat{V}_{l}^{c}\right)+D_{X} v e c\left(\hat{X}_{l}^{c}\right)$ we first use (A.23) and (A.22) to get: 


$$
\operatorname{vec}\left(\hat{Q}_{l}^{c}\right)=D_{v} \operatorname{vec}\left(\hat{V}_{l}^{c}\right)+D_{X} W_{2 X X} W_{1 X X} \operatorname{vec}\left(\hat{X}_{s l}^{i c}\right)
$$

substituting (A.42) in (B.3) and rearranging we get:

$$
\operatorname{vec}\left(\hat{Q}_{l}^{c}\right)\left[I-D_{X} W_{2 X X} W_{1 X X} C_{2}\right]=D_{v} \operatorname{vec}\left(\hat{V}_{l}^{c}\right)+D_{X} W_{2 X X} W_{1 X X} Z_{X} \operatorname{vec}\left(\hat{p}_{l}^{c}\right)
$$

It can be shown that $W_{2 X X} W_{1 X X} C_{2}=I$ and hence $\left[I-D_{X} W_{2 X X} W_{1 X X} Z_{4} Z_{6}\right]=D_{v}$ so that the above expression simplifies to:

$\operatorname{vec}\left(\hat{Q}_{l}^{c}\right)=\operatorname{vec}\left(\hat{V}_{l}^{c}\right)+D_{V}^{-1} D_{X} W_{2 X X} W_{1 X X} Z_{X}\left(I-D_{X} W_{2 X P} W_{1 X P}\right)^{-1} D_{V} v e c\left(p(\hat{V})_{l}^{c}\right)$

eliminating vec $\left(\hat{Q}_{l}^{c}\right)$ from (B.2) and (B.5) we get:

$$
\begin{aligned}
\operatorname{vec}\left(\hat{V}_{l}^{c}\right) & =\left\{\left(I_{n m}-S_{X} C_{2}\right)^{-1}\left(S_{F} Z_{F}+S_{X} Z_{X}\right)-D_{v}^{-1} D_{X} W_{2 X X} W_{1 X X} Z_{X}\right\}\left(I-D_{X} W_{2 X P} W_{1 X P}\right)^{-1} D_{V} \operatorname{vec}\left(\hat{p}_{l}^{v c}\right) \\
& +\left(I-S_{X} Z_{4} Z_{6}\right)^{-1} S_{F} Y_{3} \operatorname{vec}\left(\hat{F}^{c}\right)
\end{aligned}
$$

It is easy to show the following identities:

$$
\begin{aligned}
& \left(I_{n m}-S_{X} C_{2}\right)^{-1}=D_{Q}^{-1} B D_{Q} \\
& \left(I-D_{X} W_{2 X P} W_{1 X P}\right)^{-1}=B^{\prime}
\end{aligned}
$$

Substituting (B.7) and (B.8) in (B.6) we get (2.11) in the main text, with:

$$
W_{V}=\left[D_{Q}^{-1} B D_{Q}\left(S_{F} Z_{F}+S_{X} Z_{X}\right)-D_{V}^{-1} D_{X} W_{2 X X} W_{1 X X} Z_{X}\right] B^{\prime} D_{V}
$$

\section{Proofs of Propositions}

\section{C.1 Sketch of Proof of Proposition 2.1}

In this appendix we sketch the proof of proposition 1. Since the underlying intuition is preserved in the case with $m=1$, we will sketch the proof for this simplified case.

The expression for the weighting matrix is given by:

$$
w=\left\{D_{Q}^{-1} B D_{Q}\left(S_{F} Z_{F}+S_{X} Z_{X}\right)-D_{v}^{-1} D_{X} W_{2 X X} W_{1 X X} Z_{X}\right\} B^{\prime} D_{V}
$$


As shown in proposition (2.2), under the uniform elasticity assumption and $m=1$, the GVC-REER weighting matrix reduces to VAREER weighting matrix defined in Bems and Johnson (2012), which according to equation (18) in that paper is given by

$$
w=-I+D_{Q}^{-1} B D_{Q} S_{F} M_{2} B^{\prime} D_{v}
$$

define the matrices

$Z_{1}=Z_{4}=1_{n} \otimes I_{n} \equiv M_{2}$

$Z_{2}=Z_{5}=I_{n} \otimes 1_{n} \equiv M_{1}$

Under the uniform elasticity assumption, from (A.43) and (A.35) we have:

$$
\begin{aligned}
& Z_{X}=\sigma\left(M_{2}-M_{1}\right) \\
& Z_{F}=\theta\left(M_{2} W_{F P}-M_{1}\right)
\end{aligned}
$$

Taking the partial derivative of (C.1) wrt $\theta$

$$
\frac{\partial w}{\partial \theta}=D_{Q}^{-1} B D_{Q} S_{F}\left(M_{2} W_{F P}-M_{1}\right) B^{\prime} D_{V}
$$

using (C.2) in (C.5), the following relationship holds for the off diagonal elements of $w$

$$
\frac{\partial w^{i j}}{\partial \theta}=w^{i j}-\left[D_{Q}^{-1} B D_{Q} S_{F} M_{1} B^{\prime} D_{V}\right]_{i j}, i \neq j
$$

Simplifying the last term in the above expression gives (2.13) in the main text.

\section{C.2 Proof of Proposition (2.2):}

\section{Part 1.}

the GVC-REER weighting matrix under (A2) is given by:

$$
W_{V}=\left\{\left(I-S_{X} Z_{4} Z_{6}\right)^{-1}-D_{v}^{-1} D_{X} W_{2 X X} W_{1 X X} Z_{X}\right\}\left(I-D_{X} W_{2 X p} W_{1 X p}\right)^{-1} D_{V}
$$

where

$$
Z_{X}=\sigma_{1}\left(Z_{4} W_{1 X P}-Z_{5}\right)+\sigma_{2}\left(Z_{4} Z_{6} W_{2 X P} W_{1 X P}-Z_{4} W_{1 X P}\right)+\sigma_{3}\left(Z_{4} Z_{6}-Z_{4} Z_{6} W_{2 X P} W_{1 X P}\right)
$$

with

$Z_{1}=1_{n} \otimes I_{n m}, Z_{2}=I_{n} \otimes\left(1_{n} \otimes I_{m}\right), Z_{3}=I_{n} \otimes 1_{m},\left(Z_{4}\right)_{n^{2} m^{2} X n m^{2}}=1_{n} \otimes I_{n m^{2}},\left(Z_{5}\right)_{n^{2} m^{2} X n m}=$ $I_{n} \otimes 1_{n} \otimes I_{m} \otimes 1_{m}$ and $Z_{6}=\left(I_{n} \otimes 1_{m}\right) \otimes I_{m}$ 
for $m=1$, the different matrices in the above equation simplify as:

$Z_{1}=Z_{4}=1_{n} \otimes I_{n} \equiv M_{2}{ }^{26}$

$Z_{2}=Z_{5}=I_{n} \otimes 1_{n} \equiv M_{1}$

$Z_{3}=Z_{6}=I_{n}$

$W_{2 F P}=W_{2 X X}=W_{2 X P}=I_{n}$

$D_{X} W_{1 X p}=\Omega^{\prime}$, where $\Omega$ is the country level input output matrix with $\Omega_{i j}=\frac{p^{i} X_{i j}}{p^{j} Q_{j}}$

$$
\begin{aligned}
Z_{X} & =\sigma_{1}\left(Z_{4} W_{1 X P}-Z_{5}\right)+\sigma_{2}\left(Z_{4} Z_{6} W_{2 X P} W_{1 X P}-Z_{4} W_{1 X P}\right)+\sigma_{3}\left(Z_{4} Z_{6}-Z_{4} Z_{6} W_{2 X P} W_{1 X P}\right) \\
& =\sigma_{1}\left(M_{2} W_{1 X P}-M_{1}\right)+\sigma_{2}\left(M_{2} W_{1 X P}-M_{2} W_{1 X P}\right)+\sigma_{3}\left(M_{2}-M_{2} W_{1 X P}\right) \\
& =\sigma_{1}\left(M_{2} W_{1 X P}-M_{1}\right)+\sigma_{3}\left(M_{2}-M_{2} W_{1 X P}\right)
\end{aligned}
$$

$$
\begin{aligned}
Z_{F} & =\theta_{1}\left(Z_{1} W_{1 F P}-Z_{2}\right)+\theta_{2}\left(Z_{1} Z_{3} W_{2 F P} W_{1 F P}-Z_{1} W_{1 F P}\right) \\
& =\theta_{1}\left(M_{2} W_{F P}-M_{1}\right)
\end{aligned}
$$

Substituting all these in the expression for $Z_{V c l p}$ we get

$$
\begin{aligned}
W_{V} & =-\theta_{1}\left(I-S_{X} M_{2}\right)^{-1} S_{F}\left(M_{1}-M_{2} W_{F P}\right)\left(I-\Omega^{\prime}\right)^{-1} D_{V} \\
& +\left(I-S_{X} M_{2}\right)^{-1} S_{X}\left[\sigma_{1}\left(M_{2} W_{1 X P}-M_{1}\right)+\sigma_{3}\left(M_{2}-M_{2} W_{1 X P}\right)\right]\left(I-\Omega^{\prime}\right)^{-1} D_{V} \\
& -D_{V}^{-1} D_{X} W_{X}\left[\sigma_{1}\left(M_{2} W_{1 X P}-M_{1}\right)+\sigma_{3}\left(M_{2}-M_{2} W_{1 X P}\right)\right]\left(I-\Omega^{\prime}\right)^{-1} D_{V}
\end{aligned}
$$

This is the same as equation (33) in section 5 of BJ IOREER-BJ.

Part 2 and 3 follow directly from BJ.

\section{Part 4:}

The IMF manufacturing weights are given by (Bayoumi et al. (2005))

$$
W_{i m f m}^{i j}=\frac{\sum_{k} w^{i k} s^{j k}}{\sum_{k} w^{i k}\left(1-s^{i k}\right)}
$$

\footnotetext{
${ }^{26}$ In this section the matrices $M_{1}$ and $M_{2}$ are as defined in BJ and are different from the ones defined earlier in this paper.
} 
where $s^{j k}=\frac{\text { sales }^{j k}}{\sum_{l} \text { sales }^{l k}}$ and $w^{i k}=\frac{\text { sales }^{i k}}{\sum_{n} \text { sales }^{i n}}\left(\right.$ sales $^{i j}$ denotes gross sales from country $i$ to country j)

Substituting the expressions for $s^{j k}$ and $w^{i k}$ in $W^{i j}$ and simplifying we get:

$$
W_{i m f m}^{i j}=\frac{1}{T_{i}^{i m f m}} \sum_{k}\left(\frac{\text { sales }^{i k}}{\sum_{n} \text { sales }^{i n}}\right)\left(\frac{\text { sales }^{j k}}{\sum_{l} \text { sales }^{l k}}\right)
$$

where

$$
T_{i}^{i m f m}=1-\sum_{k}\left(\frac{\text { sales }^{i k}}{\sum_{n} \text { sales }^{i n}}\right)\left(\frac{\text { sales }^{i k}}{\sum_{l} \text { sales }^{l k}}\right)
$$

From parts 1-3 we know that under (A1), (A2) TEER and VAREER-BJ are equivalent and given by equation (24) in BJ which is reproduced below.

$$
W_{B J}^{i j}=\frac{1}{T_{i}^{B J}} \sum_{k}\left(\frac{p^{i v} V^{i k}}{P^{i v} V^{i}}\right)\left(\frac{p^{j v} V^{j k}}{P^{k} F^{k}}\right)
$$

with $T_{i}^{B J}=\sum_{k}\left(\frac{p^{i v} V^{i k}}{P^{i v} V^{i}}\right)\left(\frac{p^{i v} V^{i k}}{P^{k} F^{k}}\right)$

Under the assumption of no intermediates (A3)we have:

- $p^{i v}=p^{i}, Q^{i}=V^{i}, V^{i k}=F^{i k}$

- sales $^{i k}=p^{i v} V^{i k}=p^{i} V^{i k}$

- $\sum_{n}$ sales $^{i n}=\sum_{n} p^{i v} V^{i n}=p^{i v} V^{i}$

- $\sum_{l}$ sales $^{l k}=\sum_{l} p^{l v} V^{l k}=P^{k} F^{k}$

Substituting these in (C.10) and (C.11)

$$
W_{i m f m}^{i j}=W_{B J}^{i j}
$$

Finally, using $\alpha_{c}=\alpha_{T}=0$ we have

$W_{i m f}^{i j}=W_{B J}^{i j}$

The equivalence of IMF-REER to GOOD-SREER and IRER follows in a straightforward manner from the respective papers (Bayoumi et al. (2013) and Thorbecke (2011))

\section{Interpretation in the case of uniform elasticity}

Under the assumption that all elasticities (both in production and consumption) are the same, we can interpret the country-sector level weights purely in terms of value added trade flows. Suppose the common elasticity is $\eta$. Without loss of generality we can assume $\eta$ to be unity since it factors out. Then the weighting matrix $W$ can be written as above: 


$$
W_{V}=-I_{n m}+M_{1} M_{2}
$$

The matrix $M_{1}$ is an $n m$ by $n$ matrix with each row corresponding to a unique production entity. Along this row, the $n$ columns give the value added created by the production entity that is finally absorbed by each country. As an example, the entry corresponding to row $(i, l)$ and column $j$ gives the value added created by production entity $(i, l)$ that is eventually absorbed in country $j$ as a fraction of total value added created by the production entity $(i, l)$. Entries in this matrix can thus be interpreted as export shares in value added terms. The corresponding mathematical expression is ${ }^{27}$

$$
M_{1}((i, l), j)=\frac{v_{l}^{i} \sum_{c=1}^{n} \sum_{s=1}^{m} b_{l s}^{i c}\left(p(Q)_{s}^{c} F_{s}^{c j}\right)}{p(V)_{l}^{i} V_{l}^{i}}
$$

where $v_{l}^{i}=\frac{p_{l}^{v i} V_{l}^{i}}{p_{l}^{i} Q_{l}^{i}}$. For later, it is convenient to write this expression compactly as:

$$
M_{1}((i, l), j)=\frac{p(V)_{l}^{i} V_{l}^{i j}}{p(V)_{l}^{i} V_{l}^{i}}
$$

where $p_{l}^{v i} V_{l}^{i j}$ is the value added created by production entity $(i, l)$ that is finally absorbed in country $j$.

Matrix $M_{2}$ is an $n$ by $n m$ matrix with each column corresponding to a unique production entity and each row containing the value added created by the entity corresponding to the column that is absorbed in each country, as a fraction of the total final demand in that country. As an example, the entry corresponding to column $(i, l)$ and row $j$ gives the value added created by production entity $(i, l)$ that is ultimately absorbed in country $j$ as a fraction of total final demand of country $j$. The corresponding mathematical expression is :

$$
M_{2}(j,(i, l))=\frac{v_{l}^{i} \sum_{c=1}^{n} \sum_{s=1}^{m} b_{l s}^{i c}\left(p(Q)_{s}^{c} F_{s}^{c j}\right)}{P^{j} F^{j}}
$$

As above, it turns out to be more convenient to rewrite the above expression in short-hand notation as follows:

$$
M_{2}(j,(i, l))=\frac{p(V)_{l}^{i} V_{l}^{i j}}{P^{j} F^{j}}
$$

Using the generic terms from (C.15) and (C.17)we can write the weight assignment by country sector $(h, l)$ to country-sector $(c, s)$ where $(h, l) \neq(c, s)$ as follows:

\footnotetext{
${ }^{27}$ The raw expression of the matrix $M_{1}$ is $\frac{\sum_{c=1}^{n} \sum_{s=1}^{m} b_{l s}^{i c} p(Q)_{s}^{c} F_{s}^{c j}}{p(Q)_{l}^{i} Q_{l}^{i}}$. Multiplying and dividing by $v_{l}^{i}=\frac{p(V)_{l}^{i} V_{l}^{i}}{p(Q)_{l}^{i} Q_{l}^{i}}$ yields the expression below.
} 


$$
w_{l s}^{h c}=\sum_{k=1}^{n}\left[\frac{\left(p(V)_{l}^{h} V_{l}^{h k}\right)\left(p(V)_{s}^{c} V_{s}^{c k}\right)}{\left(p(V)_{l}^{h} V_{l}^{h}\right)\left(P^{K} F^{k}\right)}\right],(h, l) \neq(c, s)
$$

where we use lower case $w$ to denote uniform elasticity weights. In particular, the weight assigned by country sector $(h, l)$ to country-sector $(c, s)$ where $(h, l) \neq(c, s)$ is a weighted sum of the value added created by country-sector $(c, s)$ and absorbed by each of the countries $k(=1, . ., n)$, where the weights are given by the value added created by $(h, l)$ that is absorbed in the same country $k$. This captures both mutual and third country competition, because the weight is high if both $\left(p(V)_{l}^{h} V_{l}^{h k}\right)$ and $\left(p(V)_{s}^{c} V_{s}^{c k}\right)$ are high, which happens when both $(h, l)$ and $(c, s)$ have a high share of value added exports to country $k$.

\section{Equivalence of GVC-REER weighting matrices with BJ}

\section{Condition 7.1}

$$
v^{i} \sum_{c=1}^{n} b^{i c} F^{c j}=\sum_{l=1}^{m} v_{s}^{i} \sum_{c=1}^{n} \sum_{s=1}^{m} b_{l s}^{i c} F_{s}^{c j} \forall i, j
$$

where $v_{l}^{i}=\frac{p(V)_{l}^{i} V_{l}^{i}}{p(Q)_{l}^{i} Q_{l}^{i}}$ is the value added share for entity $(i, l)$ and $b$ denotes a generic element of the global inter-country Leontief inverse matrix.

\section{Proposition D.1.}

The country level weights $\left(W_{V}(G D P d e f)\right)$ defined above reduces to VAREER (and IOREER) weights defined in BJ if either of the two conditions below are satisfied.

1. (A2), (A3) and condition 5. 1

2. (A3), (A4) and $\theta_{1}=\theta_{1}^{h}=\theta_{2}$

Proof:

\section{Part 1}

We start with the following expression for GVC-REER weights at the country-sector level (C.7). 
under the uniform elasticity assumption:

$$
\begin{aligned}
& Z_{X}=-Z_{5}+Z_{4} Z_{6} \\
& Z_{F}=-Z_{2}+Z_{1} Z_{3} W_{2 F P} W_{1 F P}
\end{aligned}
$$

Here, without loss of generality we can assume that the elasticity is 1 .

$$
\begin{aligned}
\left(I-S_{X} Z_{4} Z_{6}\right)^{-1} & =D_{Q}^{-1} B D_{Q} \equiv \lambda \\
\left(I-D_{X} W_{2 X P} W_{1 X P}\right)^{-1} & =B^{\prime}
\end{aligned}
$$

Substituting (D.2), (D.3), (D.4) and (D.5) in (C.7)

$$
\begin{aligned}
W_{V} & =\left[\left(\lambda\left(S_{F} Z_{F}+S_{X} Z_{X}\right)-D_{V}^{-1} D_{X} W_{2 X X} W_{1 X X} Z_{X}\right] B^{\prime} D_{V}\right. \\
& =\lambda S_{F} Z_{1} Z_{3} W_{2 F P} W_{1 F P} B^{\prime} D_{v}+\left[\lambda S_{X} Z_{4} Z_{6}-\lambda\left(S_{F} Z_{2}+S_{X} Z_{5}\right)-D_{V}^{-1} D_{X} W_{2 X X} W_{1 X X} Z_{X}\right] B^{\prime} D_{V}
\end{aligned}
$$

Using the identities $S_{F} Z_{2}+S_{X} Z_{5}=I$ and $D_{V}-D_{X} W_{2 X X} W_{1 X X} Z_{X}=(I-A)^{\prime}=B^{\prime-1}$, we can show that the second term in (D.6) is the identity matrix, so that (D.6) reduces to:

$$
\begin{aligned}
W_{V} & =-I_{n m}+\lambda S_{F} Z_{1} Z_{3} W_{2 F P} W_{1 F P}\left[B_{l}^{c}\right]^{\prime} D_{v} \\
& =-I_{n m}+M_{1 m} M_{2 m}
\end{aligned}
$$

where

$$
\begin{aligned}
& M_{1 m}=\lambda S_{F} Z_{1} Z_{3} \\
& M_{2 m}=W_{2 F P} W_{1 F P}\left[B_{l}^{c}\right]^{\prime} D_{v}
\end{aligned}
$$

Next, the country level weights (which correspond to VAREER in BJ) are given by:

$$
W_{V}^{1}=\left\{\left(I-S_{X}^{1} Z_{4}^{1} Z_{6}^{1}\right)^{-1}\left(S_{F}^{1} Z_{F}^{1}+S_{X}^{1} Z_{X}^{1}\right)-\left(D_{v}^{1}\right)^{-1} D_{X}^{1} W_{1 X X} Z_{X}^{1}\right\}\left(I-D_{X}^{1} W_{1 X p}\right)^{-1} D_{V}^{1}
$$

(where the superscript 1 on the matrices on the RHS of (D.8) indicates that the matrix corresponds to the case where $m=1$ )

Following steps similar to those used to derive (D.7) we can get an analogous expression: 


$$
\begin{aligned}
W_{V}^{1} & =-I_{n}+\lambda^{1} S_{F}^{1} Z_{1}^{1} Z_{3}^{1} W_{1 F P}^{1}\left[B^{c}\right]^{\prime} D_{v} \\
& =-I_{n}+M_{1} M_{2}
\end{aligned}
$$

where

$$
\begin{aligned}
& M_{1}=\lambda^{1} S_{F}^{1} Z_{1}^{1} Z_{3}^{1} \\
& M_{2}=W_{1 F P}^{1}\left[B^{c}\right]^{\prime} D_{v}^{1}
\end{aligned}
$$

The 2 country level weights are equal iff

$$
R_{V} W_{V} R_{g}=W_{V}(C G)
$$

Since $R_{V} R_{g}=I_{n}$, a necessary and sufficient condition for (D.11) to hold is :

$$
\begin{aligned}
\left(R_{V} M_{1 m}\right)\left(M_{2 m} R_{g}\right)=M_{1} M_{2} \\
\left(R_{V} M_{1 m}\right)_{i j}=\sum_{c=1}^{n} \sum_{l=1}^{m} \sum_{s=1}^{m}\left(\frac{v_{s}^{i} b_{s l}^{i c} F_{l}^{c j}}{p^{v i} V^{i}}\right) \\
\left(M_{2 m} R_{g}\right)_{i j}=\sum_{c=1}^{n} \sum_{l=1}^{m} \sum_{s=1}^{m}\left(\frac{v_{s}^{j} b_{s l}^{j c} F_{l}^{c i}}{P^{i} F^{i}}\right) \\
\left(M_{1}\right)_{i j}=\sum_{c=1}^{n}\left(\frac{v^{i} b^{i c} F^{c j}}{p^{v i} V^{i}}\right) \\
\left(M_{2}\right)_{i j}=\sum_{c=1}^{n}\left(\frac{v^{j} b^{j c} F^{c i}}{P^{i} F^{i}}\right)
\end{aligned}
$$

here $v_{s}^{i}=\left(\frac{p_{s}^{v i} V_{s}^{i}}{p_{s}^{i} Q_{s}^{i}}\right)$.

From these expressions it is clear that the condition (D.12) is satisfied for all values if and only if 


$$
v^{i} \sum_{c=1}^{n} b^{i c} f^{c j}=\sum_{l=1}^{m} v_{s}^{i} \sum_{c=1}^{n} \sum_{s=1}^{m} b_{l s}^{i c} F_{s}^{c j} \forall i, j
$$

or stacking these conditions in matrix notation:

$$
\operatorname{diag}\left[v^{c}\right]_{n X n}\left[B^{c}\right]_{n X n}\left[F^{C}\right]_{n X n}=\left(M_{V}\right)_{n X n m} \operatorname{diag}\left[v_{l}^{c}\right]_{n m X n m}\left[B_{l}^{c}\right]_{n m X n m}\left[F_{l}^{c}\right]_{n m X n}
$$

\section{Part 2:}

Under (A3), (A4) and $\theta_{1}=\theta_{2}(=1($ wlog $))$ we have,

$$
\operatorname{diag}\left[v^{c}\right]_{n X n}=\left[B^{c}\right]_{n X n}=I_{n}
$$$$
\operatorname{diag}\left[v_{l}^{c}\right]_{n m X n m}=\left[B_{l}^{c}\right]_{n m X n m}=I_{n m}
$$

$\left(M_{V}\right)_{n X n m}\left[F_{l}^{c}\right]_{n m X n}=\left[F^{C}\right]_{n X n}$

With these simplifications condition (D.14) is automatically satisfied and hence GVC$\operatorname{REER}(\mathrm{CG})$ is equivalent to $\mathrm{VAREER}$.

\section{E A Stylized Three Country Global Value Chain}

We start with a simplified 3 country, 2 sector model capturing the basic Global Value Chain (GVC) features. There are three countries (J, C and U for Japan, China and USA respectively) and two sectors indexed by $\{1,2\}$. Table 13 displays the input output table. All boxes with " $\mathrm{X}$ " denote non-zero entries while the remaining entries are zero. Note that the IO matrix is sparse and contains only one (out of a possible 36) non-zero entries. The global value chain is modeled across two sectors in three different countries. The upstream sector J1 (sector 1 in country J) produces raw materials that are exported to country C. Sector 2 in country $\mathrm{C}$ combines these intermediate inputs from $\mathrm{J}$ along with its own value added to produce final goods that are then exported to countries $\mathrm{J}$ and $\mathrm{U}$ in addition to being consumed internally by country C. All other sectors (i.e J2, C1, U1 and U2) only produce goods using own value added (i.e no intermediate inputs) and sell them as final demand in the home country. Sector 2 can be interpreted as the electronics sector and sector 1 can be interpreted as a (raw) materials sector. 
Table 13 - A stylized 3 country 2 sector global value chain set up

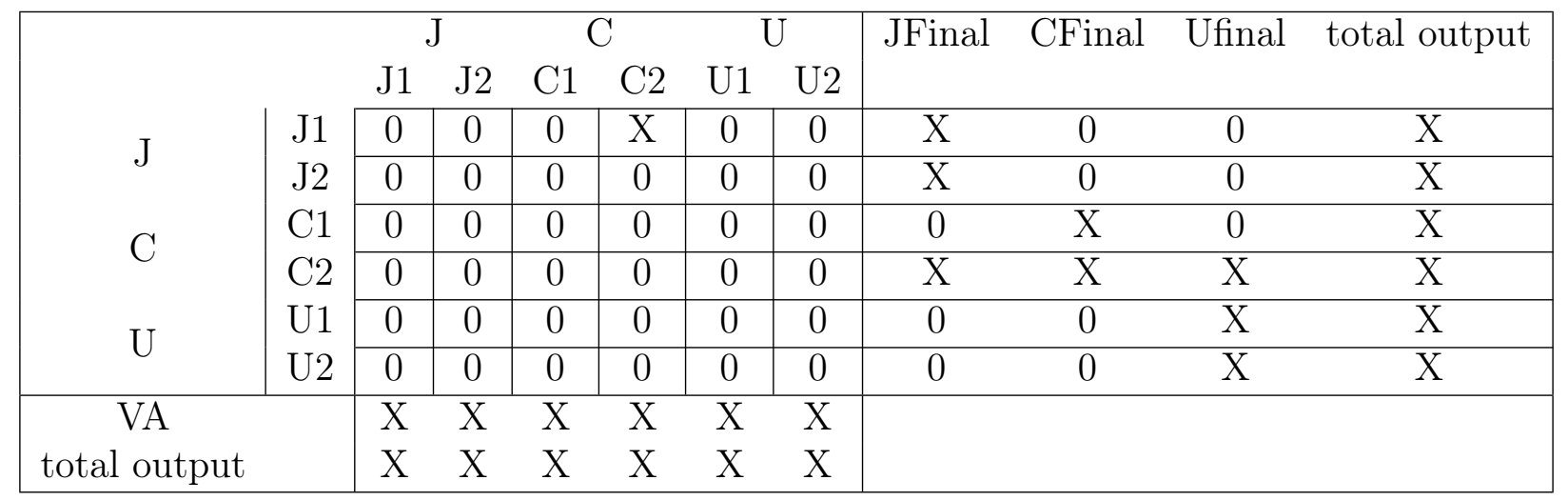

\section{Specifying the model:}

We use $Q_{l}^{h}$ to denote the gross output of sector $l$ is country $h .{ }^{28} X_{s l}^{f h}$ denotes the intermediate input from country $f$ sector $s$ used in production by $(h, l) . V_{l}^{h}$ denotes the value added by $(h, l)$. We assume a constant elasticity of substitution which is allowed to differ across consumption and production aggregators as clarified below.

\section{Production:}

The production function of $(C, 2)$ is given by

$$
Q_{2}^{C}=\left[\left(w^{V}\right)^{\frac{1}{\sigma}}\left(V_{2}^{C}\right)^{\frac{\sigma-1}{\sigma}}+\left(w^{X}\right)^{\frac{1}{\sigma}}\left(X_{12}^{J C}\right)^{\frac{\sigma-1}{\sigma}}\right]^{\frac{\sigma}{\sigma-1}}
$$

where $\sigma$ is the elasticity of substitution between the two inputs and $w^{V}$ and $w^{X}$ are weights that can be mapped to the shares of the two inputs.

Since all other production comprises entirely of own value added, the remaining production functions are of the form:

$$
Q_{l}^{h}=V_{l}^{h} \forall(h, l) \neq(C, 2)
$$

\section{Consumption:}

We use $F_{l}^{h f}$ to denote output of $(h, l)$ that is absorbed in country $f$ as final demand. Based on table 13, the consumption aggregators for the three countries are given as follows:

\footnotetext{
${ }^{28}$ Throughout this paper, superscripts will be used for countries and subscripts for sectors.
} 


$$
\begin{aligned}
& F^{J}=\left[\left(\kappa_{1}^{J J}\right)^{\frac{1}{\theta}}\left(F_{1}^{J J}\right)^{\frac{\theta-1}{\theta}}+\left(\kappa_{2}^{J J}\right)^{\frac{1}{\theta}}\left(F_{2}^{J J}\right)^{\frac{\theta-1}{\theta}}+\left(\kappa_{2}^{C J}\right)^{\frac{1}{\theta}}\left(F_{2}^{C J}\right)^{\frac{\theta-1}{\theta}}\right]^{\frac{\theta}{\theta-1}} \\
& F^{C}=\left[\left(\kappa_{1}^{C C}\right)^{\frac{1}{\theta}}\left(F_{1}^{C C}\right)^{\frac{\theta-1}{\theta}}+\left(\kappa_{2}^{C C}\right)^{\frac{1}{\theta}}\left(F_{2}^{C C}\right)^{\frac{\theta-1}{\theta}}\right]^{\frac{\theta}{\theta-1}} \\
& F^{U}=\left[\left(\kappa_{1}^{U U}\right)^{\frac{1}{\theta}}\left(F_{1}^{U U}\right)^{\frac{\theta-1}{\theta}}+\left(\kappa_{2}^{U U}\right)^{\frac{1}{\theta}}\left(F_{2}^{U U}\right)^{\frac{\theta-1}{\theta}}+\left(\kappa_{2}^{C U}\right)^{\frac{1}{\theta}}\left(F_{2}^{C U}\right)^{\frac{\theta-1}{\theta}}\right]^{\frac{\theta}{\theta-1}}
\end{aligned}
$$

We use large case $P$ to denote CPI, small case $p^{Q}$ is used to denote price of gross output; $p^{V}$ will be used to denote price of value added and $p^{X}$ for price of intermediate goods. $\theta$ is the elasticity of substitution between different goods in the final consumption good bundle and is assumed to be the same across all countries ${ }^{29} . \kappa \mathrm{s}$ are weights that denote the shares of the different components in the aggregators.

Appendix E.1 shows how the linearized version of the model can be solved to write the demand for value added for each entity as a function of all the value added prices assuming that total final demand remains constant (i.e $\hat{F}^{h}=0 \forall h$ ), or what we define as the real exchange rate (GVC-REER) following this partial equilibrium literature ${ }^{30}$ :

$$
\begin{aligned}
\triangle G V C-R E E R_{s}^{h}= & \hat{V}_{s}^{h}=w(v)_{s 1}^{h J} \hat{p}(V)_{1}^{J}+w(v)_{s 2}^{h J} \hat{p}(V)_{2}^{J}+w(v)_{s 1}^{h C} \hat{p}(V)_{1}^{C} \\
& +w(v)_{s 2}^{h C} \hat{p}(V)_{2}^{C}+w(v)_{s 1}^{h U} \hat{p}(V)_{1}^{U}+w(v)_{s 2}^{h U} \hat{p}(V)_{2}^{U}
\end{aligned}
$$

where $h \in\{J, C, U\}, s \in\{1,2\}$

To illustrate the properties of our REER weighting scheme, we focus on the weight assignment between the two sectors that are involved in the the GVC. We use the notation $p(V)_{l}^{a} V_{l}^{a b}$ to denote the total value added created in $(a, l)$ that is ultimately absorbed as country b's final demand. Our model yields the following expression for the weight assigned by $\mathrm{C} 2$ o J1:

$$
\begin{aligned}
w(v)_{21}^{C J}= & \theta\left[\left(\frac{p(V)_{2}^{C} V_{2}^{C J}}{p(V)_{2}^{C} V_{2}^{C}}\right)\left(\frac{p(V)_{1}^{J} V_{1}^{J J}}{P^{J} F^{J}}\right)+\left(\frac{p(V)_{2}^{C} V_{2}^{C C}}{p(V)_{2}^{C} V_{2}^{C}}\right)\left(\frac{p(V)_{1}^{J} V_{1}^{J C}}{P^{C} F^{C}}\right)+\left(\frac{p(V)_{2}^{C} V_{2}^{C U}}{p(V)_{2}^{C} V_{2}^{C}}\right)\left(\frac{p(V)_{1}^{J} V_{1}^{J U}}{P^{U} F^{U}}\right)\right] \\
& +\left(\frac{p(Q)_{1}^{J} X_{12}^{J C}}{p(Q)_{2}^{C} Q_{2}^{C}}\right)(\sigma-\theta)
\end{aligned}
$$

Several aspects of the weighting schemes now become evident from (E.7). Firstly, under the constant elasticity assumption $(\theta=\sigma=1)$ the weight reduces to:

\footnotetext{
${ }^{29}$ This and many other restrictions imposed so far will be relaxed in the general model presented later.

${ }^{30}$ In addition to the first order conditions, the only equilibrium conditions we need are market clearing conditions. These are listed in the appendix.
} 


$$
w(v)_{21}^{C J}=\sum_{k=J, C, U}\left[\frac{\left(p(V)_{2}^{C} V_{2}^{C k}\right)\left(p(V)_{1}^{J} V_{1}^{J k}\right)}{\left(p(V)_{2}^{C} V_{2}^{C}\right)\left(P^{K} F^{k}\right)}\right] \geq 0
$$

This is the same as the sum of the three terms inside the bracket in $(\mathrm{E} .7)^{31}$. Each of these terms can be interpreted as capturing the intensity of competition between $(C, 2)$ and $(J, 1)$ in the three final goods markets, namely $C, J$ and $U$. The higher is the intensity of competition as measured by these terms, the higher would be the weight assigned by $(C, 2)$ to $(J, 1)$, since in that case a fall in the price of $(J, 1)$ 's value added would hurt $(C, 2)$ more. As an example, if the last term in (E.7) $\left[\left(\frac{p(V)_{2}^{C} V_{2}^{C U}}{p(V)_{2}^{C} V_{2}^{C}}\right)\left(\frac{p(V)_{1}^{J} V_{1}^{J U}}{P^{U} F^{U}}\right)\right]$ is high, it conveys that value added by $(C, 2)$ and $(J, 1)$ are competing intensively in order to satisfy country $U$ 's final demand, so a fall in $(J, 1)$ 's price will hurt $(C, 2)$ to a greater extent.

Secondly, note that $w(v)_{21}^{C J}$ is strictly increasing in $\sigma$. Intuitively, the lower is the elasticity of substitution between own value added and Japanese imports in $(C, 2)$ 's production, the higher will be the co-movement between the value added by $(C, 2)$ and $(J, 1)$. In this case, the weight assigned by $(C, 2)$ to $(J, 1)$ will be lower, since a fall in the price of $(J, 1)$ 's value added, which increases demand for output of $(J, 1)$, will also end up exerting a positive effect on the demand for value added by $(C, 2)$.

Thirdly, unlike $\sigma$, the effect of an increase in $\theta$ is ambiguous. On the one hand an increase in $\theta$ exerts a positive effect on $w(v)_{21}^{C J}$ via the standard expenditure switching effect-if consumers are more willing to substitute between different goods in their consumption bundle, a fall in the price of a substitute will decrease demand for the own good to a greater extent. On the other hand, to the extent that the value added by $(C, 2)$ and $(J, 1)$ are complementary, expenditure switching towards $(J, 1)$ 's value added indirectly also implies a shift in expenditure towards $(C, 2)$ 's output and hence towards $(C, 2)$ 's value added which is embodied in its own output. In this example the two effects run in opposite directions.

Lastly, (E.7) and (E.8)also illustrate the restrictive nature of the weighting scheme in the constant elasticity case. In particular the complementarity effect discussed above is not present, and as is evident from (E.8) the weighting scheme is not flexible enough to accommodate negative weights.

The appendix shows how we can derive REERs for gross output competitiveness (as

\footnotetext{
${ }^{31}$ In fact, under the assumption of constant elasticity, all weights can be represented by a formula mimicking (E.8), i.e.

$$
w(v)_{l s}^{h k}=\sum_{k=J, C, U}\left[\frac{\left(p(V)_{l}^{h} V_{l}^{h k}\right)\left(p(V)_{s}^{c} V_{s}^{c k}\right)}{\left(p(V)_{l}^{h} V_{l}^{h}\right)\left(P^{K} F^{k}\right)}\right] \forall h, k, s, l
$$
}

This is the same as 2.12 in the case of the general model. 
opposed to competitiveness for value added which is what GVC-REER measures) and how it compares to our GVC-REER weighting scheme in this 3 by 2 world.

\section{Defining Aggregate Real Effective Exchange Rates for Countries}

We compute aggregate country level REERs by exploiting information on sector level trade flows. For comparison, further in the appendix we also compute an alternate measure that aggregates all trade flows within a country as is commonly done in the literature. Appendix E.1 shows that the demand for value added produced by country $h$ can be written as:

$$
\hat{V}^{h}=\sum_{f \in(J, C, U)} \sum_{k \in\{1,2\}}\left[\left(\frac{p(V)_{1}^{h} V_{1}^{h}}{p(V)^{h} V^{h}}\right) w(v)_{1 k}^{h f}+\left(\frac{p(V)_{2}^{h} V_{2}^{h}}{p(V)^{h} V^{h}}\right) w(v)_{2 k}^{h f}\right] \hat{p}(V)_{k}^{f}
$$

If sector level price indices are available, then (E.9) provides the most accurate measure of competitiveness for a country as a whole. Typically however, country level REER is computed using an aggregate country-wide price index (like the GDP deflator, CPI or some measure of unit labor cost). To define an analogous measure in our framework we need to make an assumption regarding the link between sector level prices and the aggregate GDP deflator of a country. We choose to make the simplest possible assumption (which is also made implicitly throughout this literature), namely that all sector level prices change by the same proportion as the change in the aggregate GDP deflator. In particular,

$$
\hat{p}(V)^{h}=\hat{p}(V)_{1}^{h}=\hat{p}(V)_{2}^{h}
$$

With this assumption we can simplify (E.9) to write:

$$
\hat{V}^{h}=\sum_{f \in(J, C, U)} \underbrace{\left[\left(\frac{p(V)_{1}^{h} V_{1}^{h}}{p(V)^{h} V^{h}}\right)\left(w(v)_{11}^{h f}+w(v)_{12}^{h f}\right)+\left(\frac{p(V)_{2}^{h} V_{2}^{h}}{p(V)^{h} V^{h}}\right)\left(w(v)_{21}^{h f}+w(v)_{21}^{h f}\right)\right]}_{w_{A}(v)^{h f}} \hat{p}(V)^{f}
$$

Here $w_{A}(v)^{h f}$ denotes the aggregate (i.e country level) weight assigned by country $h$ to country $f$ in the real exchange rate of country $h$. As is evident from (E.11), this weight is itself a weighted sum of the weights assigned by each sector in $h$ to each sector in $f$, with the weights given by the value added shares of the sectors in $h$.

In the appendix we compare our country level REER measure against the common approach of aggregating across sectors within each country and show that these two approaches 
yield different results except in knife-edge cases. ${ }^{32}$

\section{E.1 Stylized 3 by 2 GVC: Details and derivations}

The associated price indices for final goods consumption (CPIs) can be computed as follows:

$$
\begin{aligned}
P^{J} & =\left[\left(\kappa_{1}^{J J}\right)\left(p(Q)_{1}^{J}\right)^{1-\theta}+\left(\kappa_{2}^{J J}\right)\left(p(Q)_{2}^{J}\right)^{1-\theta}+\left(\kappa_{2}^{C J}\right)\left(p(Q)_{2}^{C}\right)^{1-\theta}\right]^{\frac{1}{1-\theta}} \\
P^{C} & =\left[\left(\kappa_{1}^{C C}\right)\left(p(Q)_{1}^{C}\right)^{1-\theta}+\left(\kappa_{2}^{C C}\right)\left(p(Q)_{2}^{C}\right)^{1-\theta}\right]^{\frac{1}{1-\theta}} \\
P^{U} & =\left[\left(\kappa_{1}^{U U}\right)\left(p(Q)_{1}^{U}\right)^{1-\theta}+\left(\kappa_{2}^{U U}\right)\left(p(Q)_{2}^{U}\right)^{1-\theta}+\left(\kappa_{2}^{C U}\right)\left(p(Q)_{2}^{C}\right)^{1-\theta}\right]^{\frac{1}{1-\theta}}
\end{aligned}
$$

\section{Market clearing conditions:}

Output of all entities except $(C, 2)$ is sold only as final good. Table 13 implies the following market clearing conditions:

$$
\begin{aligned}
Q_{1}^{J} & =X_{12}^{J C}+F_{1}^{J J} \\
Q_{2}^{J} & =F_{2}^{J J} \\
Q_{1}^{C} & =F_{1}^{C C} \\
Q_{2}^{C} & =F_{2}^{C C}+F_{2}^{C J}+F_{2}^{C U} \\
Q_{1}^{U} & =F_{1}^{U U} \\
Q_{2}^{U} & =F_{2}^{U U}
\end{aligned}
$$

\section{Solving the model:}

We solve the model by combining the log linearized first order conditions with the market clearing conditions. The first order condition for final good can be written as:

$$
F_{s}^{f h}=\kappa_{s}^{f h}\left(\frac{p(Q)_{s}^{f}}{P^{h}}\right)^{-\theta} F^{h}, h, f \in\{J, C, U), s \in\{1,2\}
$$

(note that only 8 out of the 18 values of $F_{s}^{f h}$ are positive).

We will work with the following log linearized version:

\footnotetext{
${ }^{32}$ The issue of aggregation is explored in more detail after we present the general model.
} 


$$
\hat{F}_{s}^{f h}=-\theta \hat{p}_{s}^{f}+\theta \hat{P}^{h}+\hat{F}^{h}
$$

Linearizing the expressions for the CPIs in the three countries we get:

$$
\begin{aligned}
\hat{P}^{U} & =\left(\frac{p_{2}^{C} F_{2}^{C U}}{P^{U} F^{U}}\right) \hat{p}(Q)_{2}^{C}+\left(\frac{p(Q)_{1}^{U} F_{1}^{U U}}{P^{U} F^{U}}\right) \hat{p}(V)_{1}^{U}+\left(\frac{p(Q)_{2}^{U} F_{2}^{U U}}{P^{U} F^{U}}\right) \hat{p}(V)_{2}^{U} \\
\hat{P}^{C} & =\left(\frac{p(Q)_{1}^{C} F_{1}^{C C}}{P^{C} F^{C}}\right) \hat{p}(Q)_{1}^{C}+\left(\frac{p(Q)_{2}^{C} F_{2}^{C C}}{P^{C} F^{C}}\right) \hat{p}(Q)_{2}^{C} \\
\hat{P}^{J} & =\left(\frac{p(Q)_{1}^{J} F_{1}^{J J}}{P^{J} F^{J}}\right) \hat{p}(Q)_{1}^{J}+\left(\frac{p(Q)_{2}^{J} F_{2}^{J J}}{P^{J} F^{J}}\right) \hat{p}(Q)_{2}^{J}+\left(\frac{p(Q)_{2}^{C} F_{2}^{C J}}{P^{J} F^{J}}\right) \hat{p}(Q)_{2}^{C}
\end{aligned}
$$

The first order conditions for production are as follows:

$$
\begin{gathered}
X_{12}^{J C}=w^{X}\left(\frac{p(Q)_{1}^{J}}{p(Q)_{2}^{C}}\right)^{-\sigma} Q_{2}^{C} \\
V_{2}^{C}==w_{2}^{V}\left(\frac{p(V)_{2}^{C}}{p(Q)_{2}^{C}}\right)^{-\sigma} Q_{2}^{C}
\end{gathered}
$$

These along with the production function and its associated price index can be linearized as follows:

$$
\begin{aligned}
\hat{X}_{12}^{J C} & =-\sigma \hat{p}(Q)_{1}^{J}+\sigma \hat{p}(Q)_{2}^{C}+\hat{Q}_{2}^{C} \\
\hat{V}_{2}^{C} & =-\sigma \hat{p}(V)_{2}^{C}+\sigma \hat{p}(Q)_{2}^{C}+\hat{Q}_{2}^{C} \\
\hat{Q}_{2}^{C} & =\left(\frac{p(V)_{2}^{C} V_{2}^{C}}{p(Q)_{2}^{C} Q_{2}^{C}}\right) \hat{V}_{2}^{C}+\left(\frac{p(V)_{1}^{J} X_{12}^{J C}}{p(Q)_{2}^{C} Q_{2}^{C}}\right) \hat{X}_{12}^{J C} \\
\hat{p}_{2}^{C} & =\left(\frac{p(V)_{2}^{C} V_{2}^{C}}{p(Q)_{2}^{C} Q_{2}^{C}}\right) \hat{p}(V)_{2}^{C}+\left(\frac{p(V)_{1}^{J} X_{12}^{J C}}{p(Q)_{2}^{C} Q_{2}^{C}}\right) \hat{p}(V)_{1}^{J}
\end{aligned}
$$

Next, the non trivial market clearing conditions (E.18) and (E.15) can be linearized as follows:

$$
\begin{aligned}
\hat{Q}_{2}^{C} & =\left(\frac{p(Q)_{2}^{C} F_{2}^{C C}}{p(Q)_{2}^{C} Q_{2}^{C}}\right) \hat{F}_{2}^{C C}+\left(\frac{p(Q)_{2}^{C} F_{2}^{C J}}{p(Q)_{2}^{C} Q_{2}^{C}}\right) \hat{F}_{2}^{C J}+\left(\frac{p(Q)_{2}^{C} F_{2}^{C U}}{p(Q)_{2}^{C} Q_{2}^{C}}\right) \hat{F}_{2}^{C U} \\
\hat{Q}_{1}^{J} & =\left(\frac{p(Q)_{1}^{J} X_{12}^{J C}}{p(Q)_{1}^{J} Q_{1}^{J}}\right) \hat{X}_{12}^{J C}+\left(\frac{p(Q)_{1}^{J} F_{1}^{J J}}{p(Q)_{1}^{J} Q_{1}^{J}}\right) \hat{F}_{1}^{J J}
\end{aligned}
$$




\section{Computation of linearized expression for $\hat{V}_{2}^{C}$ and $Q_{2}^{C}$ in section E.}

From (E.26) and (E.26) we get:

$$
\hat{Q}_{2}^{C}=\hat{V}_{2}^{C}+\left(\frac{p(Q)_{1}^{J} X_{12}^{J C}}{p(V)_{2}^{C} V_{2}^{C}}\right)\left(-\sigma \hat{p}(V)_{1}^{J}+\sigma \hat{p}(Q)_{2}^{C}\right)
$$

Using the linearized first order conditions for final goods consumption (E.34) in the market clearing condition we get:

$$
\begin{aligned}
\hat{Q}_{2}^{C}= & \left(\frac{p(Q)_{2}^{C} F_{2}^{C C}}{p(Q)_{2}^{C} Q_{2}^{C}}\right) \hat{F}_{2}^{C C}+\left(\frac{p(Q)_{2}^{C} F_{2}^{C J}}{p(Q)_{2}^{C} Q_{2}^{C}}\right) \hat{F}_{2}^{C J}+\left(\frac{p(Q)_{2}^{C} F_{2}^{C U}}{p(Q)_{2}^{C} Q_{2}^{C}}\right) \hat{F}_{2}^{C U} \\
= & \left(\frac{p(Q)_{2}^{C} F_{2}^{C C}}{p(Q) Q_{2}^{C}}\right)\left(-\theta \hat{p}(Q)_{2}^{C}+\theta \hat{P}^{C}+\hat{F}^{C}\right)+\left(\frac{p(Q)_{2}^{C} F_{2}^{C J}}{p(Q)_{2}^{C} Q_{2}^{C}}\right)\left(-\theta \hat{p}(Q)_{2}^{C}+\theta \hat{P}^{J}+\hat{F}^{J}\right) \\
& +\left(\frac{p(Q){ }_{2}^{C} F_{2}^{C U}}{p(Q)_{2}^{C} Q_{2}^{C}}\right)\left(-\theta \hat{p}(Q)_{2}^{C}+\theta \hat{P}^{U}+\hat{F}^{U}\right)
\end{aligned}
$$

Using the expressions for the linearized CPIs as well as we can write (E.34) as follows:

$\hat{Q}_{2}^{c}=w(Q)_{21}^{C J} \hat{p}(V)_{1}^{J}+w(Q)_{22}^{C J} \hat{p}(V)_{2}^{J}+w(Q)_{21}^{C C} \hat{p}(V)_{1}^{C}+w(Q)_{22}^{C C} \hat{p}(V)_{2}^{C}+w(Q)_{21}^{C U} \hat{p}(V)_{1}^{U}+w(Q)_{22}^{C U} \hat{p}(V)_{2}^{U}$

where

$$
\begin{aligned}
& w(Q)_{21}^{C J}=-\theta\left(\frac{p(Q)_{1}^{J} X_{12}^{J C}}{p(Q)_{2}^{C} Q_{2}^{C}}\right)+\theta\left(\frac{p(Q)_{1}^{J} X_{12}^{J C}}{p(Q)_{2}^{C} Q_{2}^{C}}\right)\left(\frac{p(Q)_{2}^{C} F_{2}^{C J}}{p(Q)_{2}^{C} Q_{2}^{C}}\right)\left(\frac{p(Q)_{2}^{C} F_{2}^{C J}}{P^{J} F^{J}}\right)+\theta\left(\frac{p(V)_{2}^{C} V_{2}^{C}}{p(Q)_{2}^{C} Q_{2}^{C}}\right)\left(\frac{p(Q)_{2}^{C} F_{2}^{C C}}{p(Q)_{2}^{C} Q_{2}^{C}}\right)\left(\frac{p(Q)_{2}^{C} F_{2}^{C C}}{P^{C} F^{C}}\right) \\
& +\theta\left(\frac{p(Q)_{2}^{C} F_{2}^{C J}}{p(Q){ }_{2}^{C} Q_{2}^{C}}\right)\left(\frac{p(Q)_{1}^{J} F_{1}^{J J}}{P^{J} F^{J}}\right)+\theta\left(\frac{p(Q)_{1}^{J} X_{12}^{J C}}{p(Q)_{2}^{C} Q_{2}^{C}}\right)\left(\frac{p(Q)_{2}^{C} F_{2}^{C U}}{p(Q)_{2}^{C} Q_{2}^{C}}\right)\left(\frac{p(Q)_{2}^{C} F_{2}^{C U}}{P^{U} F^{U}}\right) \\
& w(Q)_{22}^{C J}=\theta\left(\frac{p(Q)_{2}^{C} F_{2}^{C J}}{p(Q)_{2}^{C} Q_{2}^{C}}\right)\left(\frac{p(Q)_{2}^{J} F_{2}^{J J}}{P^{J} F^{J}}\right) \\
& w(Q)_{21}^{C C}=\theta\left(\frac{p(Q)_{2}^{C} F_{2}^{C C}}{p(Q)_{2}^{C} Q_{2}^{C}}\right)\left(\frac{p(Q)_{1}^{C} F_{1}^{C C}}{P^{C} F^{C}}\right) \\
& w(Q)_{22}^{C C}=-\theta+\theta\left(\frac{p(V)_{2}^{C} V_{2}^{C}}{p(Q)_{2}^{C} Q_{2}^{C}}\right)\left(\frac{p(Q)_{2}^{C} F_{2}^{C C}}{p(Q)_{2}^{C} Q_{2}^{C}}\right)\left(\frac{p(Q)_{2}^{C} F_{2}^{C C}}{P^{C} F^{C}}\right)+\theta\left(\frac{p(V)_{2}^{C} V_{2}^{C}}{p(Q)_{2}^{C} Q_{2}^{C}}\right)\left(\frac{p(Q)_{2}^{C} F_{2}^{C J}}{p(Q)_{2}^{C} Q_{2}^{C}}\right)\left(\frac{p(Q)_{2}^{C} F_{2}^{C J}}{P^{J} F^{J}}\right) \\
& +\theta\left(\frac{p(V)_{2}^{C} V_{2}^{C}}{p(Q)_{2}^{C} Q_{2}^{C}}\right)\left(\frac{p(V)_{2}^{C} F_{2}^{C U}}{p(Q){ }_{2}^{C} Q_{2}^{C}}\right)\left(\frac{p(Q)_{2}^{C} F_{2}^{C U}}{P^{U} F^{U}}\right)
\end{aligned}
$$




$$
\begin{aligned}
& w(Q)_{21}^{C U}=\theta\left(\frac{p(Q)_{2}^{C} F_{2}^{C U}}{p(Q)_{2}^{C} Q_{2}^{C}}\right)\left(\frac{p(Q)_{1}^{U} F_{1}^{U U}}{P^{U} F^{U}}\right) \\
& w(Q)_{22}^{C U}=\theta\left(\frac{p(Q)_{2}^{C} F_{2}^{C U}}{p(Q)_{2}^{C} Q_{2}^{C}}\right)\left(\frac{p(Q)_{2}^{U} F_{2}^{U U}}{P^{U} F^{U}}\right)
\end{aligned}
$$

From (E.33) and (E.36) we can write the demand for value added by $(C, 2)$ as a function of prices as follows:

$$
\begin{aligned}
\hat{V}_{2}^{c} & =w(v)_{21}^{C J} \hat{p}(V)_{1}^{J}+w(v)_{22}^{C J} \hat{p}(V)_{2}^{J}+w(v)_{21}^{C C} \hat{p}(V)_{1}^{C} \\
& +w(v)_{22}^{C C} \hat{p}(V)_{2}^{C}+w(v)_{21}^{C U} \hat{p}(V)_{1}^{U}+w(v)_{22}^{C U} \hat{p}(V)_{2}^{U}
\end{aligned}
$$

where

$$
\begin{aligned}
w(V)_{21}^{C J} & =w(Q)_{21}^{C J}+\sigma\left(\frac{p(Q)_{1}^{J} X_{12}^{J C}}{p(Q)_{2}^{C} Q_{2}^{C}}\right) \\
w(V)_{22}^{C J} & =w(Q)_{22}^{C J} \\
w(V)_{21}^{C C} & =w(Q)_{21}^{C C} \\
w(V)_{22}^{C C} & =w(Q)_{22}^{C C}+\sigma\left(\frac{p(Q)_{1}^{J} X_{12}^{J C}}{p(Q)_{2}^{C} Q_{2}^{C}}\right) \\
w(V)_{21}^{C U} & =w(Q)_{21}^{C U} \\
w(V)_{22}^{C U} & =w(Q)_{22}^{C U} \\
\hat{V}_{1}^{c}= & w(v)_{11}^{C J} \hat{p}(V)_{1}^{J}+w(v)_{12}^{C J} \hat{p}(V)_{2}^{J}+w(v)_{11}^{C C} \hat{p}(V)_{1}^{C} \\
+ & w(v)_{12}^{C C} \hat{p}(V)_{2}^{C}+w(v)_{11}^{C U} \hat{p}(V)_{1}^{U}+w(v)_{12}^{C U} \hat{p}(V)_{2}^{U}
\end{aligned}
$$

where 


$$
\begin{aligned}
w(V)_{11}^{C C} & =-\theta\left(1-\frac{p(Q)_{1}^{C} F_{1}^{C C}}{P^{C} F^{C}}\right) \\
w(V)_{12}^{C C} & =\theta\left(\frac{p(Q)_{2}^{C} F_{2}^{C C}}{P^{C} F^{C}}\right)\left(\frac{p(V)_{2}^{C} V_{2}^{C}}{p_{2}^{C} Q_{2}^{C}}\right) \\
w(V)_{11}^{C J} & =\theta\left(\frac{p(Q)_{2}^{C} F_{2}^{C C}}{P^{C} F^{C}}\right)\left(\frac{p(Q)_{1}^{J} X_{12}^{J C}}{p(Q)_{2}^{C} Q_{2}^{C}}\right) \\
w(V)_{12}^{C J} & =w(V)_{11}^{C U}=w(V)_{12}^{C U}=0
\end{aligned}
$$

The appendix shows that the weight assigned by sector 2 in country $C$ to sector 1 in country $J$ (its input supplier) is given by

$$
\begin{aligned}
w(v)_{21}^{C J}= & \left(\frac{p(Q)_{1}^{J} X_{12}^{J C}}{p(Q)_{2}^{C} Q_{2}^{C}}\right)(\sigma-\theta)+\underbrace{\theta\left(\frac{p(Q)_{1}^{J} X_{12}^{J C}}{p(Q)_{2}^{C} Q_{2}^{C}}\right)\left(\frac{p(Q)_{2}^{C} F_{2}^{C J}}{p(Q)_{2}^{C} Q_{2}^{C}}\right)\left(\frac{p(Q)_{2}^{C} F_{2}^{C J}}{P^{J} F^{J}}\right)}_{\text {term } 2} \\
& +\underbrace{\theta\left(\frac{p(V)_{2}^{C} V_{2}^{C}}{p(Q)_{2}^{C} Q_{2}^{C}}\right)\left(\frac{p(Q)_{2}^{C} F_{2}^{C C}}{p(Q)_{2}^{C} Q_{2}^{C}}\right)\left(\frac{p(Q)_{2}^{C} F_{2}^{C C}}{P^{C} F^{C}}\right)}_{\text {term } 3} \\
& +\underbrace{\theta\left(\frac{p(Q)_{2}^{C} F_{2}^{C J}}{p(Q)_{2}^{C} Q_{2}^{C}}\right)\left(\frac{p(Q)_{1}^{J} F_{1}^{J J}}{P^{J} F^{J}}\right)}_{\text {term } 4}+\underbrace{\theta\left(\frac{p(Q)_{1}^{J} X_{12}^{J C}}{p(Q)_{2}^{C} Q_{2}^{C}}\right)\left(\frac{p(Q)_{2}^{C} F_{2}^{C U}}{p(Q)_{2}^{C} Q_{2}^{C}}\right)\left(\frac{p(Q)_{2}^{C} F_{2}^{C U}}{P^{U} F^{U}}\right)}_{\text {term } 5}
\end{aligned}
$$

We can interpret the different terms on the right hand side of the above equation as follows:

$$
\begin{aligned}
\text { term } 2+\text { term } 4 & =\theta\left(\frac{p(Q)_{1}^{J} X_{12}^{J C}}{p(Q)_{2}^{C} Q_{2}^{C}}\right)\left(\frac{p(Q)_{2}^{C} F_{2}^{C J}}{p(Q)_{2}^{C} Q_{2}^{C}}\right)\left(\frac{p(Q)_{2}^{C} F_{2}^{C J}}{P^{J} F^{J}}\right)+\theta\left(\frac{p(Q)_{2}^{C} F_{2}^{C J}}{p(Q)_{2}^{C} Q_{2}^{C}}\right)\left(\frac{p(Q)_{1}^{J} F_{1}^{J J}}{P^{J} F^{J}}\right) \\
& =\theta\left[\left(\frac{p(Q)_{2}^{V} V_{2}^{C}}{p(Q)_{2}^{C} Q_{2}^{C}}\right)\left(\frac{p(Q)_{2}^{C} F_{2}^{C J}}{p(V)_{2}^{C} V_{2}^{C}}\right)\right]\left[\left(\frac{p(Q)_{1}^{J} X_{12}^{J C}}{p(Q)_{2}^{C} Q_{2}^{C}}\right)\left(\frac{p(Q)_{2}^{C} F_{2}^{C J}}{P^{J} F^{J}}\right)+\left(\frac{p_{(Q) 1}^{J} F_{1}^{J J}}{P^{J} F^{J}}\right)\right]
\end{aligned}
$$

$\left(\frac{p(V)_{2}^{C} V_{2}^{C}}{p(Q)_{2}^{C} Q_{2}^{C}}\right) p(Q)_{2}^{C} F_{2}^{C J}$ is the value added created by $(C, 2)$ that is ultimately absorbed in country $J$. Similarly $\left(\frac{p(Q)_{1}^{J} X_{12}^{J C}}{p(Q)_{2}^{C} Q_{2}^{C}}\right) p(Q)_{2}^{C} F_{2}^{C J}+p(Q)_{1}^{J} F_{1}^{J J}$ is the value added created in $(J, 1)$ that is ultimately absorbed in country $J$. Therefore we can simplify (E.43) to write: ${ }^{33}$

$$
\text { term } 2+\text { term } 4=\theta\left(\frac{p(V)_{2}^{C} V_{2}^{C J}}{p(V)_{2}^{C} V_{2}^{C}}\right)\left(\frac{p(V)_{1}^{J} V_{1}^{J J}}{P^{J} F^{J}}\right)
$$

\section{Comparison of GVC-REER and Q-REER}

With trade in intermediate inputs, competitiveness in gross output and value added can be delinked. The expression for gross output competitiveness in our model is as follows (We

\footnotetext{
${ }^{33}$ The derivation follows by multiplying and dividing both terms by $\left(\frac{p_{2}^{V C} V_{2}^{C}}{p_{2}^{C} Q_{2}^{C}}\right)$ and rearranging.
} 
label this measure of gross output competitiveness "Q-REER").

$$
\begin{aligned}
\triangle Q-R E E R_{2}^{c} & =\hat{Q}_{2}^{c}=w(Q)_{21}^{C J} \hat{p}(V)_{1}^{J}+w(Q)_{22}^{C J} \hat{p}(V)_{2}^{J}+w(Q)_{21}^{C C} \hat{p}(V)_{1}^{C} \\
& +w(Q)_{22}^{C C} \hat{p}(V)_{2}^{C}+w(Q)_{21}^{C U} \hat{p}(V)_{1}^{U}+w(Q)_{22}^{C U} \hat{p}(V)_{2}^{U}
\end{aligned}
$$

where

$$
\begin{aligned}
& w(Q)_{21}^{C J}=\theta^{\prime}\left[\left(\frac{p(V)_{2}^{C} V_{2}^{C J}}{p(V)_{2}^{C} V_{2}^{C}}\right)\left(\frac{p(V)_{1}^{J} J_{1}^{J J}}{P^{J} F^{J}}\right)+\left(\frac{p(V)_{2}^{C} V_{2}^{C C}}{p(V) V_{2}^{C} V_{2}^{C}}\right)\left(\frac{p(V)_{1}^{J} V_{1}^{J C}}{P^{C} F^{C}}\right)+\left(\frac{p(V)_{2}^{C} V_{2}^{C U}}{p(V)_{2}^{C} V_{2}^{C}}\right)\left(\frac{p(V) V_{1}^{J} V_{1}^{J U}}{P^{U} F^{U}}\right)\right] \\
& { }_{-\theta}^{-\theta}\left(\frac{p(Q)_{1}^{J} X_{12}^{J C}}{p(Q)_{2}^{C} Q_{2}^{C}}\right) \\
& =w(v)_{21}^{C J}-\sigma\left(\frac{p(Q){ }_{1}^{J} X_{12}^{J C}}{p(Q)_{2}^{C} Q_{2}^{C}}\right)
\end{aligned}
$$

The idea behind the "Goods-REER" measure of Bayoumi et al. (2013) is to measure competitiveness of gross output as opposed to value added. The analogous expression in our framework is given by (E.45), but as will be shown later, the two measures do not coincide except in very restrictive and/or knife-edge cases.

Two differences between the value added weight $w(v)_{21}^{C J}$ and gross output weight $w(Q)_{21}^{C J}$ are worth highlighting. First, note that as long as the production function is not Leontief (i.e $\sigma \neq 0$ ), the gross output competitiveness weight is always lower then the value added weight $\left(w(Q)_{21}^{C J}<w(V)_{21}^{C J}\right)$. This is a consequence of the fact that substitutability in the production function which causes the weight $w(V)_{21}^{C J}$ to increase because of the possibility of a shift occurring from $V_{2}^{C}$ to $(J, 1)$ 's value added(embodied in $X_{12}^{J C}$ ) does not affect the gross output weight $w(Q)_{21}^{C J}$, for as far as gross output is concerned the substitution between different inputs in production is irrelevant as long as the final demand for the good increases.

Secondly note that when $X_{12}^{J C}=0$, the two weights are equivalent. As will be shown in the paper later on, this is a general result-that in the absence of intermediate inputs the gross output and value added weighting matrices are identical.

\section{Computing Aggregate Real Effective Exchange Rates for Countries}

To derive the expression for country-level value added weights, we start with the following decomposition of the nominal GDP of country $h$ into its different sectoral components:

$$
p(V)^{h} V^{h}=p(V)_{1}^{h} V_{1}^{h}+p(V)_{2}^{h} V_{2}^{h}
$$

where $p^{v h}$ is the GDP deflator of country $h$. Log linearizing this equation we get: 


$$
\hat{p}(V)^{h}+\hat{V}^{h}=\left(\frac{p(V)_{1}^{h} V_{1}^{h}}{p(V)^{h} V^{h}}\right)\left[\hat{p}(V)_{1}^{h}+\hat{V}_{1}^{h}\right]+\left(\frac{p(V)_{2}^{h} V_{2}^{h}}{p(V)^{h} V^{h}}\right)\left[\hat{p}(V)_{2}^{h}+\hat{V}_{2}^{h}\right]
$$

Since (up to a first order approximation) the change in GDP deflator is a weighted sum of changes in the different sector level prices, the above equation reduces to

$$
\begin{aligned}
\hat{V}^{h} & =\left(\frac{p(V)_{1}^{h} V_{1}^{h}}{p(V)^{h} V^{h}}\right)\left[\hat{V}_{1}^{h}\right]+\left(\frac{p(V)_{2}^{h} V_{2}^{h}}{p(V)^{h} V^{h}}\right)\left[\hat{V}_{2}^{h}\right] \\
& =\left(\frac{p(V)_{1}^{h} V_{1}^{h}}{p(V)^{h} V^{h}}\right)\left[\sum_{f \in\{J, C, F\}} \sum_{k \in\{1,2\}} w(v)_{1 k}^{h f} \hat{p}(V)_{k}^{f}\right]+\left(\frac{p(V)_{2}^{h} V_{2}^{h}}{p(V)^{h} V^{h}}\right)\left[\sum_{f \in\{J, C, F\}} \sum_{k \in\{1,2\}} w(v)_{2 k}^{h f} \hat{p}(V)_{k}^{f}\right] \\
& =\sum_{f \in(J, C, U)} \sum_{k \in\{1,2\}}\left[\left(\frac{p(V)_{1}^{h} V_{1}^{h}}{p(V)^{h} V^{h}}\right) w(v)_{1 k}^{h f}+\left(\frac{p(V)_{2}^{h} V_{2}^{h}}{p(V)^{h} V^{h}}\right) w(v)_{2 k}^{h f}\right] \hat{p}(V)_{k}^{f}
\end{aligned}
$$

\section{Solution of the single sector version of the model:}

Final demand:

$$
\hat{F}^{f h}=-\theta \hat{p}(Q)_{s}^{f}+\theta \hat{P}^{h}+\hat{F}^{h},(h, f) \in\{(C, C),(J, J),(U, U),(C, J),(C, U)\}
$$

Linearizing the expressions for the CPIs in the three countries((A.22)-(A.23)) we get:

$$
\begin{aligned}
\hat{P}^{U} & =\left(\frac{p(Q)^{C} F^{C U}}{P^{U} F^{U}}\right) \hat{p}(V)^{C}+\left(\frac{p(Q)^{U} F^{U U}}{P^{U} F^{U}}\right) \hat{p}(V)^{U} \\
\hat{P}^{C} & =\hat{p}(V)^{C} \\
\hat{P}^{J} & =\left(\frac{p(Q)^{J} F^{J J}}{P^{J} F^{J}}\right) \hat{p}(Q)^{J}+\left(\frac{p(Q)^{C} F^{C J}}{P^{J} F^{J}}\right) \hat{p}(Q)^{C}
\end{aligned}
$$

The first order conditions for production are as follows:

$$
\begin{aligned}
X_{12}^{J C} & =w^{X}\left(\frac{p(Q)_{1}^{J}}{p(Q)_{2}^{C}}\right)^{-\sigma} Q_{2}^{c} \\
V_{2}^{C}= & =w_{2}^{V}\left(\frac{p(Q)_{2}^{C}}{p(Q)_{2}^{C}}\right)^{-\sigma} Q_{2}^{c}
\end{aligned}
$$

These along with the production function and its associated price index can be linearized as follows: 
Table 14 - Single sector version of the 3 by 2 model

\begin{tabular}{|cccc|cccc|}
\hline & $\mathrm{J}$ & $\mathrm{C}$ & $\mathrm{U}$ & JFinal & CFinal & Ufinal & total output \\
$\mathrm{J}$ & 0 & $\mathrm{X}$ & 0 & $\mathrm{X}$ & 0 & 0 & $\mathrm{X}$ \\
\hline $\mathrm{C}$ & 0 & 0 & 0 & $\mathrm{X}$ & $\mathrm{X}$ & $\mathrm{X}$ & $\mathrm{X}$ \\
\hline $\mathrm{U}$ & 0 & 0 & 0 & 0 & 0 & $\mathrm{X}$ & $\mathrm{X}$ \\
\hline VA & $\mathrm{X}$ & $\mathrm{X}$ & $\mathrm{X}$ & & & & \\
total output & $\mathrm{X}$ & $\mathrm{X}$ & $\mathrm{X}$ & & & & \\
\hline
\end{tabular}

$$
\begin{aligned}
\hat{X}^{J C} & =-\sigma \hat{p}(Q)^{J}+\sigma \hat{p}(Q)^{C}+\hat{Q}^{C} \\
\hat{V}^{C} & =-\sigma \hat{p}(Q)_{2}^{C}+\sigma \hat{p}(Q)_{2}^{C}+\hat{Q}_{2}^{C} \\
\hat{Q}^{C} & =\left(\frac{p(Q)^{C} V^{C}}{p(Q)^{C} Q^{C}}\right) \hat{V}_{2}^{C}+\left(\frac{p(V)^{J} X^{J C}}{p(Q)^{C} Q^{C}}\right) \hat{X}^{J C} \\
\hat{p}^{C} & =\left(\frac{p(V)^{C} V^{C}}{p(Q)^{C} Q^{C}}\right) \hat{p}(V)^{C}+\left(\frac{p(V)^{J} X^{J C}}{p(Q)^{C} Q^{C}}\right) \hat{p}(V)^{J}
\end{aligned}
$$

Next, the market clearing conditions (2.10) and (A.14) can be linearized as follows:

$$
\begin{aligned}
\hat{Q}^{C}= & \left(\frac{p(Q)^{C} F^{C C}}{p(Q)^{C} Q^{C}}\right) \hat{F}^{C C}+\left(\frac{p(Q)^{C} F^{C J}}{p(Q)^{C} Q^{C}}\right) \hat{F}^{C J} \\
& +\left(\frac{p(Q)_{2}^{C} F_{2}^{C U}}{p(Q)^{C} Q^{C}}\right) \hat{F}^{C U} \\
\hat{Q}^{J}= & \left(\frac{p(Q)_{1}^{J} X^{J C}}{p(Q)^{J} Q^{J}}\right) \hat{X}^{J C}+\left(\frac{p(Q)^{J} F^{J J}}{p(Q)^{J} Q^{J}}\right) \hat{F}^{J J}
\end{aligned}
$$

Using these linearized first order and market clearing conditions we can derive an expression for change in demand for value added by country $C$

\section{Country Level exchange rate without exploiting sector level heterogeneity}

The production functions, price indices and final demands and market clearing conditions are now given as follows:

$$
\begin{gathered}
Q^{c}=\left[\left(w^{C V}\right)^{\frac{1}{\sigma}}\left(V^{c}\right)^{\frac{\sigma-1}{\sigma}}+\left(w^{C X}\right)^{\frac{1}{\sigma}}\left(X^{J c}\right)^{\frac{\sigma-1}{\sigma}}\right]^{\frac{\sigma}{\sigma-1}} \\
p(Q)^{c}=\left[\left(w^{C V}\right)\left(p(V)^{c}\right)^{1-\sigma}+\left(w^{C X}\right)\left(p(Q)^{J}\right)^{1-\sigma}\right]^{\frac{1}{1-\sigma}}
\end{gathered}
$$




$$
Q^{h}=V^{h}, h \in\{J, U\}
$$

Consumption

$$
\begin{gathered}
F^{J=}\left[\left(\kappa^{J J}\right)^{\frac{1}{\theta}}\left(F^{J J}\right)^{\frac{\theta-1}{\theta}}+\left(\kappa^{C J}\right)^{\frac{1}{\theta}}\left(F^{C J}\right)^{\frac{\theta-1}{\theta}}\right]^{\frac{\theta}{\theta-1}} \\
F^{C}=F^{C C} \\
F^{U}=\left[\left(\kappa^{U U}\right)^{\frac{1}{\theta}}\left(F^{U U}\right)^{\frac{\theta-1}{\theta}}+\left(\kappa^{C U}\right)^{\frac{1}{\theta}}\left(F^{C U}\right)^{\frac{\theta-1}{\theta}}\right]^{\frac{\theta}{\theta-1}} \\
P^{J=}\left[\left(\kappa^{J J}\right)\left(p(Q)^{J}\right)^{1-\theta}+\left(\kappa^{C J}\right)\left(p(Q)^{C}\right)^{1-\theta}\right]^{\frac{1}{1-\theta}} \\
P^{C=} p(Q)^{C} \\
P^{U=}\left[\left(\kappa^{U U}\right)\left(p(Q)^{U}\right)^{1-\theta}+\left(\kappa^{C U}\right)\left(p(Q)^{C}\right)^{1-\theta}\right]^{\frac{1}{1-\theta}} \\
Q^{J}=X^{J C}+F^{J J} \\
Q^{C}=F^{C C}+F^{C J}+F^{C U} \\
Q^{U}=F^{U U}
\end{gathered}
$$

The appendix shows that the weight assigned by country $C$ to country $J$ in this case is given by:

$$
\hat{V}^{C}=w(v)^{C J} \hat{p}(V)^{J}+w(v)^{C C} \hat{p}(V)^{C}+w(v)^{C U} \hat{p}(V)^{U}
$$




$$
\begin{aligned}
w(v)^{C J}= & \sigma\left(\frac{p(V)^{J} X^{J C}}{p(Q)^{C} Q^{C}}\right)-\theta\left(\frac{p(V)^{J} X^{J C}}{p(Q)^{C} Q^{C}}\right)+\theta\left(\frac{p(V)^{C} F^{C C}}{p(Q)^{C} Q^{C}}\right)\left(\frac{p(V)^{C} F^{C C}}{P^{C} F^{C}}\right) \\
& +\theta\left(\frac{p(V)^{J} X^{J C}}{p(Q)^{C} Q^{C}}\right)\left(\frac{p(V)^{C} F^{C J}}{p(Q)^{C} Q^{C}}\right)\left(\frac{p(V)^{C} F^{C J}}{P^{J} F^{J}}\right)+\theta\left(\frac{p(V)^{C} F^{C J}}{p(Q)^{C} Q^{C}}\right)\left(\frac{p(V)^{C} F^{C J}}{P^{J} F^{J}}\right) \\
& +\theta\left(\frac{p(V)^{J} X^{J C}}{p(Q)^{C} Q^{C}}\right)\left(\frac{p(V)^{C} F^{C U}}{p(Q)^{C} Q^{C}}\right)\left(\frac{p(V)^{C} F^{C U}}{P^{U} F^{U}}\right) \\
w(v)^{C C}= & -\sigma\left(\frac{p(V)^{J} X^{J C}}{p(Q)^{C} Q^{C}}\right)-\theta\left(\frac{p(V)^{C} V^{C}}{p(Q)^{C} Q^{C}}\right)+\theta\left(\frac{p(V)^{C} V^{C}}{p(Q)^{C} Q^{C}}\right)\left(\frac{p(V)^{C} F^{C C}}{p(Q)^{C} Q^{C}}\right)\left(\frac{p(V)^{C} F^{C C}}{P^{C} F^{C}}\right) \\
& +\theta\left(\frac{p(V)^{C} V^{C}}{p(Q)^{C} Q^{C}}\right)\left(\frac{p(V)^{C} F^{C J}}{p(Q)^{C} Q^{C}}\right)\left(\frac{p(V)^{C} F^{C J}}{P^{J} F^{J}}\right) \\
& +\theta\left(\frac{p(V)^{C} V^{C}}{p(Q)^{C} Q^{C}}\right)\left(\frac{p(V)^{C} F^{C U}}{p(Q)^{C} Q^{C}}\right)\left(\frac{p(V)^{C} F^{C U}}{P^{U} F^{U}}\right) \\
w(v)^{C U}= & \theta\left(\frac{p(V)^{C} V^{C}}{p(Q)^{C} Q^{C}}\right)\left(\frac{p(V)^{C} F^{C U}}{p(V)^{C} V^{C}}\right)\left(\frac{p(V)^{U} F^{U U}}{P^{U} F^{U}}\right)
\end{aligned}
$$

It is evident from E.71 and E.11 that $w(v)^{C J}$ and $w_{A}(v)^{C J}$ are not equal. The issue of the non-equivalence of the two weighting matrices will be discussed after we have specified the general model. For now we just want to emphasize that our weighting matrix which exploits sector level information is unique in the literature, and so a starting point to begin a comparison with other measures in the literature is to consider the case where there is only one sector within each country.

We next move on to our general model which builds on the intuition developed from this 3 by 2 setting. After discussing the relationship to other measures in the literature based on the general model we come back to the 3 by 2 model to show some illustrative examples.

\section{F Sticky Prices, Dollar Invoicing and REER}

Derivation of equation 2.41 in section 2.6

From the $\log$ linearized production function for country $C$ :

$$
\hat{Q}^{C}=\omega^{V} \hat{V}^{C}+\left(1-\omega^{V}\right) \hat{X}^{J, C}
$$

substitute $\hat{X}^{J, C}=\omega^{V} \hat{p}^{C, C}-\left(1-\omega^{V}\right) \hat{p}^{J, C}-\hat{p}^{J, C}+\hat{Q}^{C}$ (first order condition for input demand by $C$ )in F.1 to get:

$$
\hat{Q}^{C}=\omega^{V} \hat{V}^{C}+\left(1-\omega^{V}\right)\left(\omega^{V} \hat{p}^{C, C}-\left(1-\omega^{V}\right) \hat{p}^{J, C}-\hat{p}^{J, C}+\hat{Q}^{C}\right)
$$




$$
\Longrightarrow \hat{Q}^{C}=\hat{V}^{C}+\left(1-\omega^{V}\right)\left(\hat{p}^{C, C}-\hat{p}^{J, C}\right)
$$

Next, from the market clearing condition for goods produced by $C\left(Q^{C}=F^{C, C}+F^{C, U}+\right.$ $F^{C, J}$ ), and noting that $F^{C, C=} F^{C}$

$$
\hat{Q}^{C}=\left(\frac{P(Q)^{C} F^{C, C}}{P(Q)^{C} Q^{C}}\right) \hat{F}^{C}+\left(\frac{P(Q)^{C} F^{C, U}}{P(Q)^{C} Q^{C}}\right) \hat{F}^{C, U}+\left(\frac{P(Q)^{C} F^{C, J}}{P(Q)^{C} Q^{C}}\right) \hat{F}^{C, J}
$$

using first order conditions for final demand, and the definition of price indices:

$$
\begin{gathered}
\hat{p}^{U}(F)=\eta^{U} \hat{p}^{U, U}+\left(1-\eta^{U}\right) \hat{p}^{C, U} \\
\hat{p}^{J}(F)=\eta^{J} \hat{p}^{J, J}+\left(1-\eta^{J}\right) \hat{p}^{C, J}
\end{gathered}
$$

Equation F.4 can be written as:

$$
\begin{aligned}
\hat{Q}^{C} & =\left(\frac{P(Q)^{C} F^{C, C}}{P(Q)^{C} Q^{C}}\right) \hat{F}^{C}+\left(\frac{P(Q)^{C} F^{C, U}}{P(Q)^{C} Q^{C}}\right)\left(-\hat{p}^{C, U}+\eta^{U} \hat{p}^{U, U}+\left(1-\eta^{U}\right) \hat{p}^{C, U}\right) \\
& +\left(\frac{P(Q)^{C} F^{C, J}}{P(Q)^{C} Q^{C}}\right)\left(-\hat{p}^{C, J}+\eta^{J} \hat{p}^{J, J}+\left(1-\eta^{J}\right) \hat{p}^{C, J}\right)
\end{aligned}
$$

Substituting equation 2.29 in equation F.3

$$
\begin{gathered}
\hat{V}^{C}=-\left(1-\omega^{V}\right)\left(\hat{p}^{C, C}-\hat{p}^{J, C}\right)+\left(\frac{P^{C, U} F^{C, U}}{P(Q)^{C} Q^{C}}\right)\left[\eta^{U} \hat{p}^{U, U}-\hat{p}^{C, U}+\left(1-\eta^{U}\right) \hat{p}^{C, U}\right] \\
+\left(\frac{P^{C, J} F^{C, J}}{P(Q)^{C} Q^{C}}\right)\left[\eta^{J} \hat{p}^{J, J}-\hat{p}^{C, J}+\left(1-\eta^{J}\right) \hat{p}^{C, J}\right] \\
\hat{V}^{C}=-\left(1-\omega^{V}\right)\left(\hat{p}^{C, C}-\hat{p}^{J, C}\right)+\eta^{U}\left(\frac{P^{C, U} F^{C, U}}{P(Q)^{C} Q^{C}}\right)\left[\hat{p}^{U, U}-\hat{p}^{C, U}\right] \\
+\eta^{J}\left(\frac{P^{C, J} F^{C, J}}{P(Q)^{C} Q^{C}}\right)\left[\hat{p}^{J, J}-\hat{p}^{C, J}\right]
\end{gathered}
$$


Table 15 - Input output table for G.1

\begin{tabular}{|c|c|c|c|ccccc|}
\hline \multicolumn{2}{c}{} & $\mathrm{J}$ & $\mathrm{C}$ & $\mathrm{U}$ & $\mathrm{J}$ final & $\mathrm{C}$ final & $\mathrm{U}$ final & Total output \\
\hline $\mathrm{J}$ & 0 & 1 & 0 & 1 & 0 & 0 & 2 \\
$\mathrm{C}$ & 0 & 0 & 0 & 0.1 & 0.1 & 1 & 1.2 \\
$\mathrm{U}$ & 0 & 0 & 0 & 0 & 0 & 1 & 1 \\
\cline { 2 - 5 } Value added & 2 & 0.2 & 1 & & & & \\
Total output & 2 & 1.2 & 1 & & & & \\
\hline
\end{tabular}

\section{G Heterogenous Elasticity of Substitution}

As shown in the paper, differences in the elasticity of substitution, both across product categories (intermediate vs final) as well as across countries and sectors can have an important bearing on the measurement of REER. This section begins by highlighting this with an illustrative example. We then discuss the estimation of elasticities using data from the WIOD. These elasticities are then used in the parametrization of the model to create new GVC-REER estimates. On comparing these with the uniform elasticity estimates, we find that the differences are much more stark for sectoral REERs than for country level REERs.

Example G.1. Three country world with limited trade in intermediate inputs:

Consider the following 3 country one sector example where the input output linkages are restricted to just one non-zero entry. Country $\mathrm{C}$ imports intermediates from country $\mathrm{J}$, puts in own value added and sells the output to all the three countries as final output. Table 15 displays the associated input-output table.

In this simplified example only two elasticities are relevant, namely $\sigma_{3}$ (elasticity of substitution between C's value added and intermediate input from $\mathrm{J}$ in C's gross output) and $\theta_{1}$ (elasticity of substitution between final goods in the final consumption basket of all countries. For simplicity, this elasticity is assumed to be common across countries).

Consider the weight assigned by country $\mathrm{C}$ to country $\mathrm{J}, W_{C J}$, which measures the change in demand for value added by $\mathrm{C}$ when price of value added by $\mathrm{J}$ changes. A decrease in $p(V)^{J}$ affects the demand for C's value added via two channels. Firstly, with regard to final goods consumption, a decrease in $p(V)^{J}$ leads to a shift towards J's value added (and goods containing value added by $\mathrm{J}$, namely the gross output of $\mathrm{C}$ ) in the final goods consumption bundle of all countries. The strength of this effect depends on $\theta_{1}$. A higher $\theta_{1}$ means that goods are more substitutable in the final goods consumption bundle of countries and hence the shift towards J's value added will be more pronounced when its price decreases. Secondly, with regard to intermediate goods and production mix, a decrease in the price of J's value added leads to a shift towards J's value added and a shift away from C's value added in 
Table 16 - Comparison of weights under different measures for example G.1

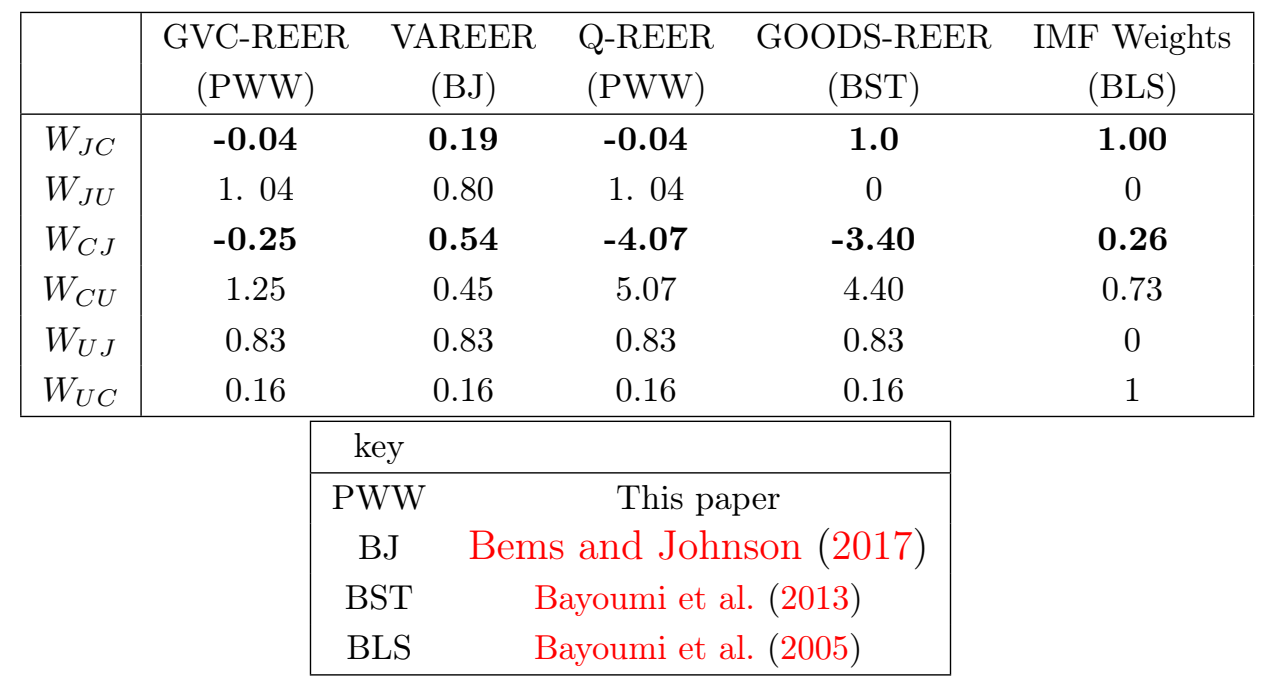

the production function of $\mathrm{C}$. The strength of this effect depends on $\sigma_{3}$. The higher is this elasticity, the higher is the shift towards J's value added in C's production (at the expense of C's own value added) and hence higher is the fall in demand for C's value added.

Table 16 presents weights based on different schemes for this example when $\sigma_{3}=1.5$, $\theta_{1}=5$. (as is done by the IMF and others, weights are normalized so that own weight is -1 and is not reported). Several aspects of the differences in the weighting schemes are noteworthy. Firstly, note that there are no negative weights in the IMF and the VAREER weighting matrix. In fact it can be easily shown that these weighting schemes are not flexible enough to accommodate negative weights under any circumstances. Next, note from column 1 that $W_{J C}$ and $W_{C J}$ are negative in the GVC-REER measure. As discussed above, this is a consequence of the input output structure and a combination of a relatively high $\theta_{1}(=5)$ and low $\sigma_{3}(=1$. 5). Column 3 illustrates that as far as gross output is concerned, the magnitude of the negative weight assigned by country $\mathrm{C}$ to country $\mathrm{J}$ is much larger. This is because only the first effect discussed above (i.e shift in final demand) affects gross output, whereas the second effect (shift towards intermediate composition) does not affect the gross output measure.

That the uniform elasticity assumption is overly restrictive can also be noted from the observation that the VAREER(BJ) weight which does take into account trade in intermediates, does worse than the IMF weight which ignores it, although both have the wrong sign.

Column 4 shows that the Goods-REER measure of Bayoumi et al. (2013) falls somewhere in between the GVC-REER and the Q-REER measures (columns 1 and 3) so that it measures neither gross output competitiveness nor value added competitiveness. Although the aim in Bayoumi et al. (2013) is to capture gross competitiveness, they fall short of doing so 
because their measure uses the IMF weighting scheme which does not account for trade in intermediates. This aspect is further illustrated by the fact that the GOODS-REER measure (which in turn inherits this property from the IMF measure) assigns a value of 0 to $W_{J U}$ because there is no direct trade between $\mathrm{J}$ and $\mathrm{U}$. However, J's value added does reach U via $\mathrm{C}$ and so the correct weighting matrix must have $W_{J U} \neq 0$.

Lastly, note from the last two rows of table 16 that the weights assigned by country $\mathrm{U}$ to the remaining two countries are the same in all the measures except IMF. This is a consequence of the fact that the in the example the US trades in only final goods and all its production comprises entirely of its own value added.

Figure G.1 shows how the weight assigned by $C$ to $J$ changes with the elasticities. The top left figure plots $W_{C J}$ for three measure(GVC-REER, VAREER(BJ) and IMF) for different values of $\sigma_{3}$ with $\theta_{1}$ fixed at 1 . 5. The top right picture plots the same weights for different values of $\theta_{1}$ with $\sigma_{3}$ fixed at 5 . The bottom left figure shows a $3 \mathrm{D}$ plot of $W_{C J}$ for the GVC-REER measure for different values of $\sigma_{3}$ and $\theta_{1}$ while the bottom right augments this graph by adding a surface each for VAREER and IMF weights.

\section{G.1 Estimation of elasticities}

\section{G.1.1 Framework}

The approach used here will be based on recent work by Soderbery (2015) which outlines certain drawbacks in the preceding two papers and proposes an estimator which outperforms them. Consider a generic CES Armington aggregator defined as follows:

$$
D_{t}=\left[\sum_{k \in K}\left(w_{k}\right)^{1 / \eta}\left(D_{k t}\right)^{\frac{\eta-1}{\eta}}\right]^{\frac{\eta}{\eta-1}}
$$

The objective is to estimate the demand elasticity $\eta$. The double differenced demand equation in terms of expenditure shares is given by ${ }^{34}$ :

$$
\triangle^{r} \ln \left(s_{k t}\right)=-(\eta-1) \triangle^{r} \ln \left(p_{k t}\right)+\epsilon_{k t}^{r}
$$

where $\triangle^{r} \ln \left(x_{k t}\right)=\triangle \ln \left(x_{k t}\right)-\triangle \ln \left(x_{r t}\right)$ and $\triangle \ln \left(x_{j t}\right)=\ln \left(x_{j t}\right)-\ln \left(x_{j(t-1)}\right), x=s, p r$ is called a reference variety and is typically chosen to be the one with the largest share . $s_{k t}$ is the expenditure share of the $k^{\text {th }}$ variety and is given by:

\footnotetext{
${ }^{34}$ See Soderbery (2015), Broda and Weinstein (2006) or Feenstra (1994) for further details including the actual derivation
} 
Figure G.1 - Illustration of Role of Elasticities: Example G.1
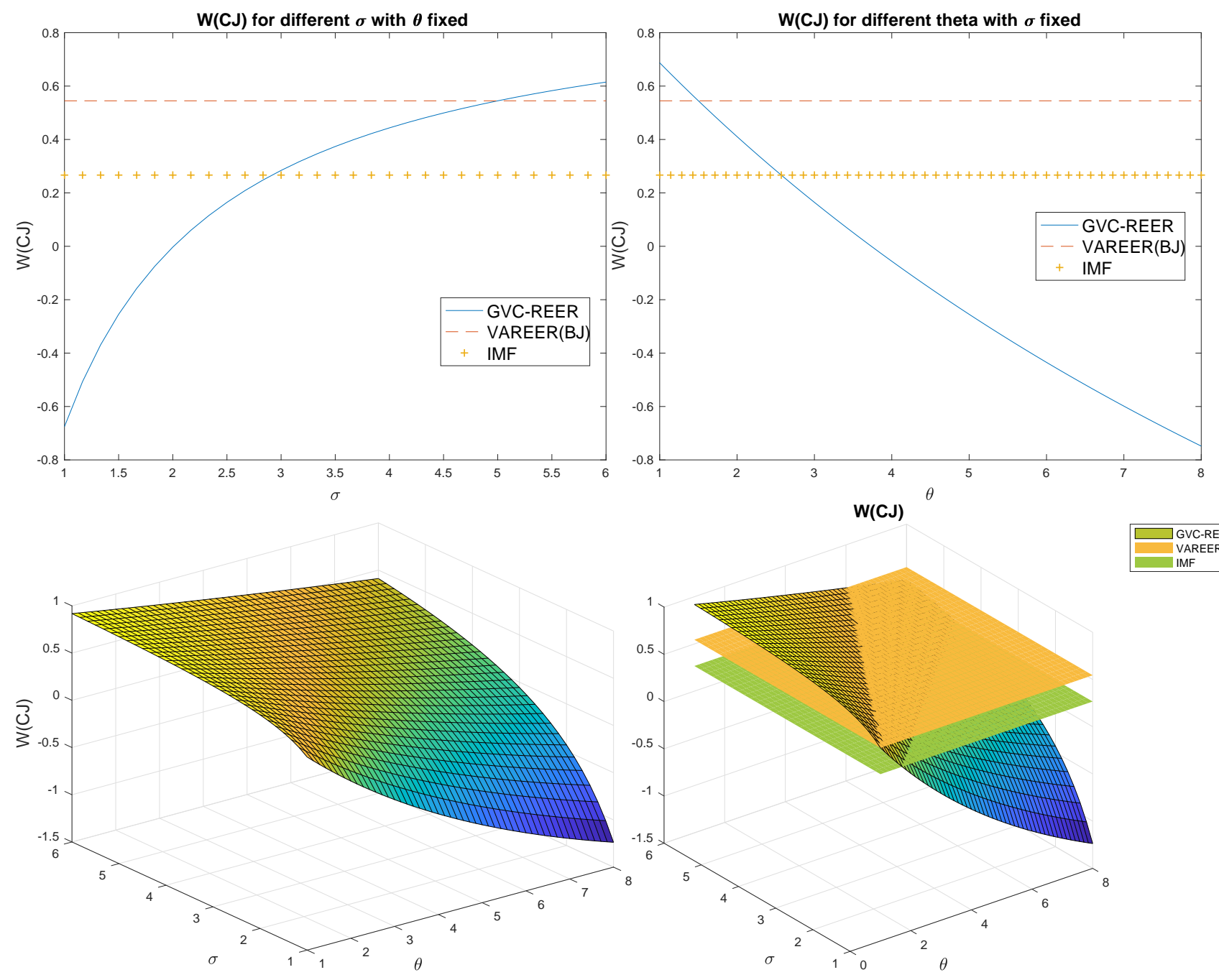


$$
s_{k t}=\frac{p_{k t} D_{k t}}{\sum_{k \in K} p_{k t} D_{k t}}
$$

Next, given a supply curve with elasticity $\rho$, the supply curve in terms of differenced shares and prices can be written as:

$$
\triangle^{r} \ln \left(p_{k t}\right)=\left(\frac{\rho}{1+\rho}\right) \triangle^{r} \ln \left(s_{k t}\right)+\delta_{k t}^{r}
$$

If the demand and supply disturbances are independent across time, then the 2 equations can be multiplied and scaled to yield:

$$
Y_{k t}=\theta_{1} Z_{1 k t}+\theta_{2} Z_{2 k t}+u_{k t}
$$

where $Y_{k t}=\left(\triangle^{r} \ln \left(p_{k t}\right)\right)^{2}, Z_{1 k t}=\left(\triangle^{r} \ln \left(s_{k t}\right)\right)^{2}, Z_{2 k t}=\left(\triangle^{r} \ln \left(p_{k t}\right)\right)\left(\triangle^{r} \ln \left(s_{k t}\right)\right)$, and $u_{k t}=$ $\frac{\epsilon_{k t}^{r} \delta_{k t}^{r}}{1-\phi}$.

Further, the parameters of this regression model can be mapped to the primitive parameters of the demand and supply system as follows:

$$
\begin{aligned}
& \phi=\frac{\rho(\eta-1)}{1+\rho \eta} \in\left[0, \frac{\sigma-1}{\sigma}\right) \\
& \theta_{1}=\frac{\phi}{(\eta-1)^{2}(1-\phi)} \theta_{2}=\frac{2 \phi-1}{(\eta-1)(1-\phi)}
\end{aligned}
$$

Consistent estimates of $\theta_{1}$ can be obtained by using the moment condition $E\left(u_{k t}\right)=0$, where consistency relies on $T \rightarrow \infty$. ${ }^{35}$ If standard procedures (2SLS or LIML) yield a value of $\theta_{1}$ that gives imaginary values for $\eta$ and $\rho$ or values with the wrong sign, then the grid search or the non-linear search method of Soderbery (2015) can be used.

\section{G.1.2 Results}

We construct sectoral price indices for all cells in the WIOD input output table using the tables in previous year prices. For a fixed production entity (identified by the country-sector pair $(c, l))$ and a fixed sector $s$, table 17 shows how the estimation of the different elasticities in the model maps onto the procedure outlined above.

Table 18 provides median estimates for each elasticity computed using the WIOD sample form 1995-2009. The medians are computed across all estimates, whose number differs according to the degree of aggregation in the nested CES framework. Although slightly on the higher side, these numbers are broadly in the range of estimates obtained in the trade literature (Broda and Weinstein (2006)), but fairly high compared to the estimates obtained

\footnotetext{
${ }^{35}$ Given the nature of the data, the value of $\mathrm{T}$ is typically very small. For example Soderbery (2015) uses an unbalanced panel with 15 years of data
} 
Table 17 - Elasticity Estimation

\begin{tabular}{cccc}
\hline & $D$ & $D_{k}$ & $p_{k}$ \\
\hline Production elasticities & & & \\
$\sigma_{s}^{1}(c, l)$ & $\left(X(f)_{s l}^{c}\right)$ & $\left(X_{s l}^{k c}\right)$ & $p(Q)_{s}^{k}$ \\
$\sigma_{s}^{1 h}(c, l)$ & $\left(X_{s l}^{c}\right)$ & $\left(X_{s l}^{c c}\right),\left(X(f)_{s l}^{c}\right)$ & $p(Q)_{s}^{k}$ \\
$\sigma^{2}(c, l)$ & $\left(X_{l}^{c}\right)$ & $\left(X_{k l}^{c}\right)$ & $p(X)_{k l}^{c}$ \\
$\sigma^{3}(c, l)$ & $\left(Q_{l}^{c}\right)$ & $\left(X_{l}^{c}, V_{l}^{c}\right)$ & $\left(p(Q)_{l}^{c}, p(V)_{l}^{c}\right)$
\end{tabular}

Consumption elasticities

$\begin{array}{cccc}\theta_{s}^{1}(c) & \left(F(f)_{s}^{c}\right) & \left(F_{s}^{k c}\right) & p(Q)_{s}^{k} \\ \theta_{s}^{1 h}(c) & \left(F_{s}^{c}\right) & \left(F_{s}^{c}\right),\left(F(f)_{s}^{c}\right) & p(Q)_{s}^{k} \\ \theta^{1}(c) & \left(F^{c}\right) & \left(F_{k}^{c}\right) & P_{k}^{c}\end{array}$

This table shows how the model in section 2.2 maps into the general framework for estimation of elasticities discussed in section G.1

Table 18 - Estimates of elasticities of substitution by sector (for production) and by country (for consumption elasticity) groups

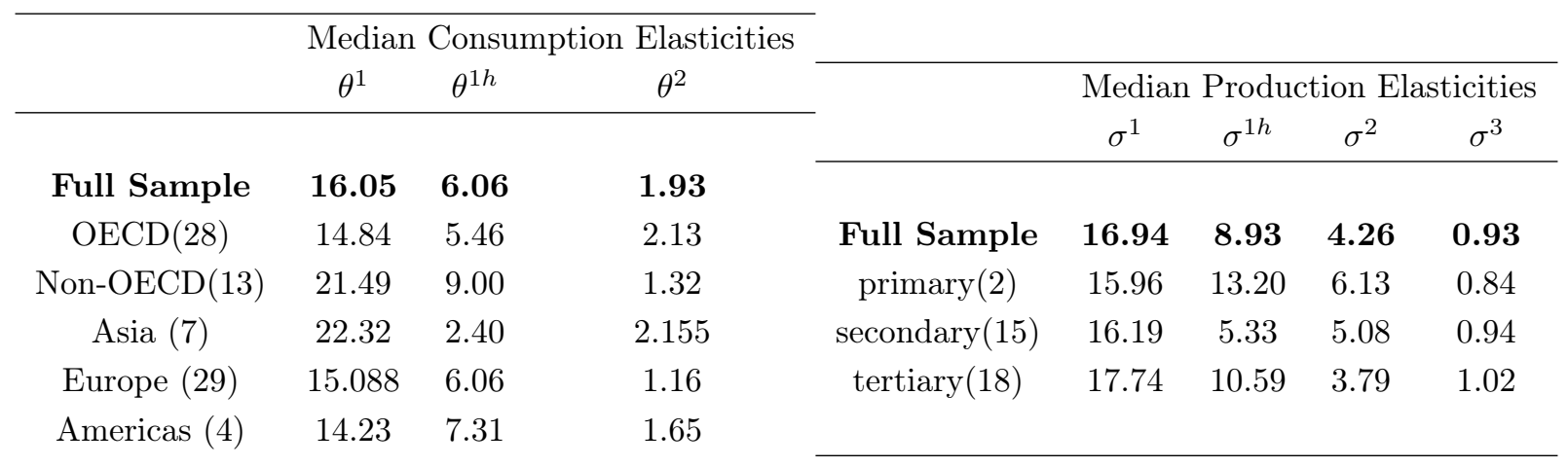

in the macro literature (Justiniano and Preston $(2010))^{36}$ Our goal in this paper is to illustrate the extent to which relaxing the uniform elasticity assumption impacts the measurement of REER. To that end, we take a first step by only introducing a single estimate for each of the seven structural elasticities in the model. The role of heterogeneity in elasticities of substitution across different sector and country groups would also be of interest and can be easily incorporated and studied in our framework. Table 18 in appendix G.1 provides some estimates for different sector and country groups.

\footnotetext{
${ }^{36}$ As shown in Imbs and Mejean (2015), the macro estimates suffer from a downward bias due to aggregation.
} 
Table 19 - Divergence index for Countries and sectors

\begin{tabular}{ccc}
\hline level of Aggregation & Country & Country-Sector \\
\hline Sample size & 41 & 1435 \\
Mean $\left(d^{e}\right)$ & 0.10 & 0.24 \\
Median $\left(d^{e}\right)$ & 0.07 & 0.21 \\
$\operatorname{Stdev}\left(d^{e}\right)$ & 0.07 & 0.14 \\
& & \\
$\min \left(d^{e}\right)$ & 0 & 0 \\
$\max \left(d^{e}\right)$ & 0.29 & 0.79 \\
\hline
\end{tabular}

\section{G.2 Comparing GVC-REERs: uniform elasticity vs heterogenous elasticity}

In order to assess the importance of incorporating heterogeneity in the elasticity of substitution emphasized above, we define a statistic to qualitatively capture the differences in REER based on uniform and heterogenous elasticity. For each entity (e) and for each year, we create a variable $d_{t}^{e}$ which takes the value one if the GVC-REER uniform elasticity and heterogenous elasticity indices move in opposite directions and zero otherwise.

$$
d_{t}^{e}=1\left(\operatorname{sign}\left(\triangle G V C-R E E R(B M)_{t}\right) \neq \operatorname{sign}\left(\triangle G V C-R E E R(C E)_{t}\right)\right)
$$

We then compute the mean of $d_{t}^{e}$ for each $e$ across all time periods and to define the "Divergence index" for entity $e$ as follows:

$$
d^{e}=\frac{\sum_{t=2}^{T} d_{t}^{e}}{T-1}
$$

Note that $d^{e}$ takes the value zero if the two REER measures always agree in their direction of movement and takes the value of 1 if they never agree, i.e always move in opposite directions.

Table 19 summarizes the distribution of the divergence index for GVC-REER. ${ }^{37}$ At the country level, the maximum number of times the measures move in opposite directions is 4 out of 14 years (29\%). This happens for the Netherlands. At the country-sector level, the divergence index is much larger on average and reaches as high as 79\% (11 out of 14 years) for certain country-sectors in the sample. The main takeaway from these results is that the consequences of heterogeneity in elasticities, at least qualitatively, are more evident in the case of REERs at the country-sector rather than at the aggregate country level.

\footnotetext{
${ }^{37}$ The results for other REERs including Q-REER are qualitatively similar
} 


\section{H Bilateral GVC-RER: Example}

Consider a two country world where each country has two sectors. There is no trade in intermediate goods and production comprises entirely of own value added. Table 20 shows how the final demand is distributed across sectors.

Table 20 - IO table for bilateral RER

\begin{tabular}{|c|c|c|c|c|c|c|c|c|}
\hline & & \multicolumn{2}{|c|}{$\mathrm{C}$} & \multicolumn{2}{|c|}{$\mathrm{U}$} & \multirow[t]{2}{*}{ CFinal } & \multirow[t]{2}{*}{ Ufinal } & \multirow[t]{2}{*}{ total output } \\
\hline & & $\mathrm{C} 1$ & $\mathrm{C} 2$ & U1 & U2 & & & \\
\hline \multirow{2}{*}{$\mathrm{C}$} & $\mathrm{C} 1$ & 0 & 0 & 0 & 0 & 1 & 1 & 2 \\
\hline & $\mathrm{C} 2$ & 0 & 0 & 0 & 0 & 3 & 0 & 3 \\
\hline \multirow{2}{*}{ U } & U1 & 0 & 0 & 0 & 0 & 0 & 1 & 1 \\
\hline & U2 & 0 & 0 & 0 & 0 & 0 & 1 & 1 \\
\hline VA & & 2 & 3 & 1 & 1 & & & \\
\hline total output & & 2 & 3 & 1 & 1 & & & \\
\hline
\end{tabular}

Suppose in addition, $\hat{p}(V)_{1}^{C}=-0.01, \hat{p}(V)_{2}^{C}=0.02, \hat{p}(V)_{1}^{U}=0, \hat{p}(V)_{2}^{U}=0$ (all prices are in a common currency, so nominal exchange rate is already incorporated)

Based on the conventional RER definition using an aggregate country level price index,

$$
R \hat{E} R^{U S-C H}=\hat{p}(V)^{C}-\hat{p}(V)^{U}=0.008
$$

and hence the conventional RER measure would indicate an increase in competitiveness of the US. This however is misleading since the entire price increase comes from China's sector 2 which does not compete with any of the US sectors. Moreover, the Chinese sector which does compete with the US is C1, which actually experiences a decrease in its price, so the correct measure of competitiveness must signal an appreciation of the US exchange rate against China, not a depreciation as measured by the standard RER in 3.1.

\section{List of countries and sectors}

List of countries: Australia, Austria, Belgium, Bulgaria, Brazil (EME) Canada, China (EME), Cyprus , Czech Republic (EME), Germany, Denmark, Spain, Estonia, Finland, France, United Kingdom, Greece, Hungary (EME), Indonesia (EME), India (EME), Ireland, Italy, Japan, Korea (EME), Lithuania, Luxembourg, Latvia, Mexico (EME), Malta, Netherlands, Poland (EME), Portugal, Romania, Russia (EME), Slovak Republic, Slovenia, Sweden, Turkey (EME), Taiwan (EME)United States. 
Table 21 - Sectoral classification and description

\begin{tabular}{|c|c|c|c|}
\hline WIOD sector & Sector description & NACE code & $\begin{array}{c}\text { Broad } 3 \text { sector Classification } \\
\text { (Primary, secondary and tertiary) }\end{array}$ \\
\hline $\mathrm{c} 01$ & AGRICULTURE, HUNTING, FORESTRY AND FISHING & AtB & Primary \\
\hline $\mathrm{c} 02$ & MINING AND QUARRYING & $\mathrm{C}$ & Primary \\
\hline c03 & FOOD, BEVERAGES AND TOBACCO & $15 \mathrm{t} 16$ & Primary \\
\hline c04 & Textiles and textile & $17 \mathrm{t} 18$ & Secondary \\
\hline $\mathrm{c05}$ & Leather, leather and footwear & 19 & Secondary \\
\hline c06 & WOOD AND OF WOOD AND CORK & 20 & Secondary \\
\hline $\mathrm{c} 07$ & PULP, PAPER, PAPER, PRINTING AND PUBLISHING & $21 \mathrm{t} 22$ & Secondary \\
\hline $\mathrm{c} 08$ & Coke, refined petroleum and nuclear fuel & 23 & Secondary \\
\hline c09 & Chemicals and chemical & 24 & Secondary \\
\hline c10 & Rubber and plastics & 25 & Secondary \\
\hline c11 & OTHER NON-METALLIC MINERAL & 26 & Secondary \\
\hline c12 & BASIC METALS AND FABRICATED METAL & $27 \mathrm{t} 28$ & Secondary \\
\hline c13 & MACHINERY, NEC & 29 & Secondary \\
\hline c14 & ELECTRICAL AND OPTICAL EQUIPMENT & $30 \mathrm{t} 33$ & Secondary \\
\hline c15 & TRANSPORT EQUIPMENT & $34 \mathrm{t} 35$ & Secondary \\
\hline c16 & MANUFACTURING NEC; RECYCLING & $36 \mathrm{t} 37$ & Secondary \\
\hline c17 & ELECTRICITY, GAS AND WATER SUPPLY & $\mathrm{E}$ & Secondary \\
\hline c18 & CONSTRUCTION & $\mathrm{F}$ & Secondary \\
\hline c19 & Sale, maintenance and repair of motor vehicles and motorcycles; retail sale of fuel & 50 & Tertiary \\
\hline c20 & Wholesale trade and commission trade, except of motor vehicles and motorcycles & 51 & Tertiary \\
\hline c21 & Retail trade, except of motor vehicles and motorcycles; repair of household goods & 52 & Tertiary \\
\hline c22 & HOTELS AND RESTAURANTS & $\mathrm{H}$ & Tertiary \\
\hline
\end{tabular}

Table 21 - Sectoral classification and description cont.

\begin{tabular}{|c|c|c|c|}
\hline WIOD sector & Sector description & NACE code & $\begin{array}{c}\text { Broad } 3 \text { sector Classification } \\
\text { (Primary, secondary and tertiary) }\end{array}$ \\
\hline c23 & Other Inland transport & 60 & Tertiary \\
\hline c24 & Other Water transport & 61 & Tertiary \\
\hline c25 & Other Air transport & 62 & Tertiary \\
\hline c26 & Other Supporting and auxiliary transport activities; activities of travel agencies & 63 & Tertiary \\
\hline $\mathrm{c} 27$ & POST AND TELECOMMUNICATIONS & 64 & Tertiary \\
\hline $\mathrm{c} 28$ & FINANCIAL INTERMEDIATION & $\mathrm{J}$ & Tertiary \\
\hline c29 & Real estate activities & 70 & Tertiary \\
\hline c30 & Renting of m\&eq and other business activities & $71 \mathrm{t} 74$ & Tertiary \\
\hline c31 & PUBLIC ADMIN AND DEFENCE; COMPULSORY SOCIAL SECURITY & $\mathrm{L}$ & Tertiary \\
\hline c32 & EDUCATION & M & Tertiary \\
\hline c33 & HEALTH AND SOCIAL WORK & $\mathrm{N}$ & Tertiary \\
\hline c34 & OTHER COMMUNITY, SOCIAL AND PERSONAL SERVICES & $\mathrm{O}$ & Tertiary \\
\hline c35 & PRIVATE HOUSEHOLDS WITH EMPLOYED PERSONS & $\mathrm{P}$ & Tertiary \\
\hline
\end{tabular}


Figure J.1 - Correlation between Value added and Gross Output REER Weights

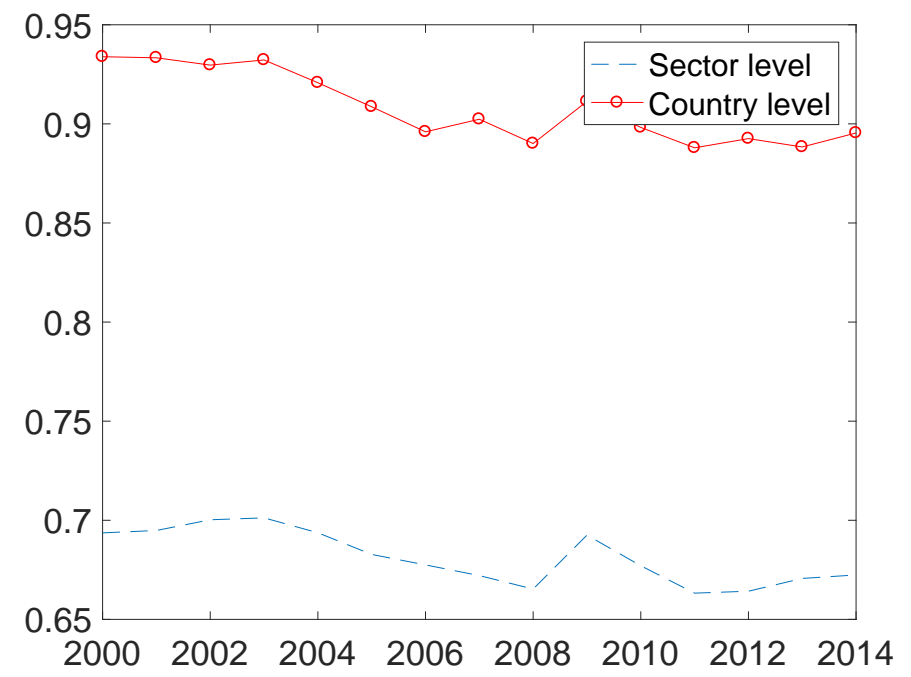

\section{J Corresponding figures for section 3 based on the WIOD 2016 release $(2000-2014)$}


Figure J.2 - Comparison of three REER indices for select countries
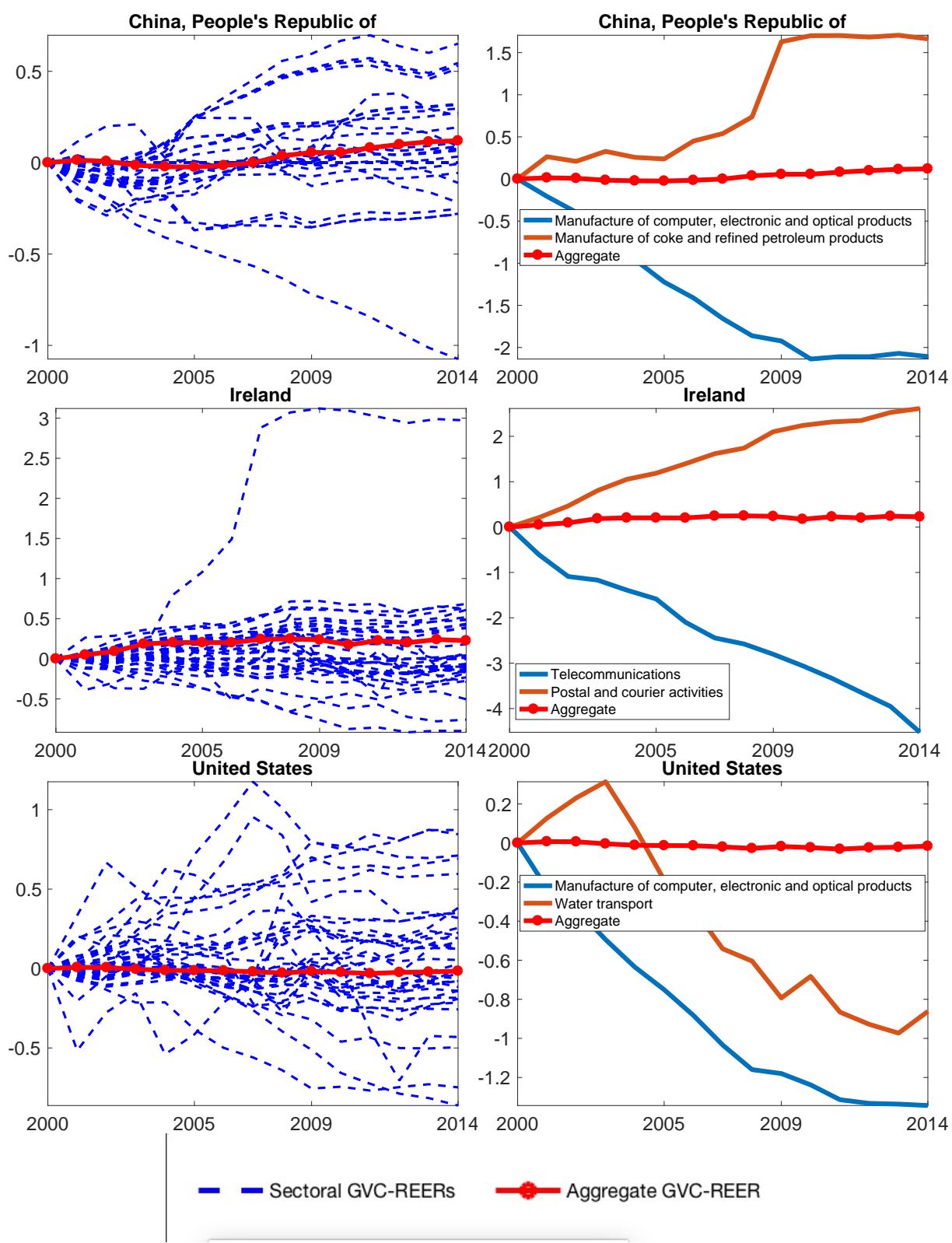

Sectors in the right hand panel do not correspond to ones in the manuscript due to lack of correspondence between sectoral classifications in the two WIOD data releases. 
Figure J.3 - Comparison of sectoral REERs indices for the electronics sector
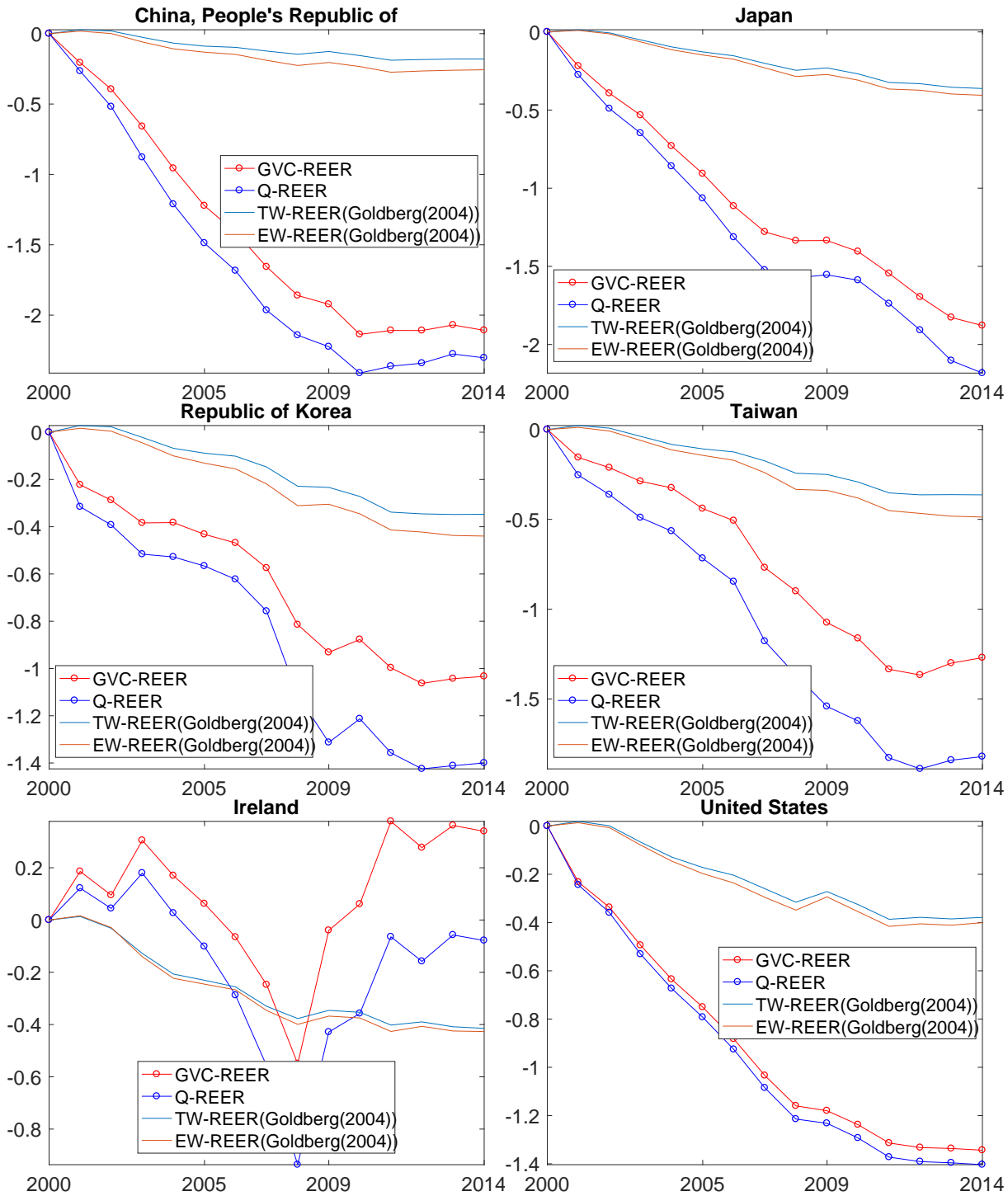

Notes: GVC-REER and Q-REER are measures proposed in this paper. TW-REER and EW-REER are trade and export weighted REERs respectively, computed at the sector level using the framework proposed by Goldberg (2004). Electronics sector (Code 17 in WIOD 2016 release, the correspondence with WIOD 2013 release reported int eh main paper is not exact) 
Figure J.4 - Comparison of three REER indices for select countries
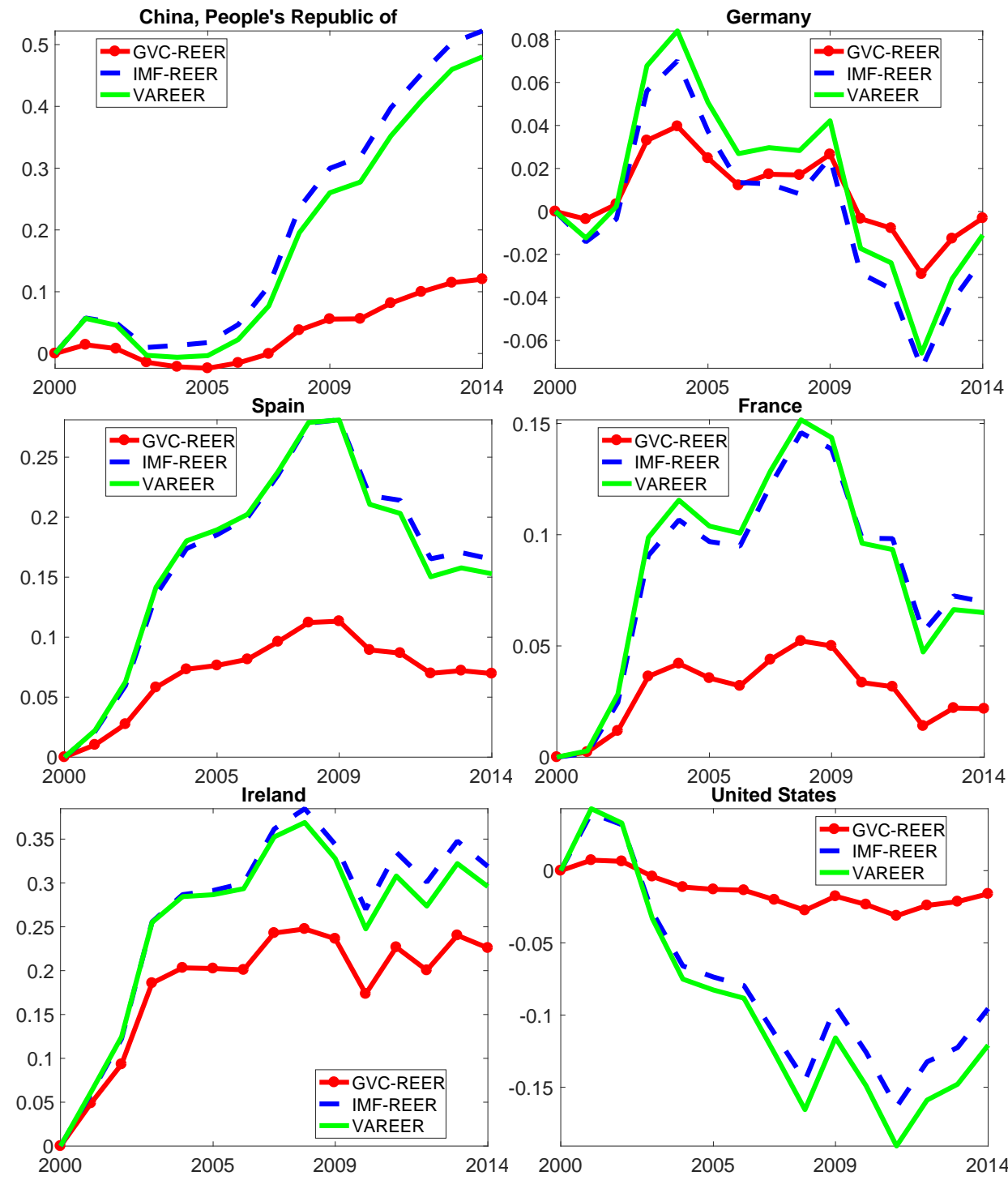

Comparison of three REER indices for select countries. The GVC-REER is our proposed measure of REER which incorporates input-output linkages as well as sectoral heterogeneity (in both REER weights as well as price indices). The VAREER corresponds to the valueadded REER measure proposed in Bems and Johnson (2017) which accounts for input-output linkages but not sectoral heterogeneity. IMF-REER is a measure which uses the IMF weighting scheme that ignores both input-output linkages as well as sectoral heterogeneity. 
Figure J.5 - Comparison of GVC-REER and Q-REER for select countries
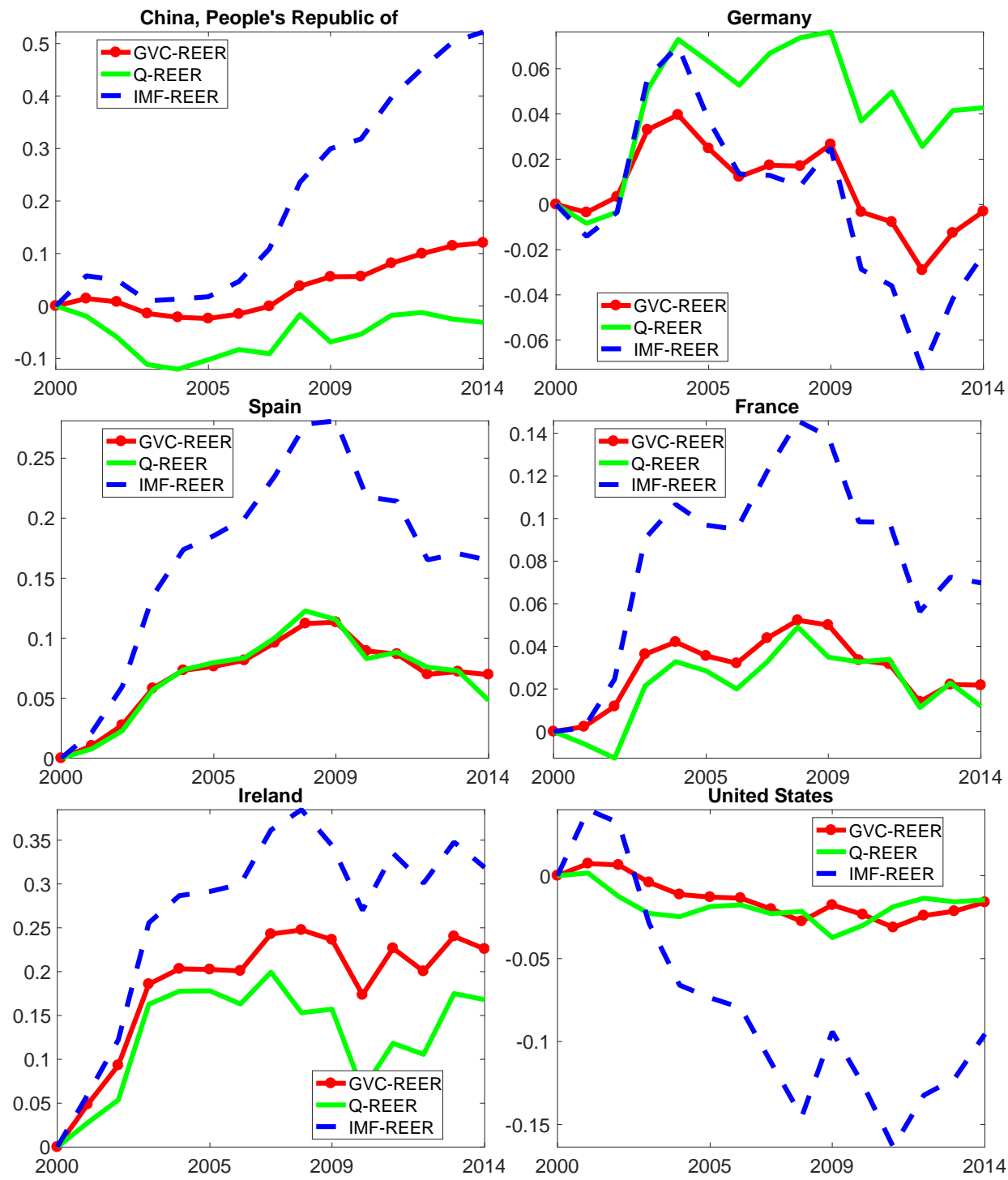

Comparison of GVC-REER and Q-REER for select countries. GVC-REER measures value added competitiveness, whereas Q-REER measures competitiveness of gross output produced by the country. 
Figure J.6 - Comparison of VAREER and GVC-REER weights for China and Ireland
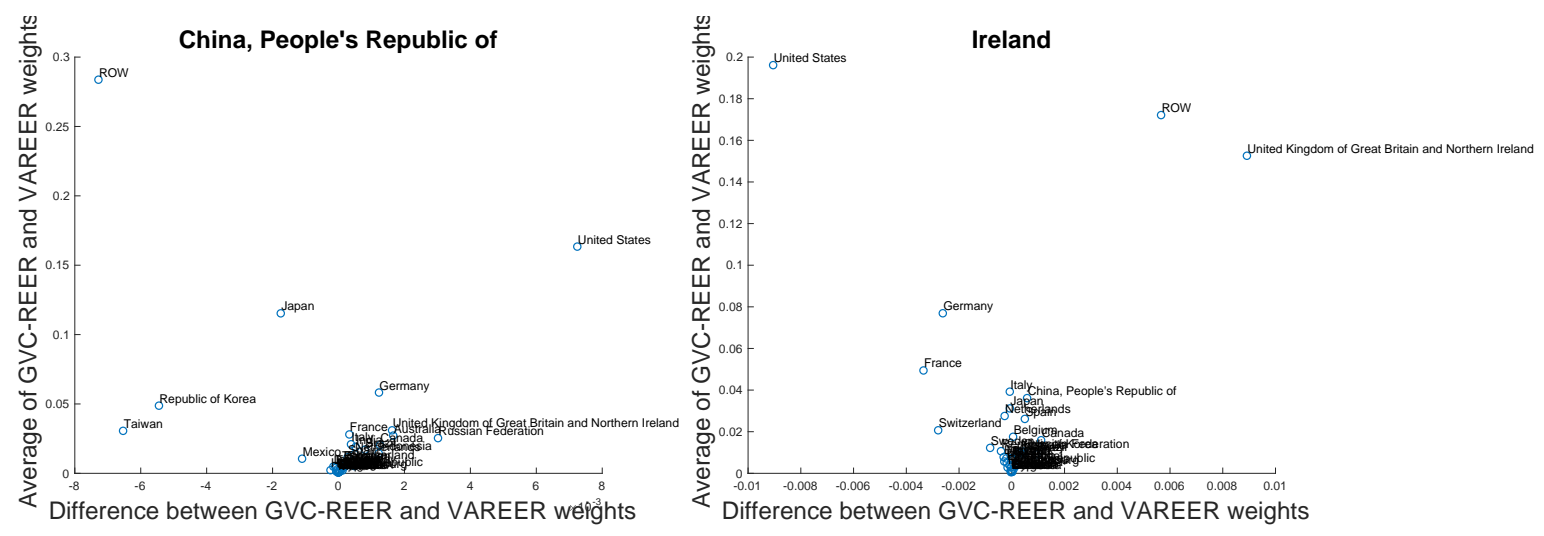